ADILSON DE OLIVEIRA

\title{
ANÁLISE INTELIGENTE DE FALHAS PARA APOIAR DECISÕES ESTRATÉGICAS EM PROJETOS DE SISTEMAS CRÍTICOS
}

São Paulo 


\title{
ADILSON DE OLIVEIRA
}

\section{ANÁLISE INTELIGENTE DE FALHAS PARA APOIAR DECISÕES ESTRATÉGICAS EM PROJETOS DE SISTEMAS CRÍTICOS}

\author{
Tese apresentada à Escola Politécnica \\ da Universidade de São Paulo para a \\ obtenção do título de Doutor em \\ Engenharia Elétrica.
}

São Paulo 


\title{
ADILSON DE OLIVEIRA
}

\section{ANÁLISE INTELIGENTE DE FALHAS PARA APOIAR DECISÕES ESTRATÉGICAS EM PROJETOS DE SISTEMAS CRÍTICOS}

\author{
Tese apresentada à Escola Politécnica \\ da Universidade de São Paulo para a \\ obtenção do título de Doutor em \\ Engenharia Elétrica.
}

Área de concentração:

Engenharia de Computação e Sistemas Digitais.

Orientador: Prof. Livre-Docente Jorge Rady de Almeida Junior

\section{São Paulo}


Este exemplar foi revisado e alterado em relação à versão original, sob responsabilidade única do autor e com a anuência de seu orientador.

São Paulo, 09 de novembro de 2009.

Assinatura do autor

Assinatura do orientador

FICHA CATALOGRÁFICA

Oliveira, Adilson de

Análise inteligente de falhas para poiar decisões estratégicas

em projetos de sistemas críticos / A. de Oliveira. -- ed.rev. -- São Paulo, 2009.

$131 \mathrm{p}$.

Tese (Doutorado) - Escola Politécnica da Universidade de São Paulo. Departamento de Engenharia de Computação e Sistemas Digitais.

1. Banco de dados 2. Sistemas de informação 3. Segurança nos transportes I. Universidade de São Paulo. Escola Politéc nica. Departamento de Engenharia de Computação e Sistemas Dinitais II t 


\section{DEDICATÓRIA}

Aos meus pais, Osvaldo e Nirce, que me propiciaram uma vida digna onde eu pudesse crescer, acreditando que tudo é possível, desde que sejamos honestos.

Aos meus irmãos, Claudio e Sérgio, exemplos de sabedoria, dignidade e caráter.

A meu tio José, um homem maravilhoso que, como um pai, sempre esteve ao meu lado durante a minha infância e juventude.

A minha querida esposa Alessandra, uma grande companheira e amiga, sempre me contagiando com sua infinita alegria. 


\section{AGRADECIMENTOS}

Agradeço a Deus por ter me dado a oportunidade de conhecer pessoas maravilhosas, que me deram ensinamentos de perseverança para alcançar este objetivo.

Ao professor Jorge Rady de Almeida Junior pela confiança, incansável orientação, dedicação e paciência, atitudes de um grande homem.

Aos professores João Batista Camargo Junior e Paulo Sérgio Cugnasca pelas brilhantes contribuições no exame de qualificação.

Aos demais professores da Escola Politécnica da USP que me acolheram em suas disciplinas e me proporcionaram as bases acadêmicas para chegar até aqui.

Aos familiares e amigos que participaram e ainda participam da minha vida pessoal, acadêmica e profissional, e que muito contribuíram para a realização deste trabalho. 


\section{RESUMO}

Este trabalho propõe o uso de Sistemas de Informação e Inteligência Empresarial visando a Análise Inteligente de Falhas para Apoiar Decisões Estratégicas em Projetos de Sistemas Críticos. Tal proposta estabelece uma correlação entre a dinâmica proveniente de recursos e ferramentas de Sistemas de Informação e Inteligência Empresarial, e a necessidade de se obter informações precisas, em intervalos de tempo aceitáveis para agregar valores tangíveis na segurança, confiabilidade, disponibilidade e mantenabilidade de Sistemas Críticos. A proposta aqui apresentada vem ao encontro da necessidade premente de disponibilizar, com maior eficácia, informações precisas para a aferição de indicadores importantes ao Projeto de Sistemas Críticos, e favorecer a implementação de ações mitigadoras de falhas que possam vir a comprometer o funcionamento desses sistemas. De forma a completar e consolidar a proposta em questão desenvolveu-se um ambiente computacional, utilizando-se dos fundamentos teóricos e das melhores práticas de Sistemas de Informação e Inteligência Empresarial, com as especificidades inerentes a Sistemas Críticos. Avaliou-se tal ambiente em um estudo de caso desenvolvido no Sistema Metroviário de São Paulo. Esse estudo de caso contribuiu, no aspecto conceitual, com a realização de ensaios de análises qualitativas e quantitativas de falhas, fornecendo informações relevantes para apoiar possíveis decisões estratégicas no sistema estudado.

Palavras-Chave: Sistemas Críticos, Sistema de Informação, Inteligência Empresarial, Análise de Falhas, Tomada de Decisões Estratégicas. 


\begin{abstract}
This work proposes the use of Information Systems and Business Intelligence aiming an Intelligent Analysis of Failure that supports Strategic Decision Making in Critical Systems Projects. This proposition establishes a correlation between the dynamics of resources and tools from Information Systems and Business Intelligence, and the need to obtain accurate information within an acceptable time interval to add tangible value in security, reliability, availability and maintainability of Critical Systems. The proposition presented here meets the need to provide, more efficiently, accurate information to measure relevant indicators of the projects in Critical Systems, and favor the implementation of failure mitigating actions that could come to compromise the functioning of these systems. In order to complete and consolidate the proposition in question, a computational environment was developed, making use of the theoretical bases and of the best practices of Systems of Information and Business Intelligence, with the peculiarities inherent to Critical Systems. Such environment was evaluated in a case study in the Metrorail Company of São Paulo State, in which qualitative and quantitative analysis of failures were tested, providing relevant information to support possible strategic decisions in the system studied.
\end{abstract}

Keywords: Critical Systems, Information System, Business Intelligence, Failure Analysis, Strategic Decision-Making. 


\section{LISTA DE ILUSTRAÇÕES}

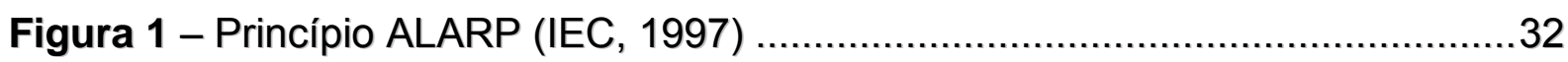

Figura 2 - Desencadeamento da Falha, adaptado (ALMEIDA JR, 2003) …............37

Figura 3 - Alinhamento das Falhas Ativas Inseguras (REASON, 2000) ..................39

Figura 4 - Cenários de Tomada de Decisões com e sem recursos de Sistema de Informação e Inteligência Empresarial.

Figura 5 - Corporate Information Factory (INMON, 2007) …..............................49

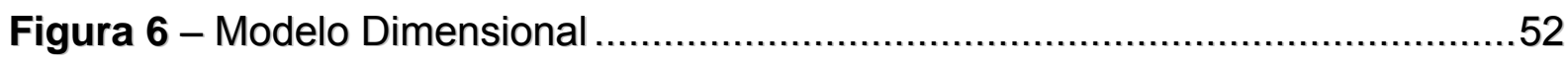

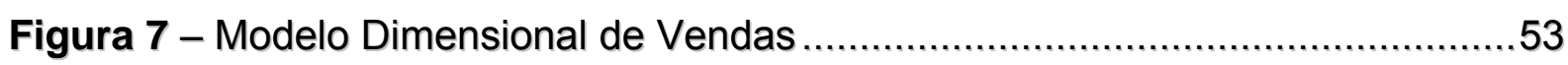

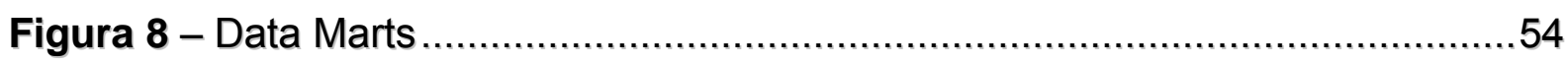

Figura 9 - Extração Transformação e Carga de Dados ..........................................55

Figura 10 - Modelo SECI (NONAKA e TAKEUCHI, 1997) ....................................58

Figura 11- Limitações no Fluxo de Informações de Falhas .......................................63

Figura 12-Pirâmide da Informação Organizacional no Sistema Metroviário, adaptado de (LAUDON e LAUDON, 2007) ....................................... 68

Figura 13 - Ciclo de vida da informação em Sistemas Metroviários ........................70

Figura 14 - Fluxo Padrão de Análise de Falhas em um Sistema Metroviário ..........71

Figura 15 - Fluxo informacional proposto para o Sistema Metroviário ......................72

Figura 16 - Perspectiva de um Projeto no Sistema Metroviário ...............................73

Figura 17-Ambiente Computacional para a Análise Inteligente de Falhas no Sistema Metroviário .82

Figura 18 -Etapas do Estudo de Caso no Sistema Metroviário

Figura 19 - Indicadores Estratégicos de Confiança no Sistema Metroviário.............86

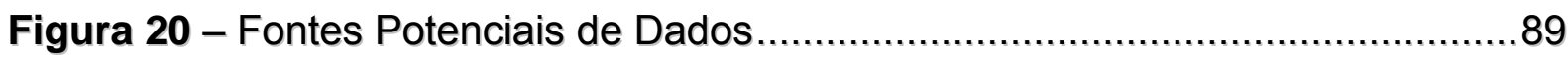


Figura 21 - Mapeamento de Dados dos Sistemas Fonte 90

Figura 22 - Matriz de Barramento nas três Perspectivas do Sistema Metroviário ...92

Figura 23 - Modelo Dimensional Proposto para o Sistema Metroviário .93

Figura 24 - Modelo Dimensional Implementado no Sistema Metroviário. .94

Figura 25 - Relação entre IECs, Tabelas Operacionais e Tabelas Dimensionais....96

Figura 26 - llustração do Processo de ETL 98

Figura 27 - Interface de Consulta OLAP Quantitativa ...............................................99

Figura 28 - Interface de Consulta OLAP Qualitativa ........................................100

Figura 29 - Interface de Consulta OLAP com Drill Down ...................................100

Figura 30 - Tecnologias Utilizadas no Ambiente Computacional Implementado ...102 Figura 31 - Variável de Tempo na Tomada de Decisões Estratégicas em Projetos de Sistemas Metroviários. 110

Figura 32 - Valor agregado na decisão estratégica, adaptado de (JUDITH, 2006) 


\section{LISTA DE TABELAS}

Tabela 1 - Acidentes de grandes proporções em Sistemas Metroviários

Tabela 2 - Parte dos acidentes de grandes proporções em Sistema Aeronáutico...24

Tabela 3 - Classificação dos Tipos de Falhas em Sistemas Críticos .36

Tabela 4 - Análises Qualitativas de Falhas no Sistema Metroviário 104

Tabela 5 - Análises Quantitativas de Falhas no Sistema Metroviário 105

Tabela 6 - Fator Tempo nas Decisões Estratégicas 


\section{LISTA DE ABREVIATURA E SIGLAS}

ALARP - As Low as Reasonably Possible

ATO - Automatic Train Operation

ATP - Automatic Train Protection

$\mathrm{BI}$ - Business Intelligence

CDM - Collaborative Decision Making

DOLAP - Desktop Online Analytical Processing

DW - Data Warehouse

DSS - Decision Support System

EIS - Executive Information System

ETL - Extract, Transform and Load

FMEA - Failure Mode and Effects Analysis

FMECA - Failure Modes, Effects and Criticality Analysis

FTA - Fault Tree Analysis

HOLAP - Hybrid Online Analytical Processing

KPI - Key Performance Indicator

MIS - Management Information System

MKBF - Mean Kilometer Between Failures

MTBF - Mean Time Between Failures

MTTF - Mean Time to Failures

MTTR - Mean Time to Repair

MOLAP - Multidimensional On Line Analytical Processing

OLAP - Online Analytical Processing

OLTP - Online Transaction Processing

ROLAP - Relational On Line Processing 


\section{SUMÁRIO}

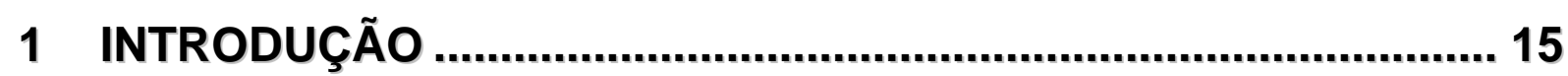

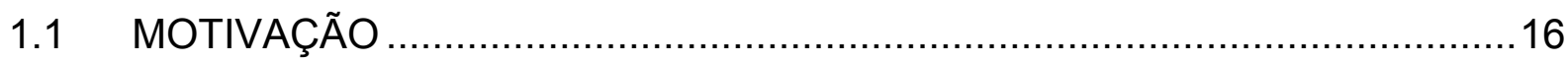

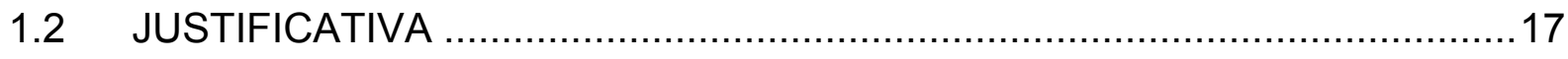

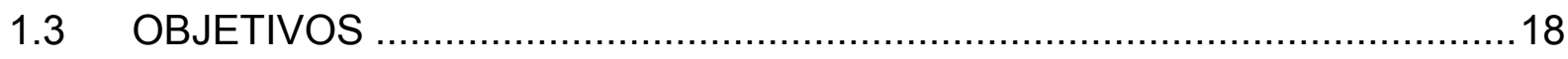

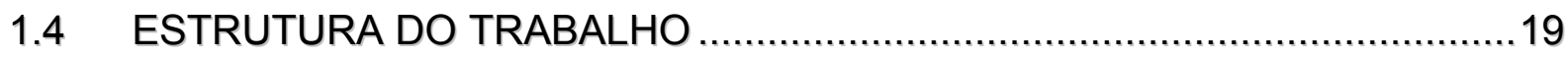

2 SISTEMAS CRÍTICOS ............................................................... 20

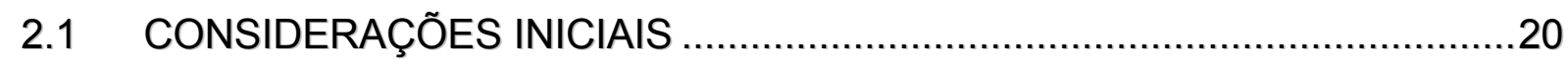

2.2 SISTEMAS CRÍTICOS NO CENÁRIO MUNDIAL.......................................21

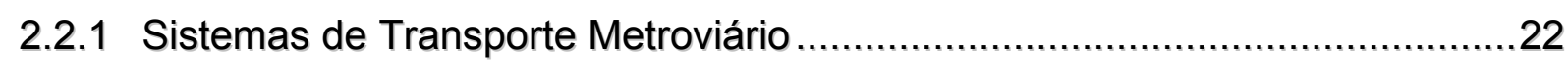

2.2.2 Sistema de Transporte Aeronáutico Civil.....................................................23

2.2.3 Sistemas de Controle De Usinas Nucleares .............................................25

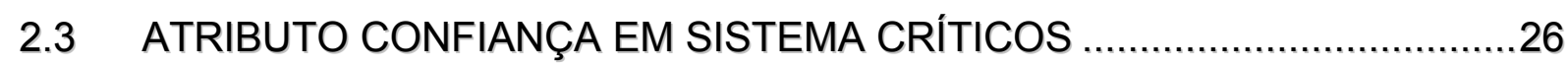

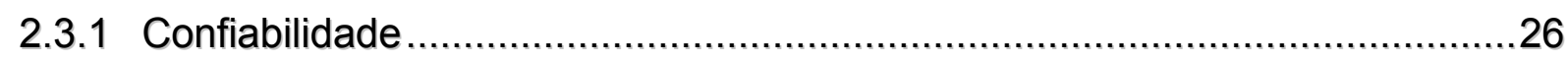

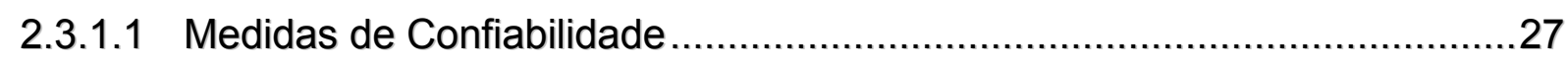

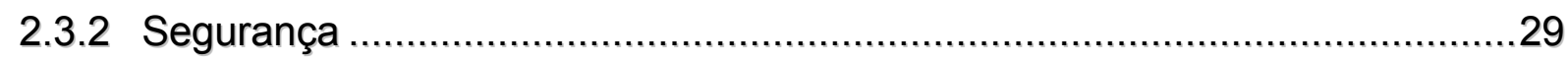

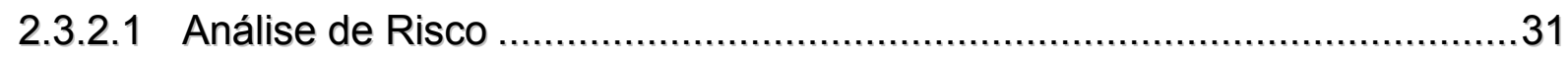

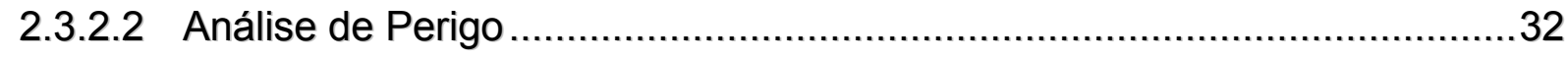

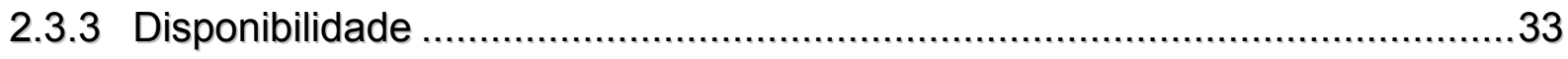

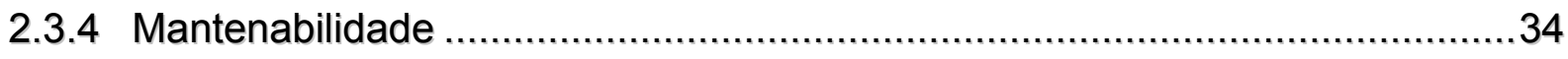

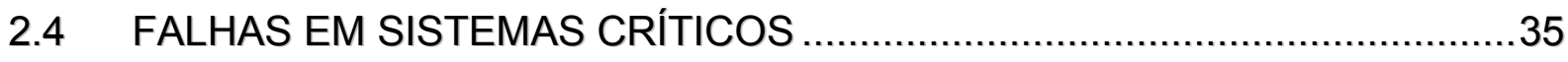

2.4.1 Classificação das Falhas em Sistemas Críticos ..............................................35

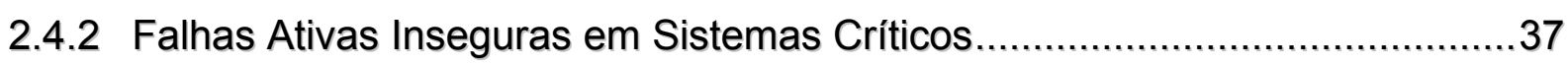

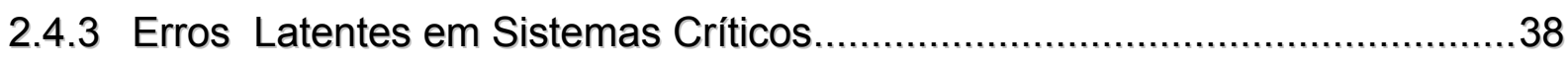




\section{SISTEMAS DE INFORMAÇÃO E INTELIGÊNCIA EMPRESARIAL..}

3.1 CONSIDERAÇÕES INICIAIS 44

3.2 PERSPECTIVAS DE SISTEMAS DE INFORMAÇÃO E DE INTELIGÊNCIA EMPRESARIAL 46

3.2.1 Perspectiva Organizacional 46

3.2.2 Perspectiva Sistêmica de Inteligência Empresarial 47

3.3 DATA WAREHOUSE. .48

3.3.1 Modelagem Dimensional 51

3.3.2 Extração, Transformação e Carga de Dados - ETL 54

3.3.3 Ferramentas Olap - Online Analytical Process 56

3.4 GESTÃO DO CONHECIMENTO. 57

4 ANÁlise INTELIGENTE DE FALHAS E A TOMADA DE DECISÕES ESTRATÉGICAS EM SISTEMAS METROVIÁRIOS

4.1 CONSIDERAÇÕES INICIAIS 60

4.2 A TOMADA DE DECISÃO 60

4.3 LIMITAÇÕES COGNITIVAS E TECNOLÓGICAS NO PROCESSO DECISÓRIO EM SISTEMAS METROVIÁRIOS

4.4 A NFORMAÇÃO EM PROJETOS DE SISTEMAS METROVIÁRIOS 65

4.5 A ARQUITETURA DA INFORMAÇÃO DECISÓRIA EM SISTEMAS METROVIÁRIOS

4.6 CICLO DE VIDA DAS INFORMAÇÕES EM SISTEMAS METROVIÁRIOS ....69

4.7 PERSPECTIVAS DE PROJETOS NO SISTEMA METROVIÁRIO. .72 


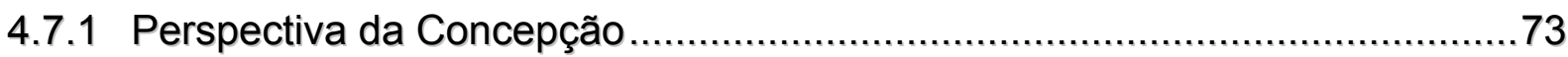

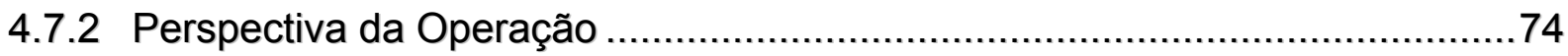

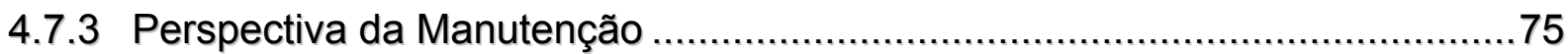

4.8 A TOMADA DE DECISÕES ESTRATÉGICAS EM PROJETOS DE SISTEMAS

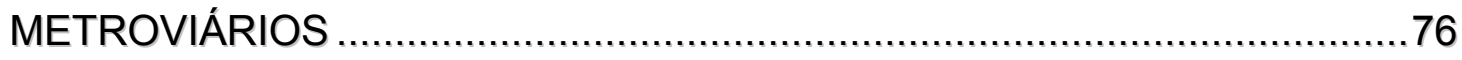

4.8.1 Decisões em Projetos de Sistemas Metroviários ............................................77

4.8.2 Elementos da Decisão em Projetos de Sistemas Metroviários........................79

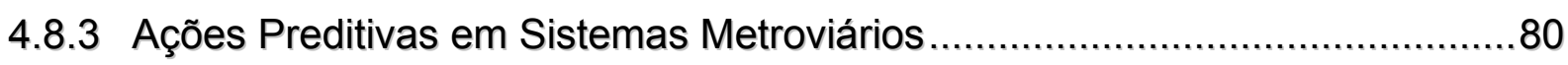

5 PROPOSTA DE ANÁLISE INTELIGENTE DE FALHAS EM SISTEMAS METROVIÁRIOS.......................................................... 82

5.1 ESTUDO DE CASO NO SISTEMA METROVIÁRIO DE SÃO PAULO ............84

5.1.1 Etapa 1: Levantamento das Necessidades de Informações .......................... 85

5.1.2 Etapa 2: Identificação das Fontes Potenciais de Dados de Falha ...................88

5.1.3 Etapa 3: Modelagem Dimensional dos Dados ...........................................91

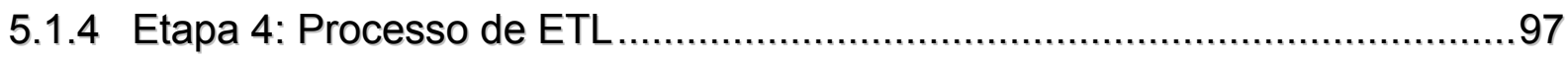

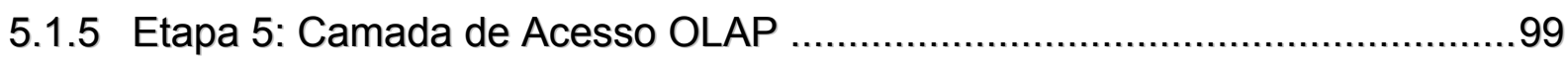

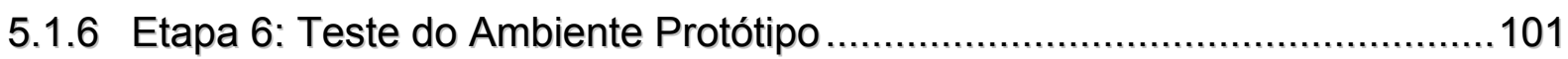

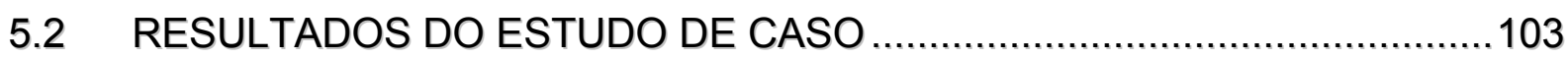

5.2.1 Consultas Olap Realizadas No Ambiente Protótipo ...................................103

5.2.2 Possíveis Decisões Estratégicas Definidas Na Análise Do Estudo De Caso106

5.2.3 A Influência do Tempo na Tomada de Decisões Estratégicas em Projetos De

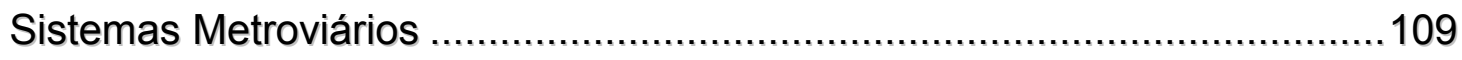

5.2.4 Valor Agregado Das Decisões Estratégicas Em Sistemas Metroviários.......110

5.2.5 Análise Do Fator Tempo No Processo Decisório ......................................112 
6 CONCLUSÕES

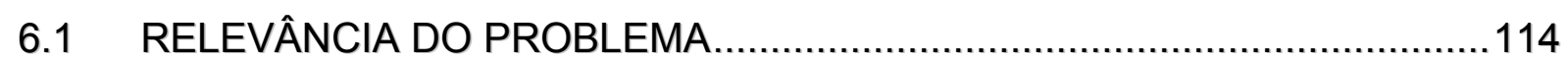

6.2 RESULTADOS ALCANÇADOS ..............................................................114

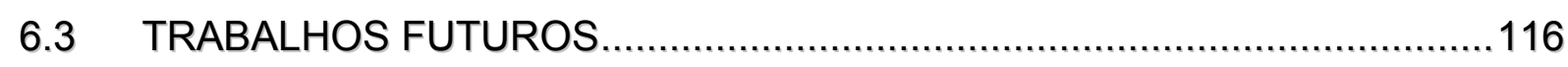

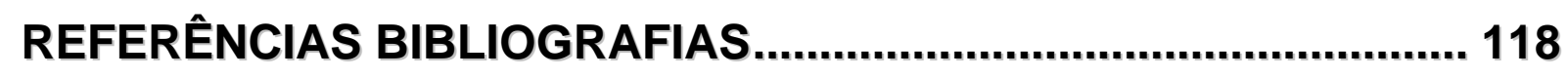

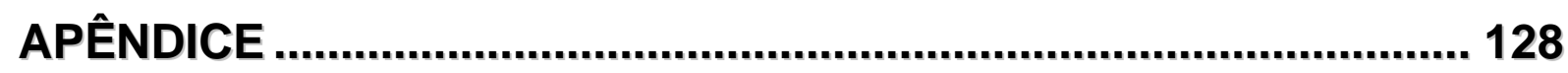




\section{INTRODUÇÃO}

Pode-se definir Sistemas Críticos como sistemas sociotécnicos dos quais as pessoas ou os negócios dependem. Por sistemas sociotécnicos entende-se que são sistemas compostos de subsistemas, ou módulos sociais (pessoas, relações, habilidades, capacidades, necessidades, etc.), e subsistemas tecnológicos (instalações, máquinas, equipamentos, tecnologia, etc.). Se tais sistemas falharem, de forma insegura, ao desempenharem suas funções previamente especificadas, podem acarretar grandes perdas econômicas, danos ambientais e ainda ameaça à vida humana (SOMMERVILLE, 2007).

Sistemas Aeronáuticos, Metroferroviários, Nucleares, Petroquímicos, entre outros, classificam-se no âmbito desta Tese como Sistemas Críticos, os quais demandam especial atenção em todas as fases de seu ciclo de vida, incluindo a concepção, a operação e a manutenção de seus módulos eletrônicos, eletroeletrônicos, mecânicos, eletromecânicos, hidráulicos, pneumáticos, computacionais, humanos, entre outros.

Além de Sistemas Críticos, outra área importante de pesquisa coberta nesta Tese refere-se a Sistemas de Informação e Inteligência Empresarial (BI - Business Intelligence). O termo Inteligência Empresarial, no aspecto da computação, foi originalmente introduzido por Hans Peter Luhn em 1958, que descreve Inteligência Empresarial como um meio de as organizações agruparem seus dados dispersos e transformá-los em informação, no tempo certo e no formato correto, para apoiar decisões estratégicas (LUHN, 1958).

Também pode-se definir Inteligência Empresarial como um conjunto de técnicas e ferramentas computacionais apropriadas para coletar, armazenar e analisar dados de diversas fontes potenciais, dentro de um intervalo de tempo aceitável para o negócio (HART, et. al 2007).

Nesse contexto, o sentido aqui empregado para inteligência refere-se à capacidade de organizar os dados de uma determinada situação, em circunstâncias para as quais o instinto, a aprendizagem e o hábito não oferecem, normalmente, subsídios 
suficientes para se obter a solução mais adequada (HOUAISS, 2007). Ressalta-se ainda que os aspectos semânticos da palavra inteligência, utilizados nesse trabalho, não têm qualquer relação com o termo Inteligência Artificial (IA).

Outro aspecto relevante para compreender a proposta deste trabalho é reconhecer que a Tomada de Decisões Estratégicas é, por natureza, não rotineira, orientada por critérios técnicos, e muitas vezes, de médio e longo prazo, situando-se a um nível institucional acima dos níveis tático e operacional. Após a decisão ter sido tomada, a estratégia escolhida deve determinar as estratégias mais específicas ao nível dos planos táticos e operacionais. Em outras palavras, a estratégia organizacional deve ser convertida em resultados e em ações concretas, uma vez que a capacidade de implementar a estratégia mais adequada é extremamente importante para agregar valores a uma organização (PORTER, 1996).

\subsection{MOTIVAÇÃO}

A importância socioeconômica em proteger Sistemas Críticos, perante os riscos e perigos existentes no ambiente em que estes estão inseridos, exige que se tenha cada vez mais rapidez em obter a informação necessária para apoiar a Tomada de Decisões Estratégicas nas perspectivas da concepção, operação e manutenção de tais sistemas. Tal panorama compõe a principal motivação para o desenvolvimento deste trabalho.

Desta forma, a rapidez em obter informações íntegras revela-se de fundamental importância para desencadear ações de melhorias na concepção, operação e manutenção de Sistemas Críticos. Tal prática já está consolidada em setores mercadológicos de sucesso, os quais, em sua maioria, encontraram o ponto de equilíbrio entre identificar problemas nos negócios, e desenvolver, rapidamente, ações para amenizar impactos negativo futuros (PORTER, 1996).

Daí a motivação em apresentar uma proposta visando a Análise Inteligente de Falhas para Apoiar a Tomada de Decisões Estratégicas em Projetos de Sistemas Críticos, escorando-se em recursos computacionais aplicados no desenvolvimento 
de Sistemas de Informação que viabilizam a implementação da Inteligência Empresarial, recurso destinado ao apoio na tomada de decisões estratégicas.

\subsection{JUSTIFICATIVA}

O uso da computação como recurso para apoiar decisões é uma prática comum em diferentes atividades organizacionais. Recursos como o CDM (Collaborative Decision Making) são utilizados na aviação para auxiliar profissionais desse setor na tomada de decisões de maneira colaborativa (ZANGISKI e LIMA , 2007).

Contudo, não há relatos acadêmicos expressivos que indiquem o uso de recursos específicos de Sistemas de Informação e Inteligência Empresarial, para apoiar a Tomada de Decisões Estratégicas em projetos de Sistemas Críticos. Verifica-se, entretanto, que organizações que operam Sistemas Críticos já vêm empregando, com sucesso, tais recursos em seus segmentos administrativos.

Um exemplo relevante do uso de Sistemas de Informação e Inteligência Empresarial em segmentos administrativos de organizações que concebem, operam e mantêm Sistemas Críticos foi identificado na Companhia do Metropolitano de São Paulo Metrô. Em 2007 a empresa recebeu o Prêmio Padrão de Qualidade em Business-toBusiness (B2B) pelos casos de sucesso na implantação de soluções de Sistemas de Informação e Inteligência Empresarial para apoiar a tomada de decisões nas áreas administrativas. Na ocasião, nenhuma das soluções destinava-se a apoiar, diretamente, decisões estratégicas em projetos de concepção, operação e manutenção do Sistema Metroviário (B2BMAGAZINE, 2008).

Verifica-se prática semelhante na indústria de transporte aeronáutico, segundo caso de sucesso divulgado pela companhia de aviação American Airlines que apontou o uso de ferramentas de Sistemas de Informação e Inteligência Empresarial na identificação de fraudes com passagens aéreas e demais indicadores econômicos (HAGEN, 2008). Até meados de 2007 não foram identificados registros públicos do uso de soluções de Sistemas de Informação e Inteligência Empresarial em setores que desenvolvem projetos de natureza crítica na companhia aérea em questão. 
Outra empresa que opera Sistemas Críticos e que também investiu em Sistemas de Informação e Inteligência Empresarial, em segmentos administrativos, foi a Petrobrás Petróleo Brasileiro S.A. Em 2002 a empresa iniciou um projeto piloto visando unificar informações dos diferentes departamentos administrativos. Em 2006 a empresa apresentou outro caso de sucesso com o uso dos mesmos recursos em segmentos administrativos (PEDROSA, 2006).

Diante do exposto, este trabalho justifica-se pela contribuição interdisciplinar de apresentar uma proposta para disseminar os fundamentos teóricos e as melhores práticas no uso de ferramentas de Sistemas de Informação e Inteligência Empresarial em indústrias que concebem, operam e mantêm Sistemas Críticos. Assim, busca-se legitimar o uso eficaz de Sistemas de Informação e Inteligência Empresarial, auxiliando, de maneira expressiva, a Tomada de Decisões Estratégicas e contribuindo com ações de melhoria no contexto de Sistemas Críticos.

\subsection{OBJETIVOS}

O principal objetivo deste trabalho é apresentar uma proposta para analisar falhas, de maneira inteligente, e subsidiar a Tomada de Decisões Estratégicas em projetos de Sistemas Metroviários, os quais classificam-se no âmbito desta tese como Sistemas Críticos. Tal proposta pretende estabelecer uma correlação entre a dinâmica proveniente de recursos e ferramentas de Sistemas de Informação e Inteligência Empresarial, e a necessidade de se obter informações precisas, em intervalos de tempo aceitáveis para agregar valores tangíveis na segurança, confiabilidade, disponibilidade e mantenabilidade de Sistemas Críticos.

A proposta aqui apresentada vem ao encontro da necessidade premente de disponibilizar, com maior eficácia, informações precisas para a aferição de indicadores importantes a um Sistema Crítico, e favorecer a implementação (em menor tempo possível) de ações mitigadoras de falhas que possam vir a comprometer o funcionamento de tais sistemas.

De forma a completar e consolidar a proposta em questão, agrega-se um segundo objetivo que é o de desenvolver e apresentar um método de análise de dados utilizando-se de recursos computacionais para análise de falhas no Sistema 
Metroviário. Tal método escora-se em fundamentos teóricos e melhores práticas de Sistemas de Informação e Inteligência Empresarial, com as especificidades inerentes a Sistemas Críticos. Busca-se avaliar tal método em um estudo de caso desenvolvido no Sistema Metroviário de São Paulo.

Esse estudo de caso deve contribuir, no aspecto conceitual, com a realização de ensaios de análises qualitativas e quantitativas de falhas, e ainda, provê informações para apoiar possíveis decisões estratégicas no sistema estudado.

\subsection{ESTRUTURA DO TRABALHO}

O Capítulo 2 apresenta fundamentos teóricos relacionados a Sistemas Críticos, tipificando-os e exemplificando, em números, sua grandeza no cenário mundial. 0 capítulo descreve ainda, conceitos relacionados ao Atributo Confiança (Dependability), a falhas ativas e erros latentes e, finalmente, a importância da informação para a tomada de ações estratégicas em Sistemas Críticos.

No Capítulo 3 são apresentados aspectos conceituais dos recursos computacionais destinadas à implementação de soluções de Sistemas de Informação e Inteligência Empresarial. Um dos principais aspectos detalhados nesse capítulo refere-se à modelagem de Data Warehouse.

No Capítulo 4 estabelece-se uma correlação entre os aspectos de Sistemas de Informação e Inteligência Empresarial, e a Teoria da Tomada de Decisões, enfatizando-se a aplicabilidade de ambos os conceitos em um Sistema Metroviário, objeto do estudo.

O Capítulo 5, apresenta a proposta central deste trabalho enfatizando-se a aplicação da tal proposta em um estudo de caso desenvolvido no Sistema Metroviário, de São Paulo, no qual busca-se enfatizar aspectos analíticos e decisórios nas perspectivas da concepção, operação e manutenção do sistema estudado.

Finalmente no Capítulo 6 são apresentadas as principais conclusões deste trabalho, bem como as propostas de trabalhos futuros. 


\section{SISTEMAS CRÍTICOS}

Neste capítulo são apresentados conceitos relevantes sobre Sistemas Críticos, destacando-se, de início, sistemas potenciais para o estudo proposto neste trabalho, como o Sistema de Transporte Aeronáutico Civil, o Sistema de Controle de Usinas Nucleares e o Sistema de Transporte Metroviário, objeto do estudo de caso. Em seguida destacam-se temas como Confiança, Falhas, Projetos e Informação em Sistemas Críticos.

\subsection{CONSIDERAÇÕES INICIAIS}

Há, na literatura, diferentes abordagens para tratar da temática "Sistemas Críticos". A preocupação em não incorrer em ambigüidade propiciada pela palavra sistema, possivelmente uma das mais excessivamente usadas e que mais sofre abusos no léxico técnico, impõe o desafio de contextualizar a natureza do sistema em estudo (PRESSMAN, 2006).

Assim, neste trabalho, busca-se enfatizar que a abordagem escolhida para referenciar Sistemas Críticos é a que os define como sistemas sociotécnicos, ou seja, sistemas compostos de muitos subsistemas ou módulos interdependentes funcionando com um objetivo.

Os Sistemas Críticos são compostos por diversos módulos potencialmente falíveis, nos quais diversos módulos funcionam entre si em numerosas relações de interdependência e que demandam, constantemente, ações preditivas, preventivas e corretivas para manterem-se protegidos de perigos, e operarem com níveis de riscos aceitáveis.

Contudo, sob o aspecto conceitual, os módulos que compõem um Sistema Crítico não podem falhar de forma insegura, ainda que em primeira instância, uma falha de menor vulto seja imperceptível, o seu desdobramento pode desencadear acidentes de grandes magnitudes, com prejuízos socioeconômicos imensuráveis e irreversíveis, acarretando, muitas vezes, a descontinuidade do sistema. 
Diante desta preocupação, pesquisadores empenham-se cada vez mais na modernização e aperfeiçoamento de mecanismos de supervisão e controle de Sistemas Críticos. Essa tendência tem uma forte ligação com a evolução dos sistemas computacionais. A computação está cada vez mais presente nos módulos de controle de Sistemas Críticos, substituindo antigos mecanismos eletrônicos e eletromecânicos convencionais (ALMEIDA JR, 2003).

No entanto, as falhas continuam presentes em Sistemas Críticos que contam com mecanismos computacionais, com o agravante da inclusão de novos problemas como erros de lógica de programação, identificados quando as rotinas operacionais estão em desacordo com as características dos mecanismos de controle, comprometendo a segurança do sistema (IAEA, 2008).

Contudo, a tendência é que os recursos da computação possam ser cada vez mais utilizados em Sistemas Críticos, seja no aperfeiçoamento de mecanismos de operação e segurança, seja no desenvolvimento de ferramentas de apoio na Tomada de Decisões Estratégicas na concepção, operação e manutenção desses sistemas.

\subsection{SISTEMAS CRÍTICOS NO CENÁRIO MUNDIAL}

O uso de Sistemas Críticos está em constante expansão no cenário mundial, o que exige dos governos, das organizações e em especial do meio acadêmico, esforços concentrados no desenvolvimento de métodos e técnicas de proteção, voltados para manter a integridade do sistema perante as ameaças do ambiente, e, por sua vez, manter o ambiente protegido perante as ameaças do sistema.

Conforme já mencionado na introdução deste trabalho, Sistemas Aeronáuticos, Metroviários, Nucleares, Petroquímicos, entre outros, classificam-se no âmbito desta tese como Sistemas Críticos. Ao identificá-los e mensurá-los no cenário mundial, enaltece-se a importância em concentrar esforços orientados a prover confiança em sistemas dessa natureza. 
Nos três subitens a seguir, sintetizam-se aspectos quantitativos de Sistemas Críticos no tocante à dimensão, ao volume de operação e aos impactos negativos causados por acidentes.

\subsubsection{Sistemas de Transporte Metroviário}

O Sistema Metroviário, é, por concepção, um sistema de transporte urbano de massa realizado por trens elétricos que circulam numa rede exclusiva, total ou parcialmente subterrânea. O sistema classifica-se como crítico, dada a premissa de manter disponível um serviço que demanda altas taxas de confiança no funcionamento de seus módulos como: material rodante, vias férreas, sistemas computacionais de controle locais e remotos, estações de embarque e desembarque, pátios de manutenção e manobra e subestações elétricas, dentre outros.

Segundo estudos publicados no periódico Jane's Urban Transport System (2007), entre os anos de 1995 e 2005 foram registrados, no mundo, 96 sistemas totalmente Metroviários (full metro), os quais compõem os seguintes indicadores:

- 44 países e 96 cidades com sistemas Metroviários em operação;

- $\quad 5.183$ estações de embarque e desembarque;

- 344 linhas com aproximadamente 9.948 km em vias férreas;

- Cerca de dezoito bilhões de passageiros transportados entre os anos de 1995 e 2005.

O Sistema Metroviário, é considerado um dos sistemas de transporte urbano mais seguro e eficiente (BNDES, 2008). Contudo, o sistema é potencialmente falível, e suas falhas inseguras podem acarretar acidentes de grandes proporções, conforme mostra a Tabela 1, composta por registros da agência mundial de noticias - AFP (Agence France-Presse) referente aos acidentes de metrô, no mundo, a partir da década de 1960 (AFP, 2007). 
Tabela 1 - Acidentes de grandes proporções em Sistemas Metroviários

\begin{tabular}{|c|c|c|l|c|}
\hline Países & Cidades & $\begin{array}{c}\text { Número de } \\
\text { Vítimas } \\
\text { Fatais }\end{array}$ & \multicolumn{1}{|c|}{ Histórico resumido do acidente } & Ano \\
\hline Alemanha & Hamburgo & 33 & Choque entre trem e metrô de superfície & 1961 \\
\hline Inglaterra & Londres & 43 & Acidente na estação de Moorgate. & 1975 \\
\cline { 2 - 6 } & 31 & Incêndio na estação de King's Cross & 1987 \\
\hline México & $\begin{array}{c}\text { Cidade do } \\
\text { México }\end{array}$ & 23 & $\begin{array}{l}\text { Duas composições do metrô se chocam } \\
\text { um contra ou outro. }\end{array}$ & 1975 \\
\hline Estados & Chicago & 11 & $\begin{array}{l}\text { Três vagões do metrô de superfície } \\
\text { descarrilam e caem rua abaixo }\end{array}$ & 1977 \\
\hline Rúdos & Moscou & 10 & Quebra de uma escada automática & 1982 \\
\hline Azerbaijão & Baku & 290 & $\begin{array}{l}\text { Incêndio acidental numa hora de grande } \\
\text { movimento entre duas estações }\end{array}$ & 1995 \\
\hline Espanha & Valência & 41 & Descarrilamento de um trem & 2006 \\
\hline
\end{tabular}

\section{Fonte: Agence France-Presse - AFP (2007).}

Diante das inúmeras variáveis existentes em projetos de Sistemas Metroviários, sempre abrangendo as perspectivas da concepção, operação e manutenção, as possibilidades de falhas em seus módulos são inúmeras, ocasionando, com certa freqüência, incidentes notáveis e acidentes de diferentes proporções. Tal cenário conclama para uma análise minuciosa de falhas e o desenvolvimento frequente de ações preditivas para assegurar a confiança nesses sistemas.

\subsubsection{Sistema de Transporte Aeronáutico Civil}

O Sistema de Transporte Aeronáutico Civil é controlado pelo órgão regulamentador da aviação civil internacional ICAO (International Civil Aviation Organization). A ele compete promover, incentivar e estabelecer padrões para a aviação civil internacional. Idealizado na convenção de Chicago em 1944, e instituído em outubro de 1947, o ICAO tem como sede a cidade de Montreal no Canadá (ICAO, 2008). No Brasil o sistema é regulamentado pela Instrução de Aviação Civil - IAC, e controlado pela Agência Nacional de Aviação Civil - ANAC.

O Sistema Aeronáutico Civil responde pelo movimento de pessoas e mercadorias pelo ar com a utilização de aviões ou helicópteros. A partir da Segunda Guerra Mundial o Sistema de Transporte Aeronáutico foi o que mais contribuiu para o traslado de longas distâncias em curto espaço de tempo. Os principais módulos do Sistema de Transporte Aeronáutico são: aeronaves, aeroportos, centros de manutenção, aerovias e sistemas de controle de tráfego aeronáutico, dentre outros. 
Desde o início da década de 1990, a aviação comercial passou a desenvolver tecnologias que buscam tornar os aviões cada vez mais automatizados, reduzindo, gradativamente, as atribuições do piloto na operação da aeronave, visando diminuir os acidentes aéreos causados por falhas humanas. Os fabricantes de aviões comerciais continuam pesquisando maneiras de melhorar os aviões, tornando-os cada vez mais seguros, eficientes e silenciosos (EMBRAER, 2008).

Evidencia-se a importância do Sistema de Transporte Aeronáutico Civil ao observar os números da International Air Transport Association (IATA), associação composta por 244 organizações aéreas, representando $97 \%$ do transporte aeronáutico regular internacional de passageiros e cargas. As companhias aéreas associadas à IATA transportam, atualmente, mais de 2 bilhões de passageiros e aproximadamente 41 milhões de toneladas de carga por ano (IATA, 2008). No Brasil, segundo a Agência Nacional de Aviação Civil (ANAC), entre os meses de janeiro a abril de 2009 foram transportados, somente por empresas nacionais, cerca de 16,6 milhões de passageiros (ANAC, 2009).

Ainda que o Sistema Aeronáutico Civil seja considerado um sistema de transporte extremamente rápido, seguro e eficaz, entre os anos de 1997 e 2007, o número de vítimas fatais em acidentes aeronáuticos de grandes proporções (mais de 150 vítimas) foi de aproximadamente 1180 pessoas, conforme descrito na Tabela 2, a qual indica o vôo, o local do acidente, o número de vítimas fatais, um histórico resumido do acidente e o ano do acontecimento (FSF, 2008).

Tabela 2 - Acidentes de grandes proporções em Sistema Aeronáutico

\begin{tabular}{|c|c|c|c|c|}
\hline Vôo / Aeronave & Local do acidente & $\begin{array}{c}\text { Número de } \\
\text { Vítimas Fatais }\end{array}$ & Histórico resumido do acidente & Ano \\
\hline Vôo Korean Air 801 & Hagåtña, Guam & 228 & Colisão próxima ao aeroporto & 1997 \\
\hline Vôo Iran Air 655 & Espaço aéreo & 290 & Ataque por míssil antiaéreo & 1998 \\
\hline $\begin{array}{c}\text { Vôo UTA 141 da } \\
\text { Union des } \\
\text { Transports Aériens }\end{array}$ & Guiné, África & 151 & $\begin{array}{c}\text { Queda Devido à falha em } \\
\text { equipamento }\end{array}$ & 2003 \\
\hline $\begin{array}{c}\text { Tupolev Tu-154 } \\
\text { Pulkovo Airlines }\end{array}$ & Rússia & 170 & $\begin{array}{c}\text { Queda Devido a ocorrência de } \\
\text { falha em equipamento }\end{array}$ & 2006 \\
\hline $\begin{array}{c}\text { Boeing 737 da Gol } \\
\text { Transporte Aéreo }\end{array}$ & $\begin{array}{c}\text { Mato Grosso, } \\
\text { Brasil }\end{array}$ & 154 & $\begin{array}{c}\text { Queda devido à colisão com jato } \\
\text { Legacy }\end{array}$ & 2006 \\
\hline Airbus A-320 & São Paulo & 187 & Problemas na aterrissagem & 2007 \\
\hline
\end{tabular}

Fonte: Flight Safety Foundation (2008) 


\subsubsection{Sistemas de Controle de Usinas Nucleares}

As Usinas Nucleares representam uma das principais fontes de energia do mundo atual. O sistema é regulamentado pela IAEA - International Atomic Energy Agency, uma organização autônoma criada pela ONU em 1957. O seu objetivo é a promoção do uso pacífico da energia nuclear no mundo (ONU, 2008).

Em Usinas Nucleares, a geração de vapor não ocorre em consequência da combustão de um material combustível como o carvão ou óleo, e sim devido à fissão de núcleos de átomos de urânio (NEA, 2004). Os principais módulos do Sistema Nuclear são: instalações industriais, reator nuclear, sistema de geração de vapor, turbinas para transformação de vapor em energia mecânica, gerador para a transformação de energia mecânica em elétrica e sistema de operação e controle.

Até março de 2008, 439 usinas estavam em operação, no mundo, representando $16 \%$ da geração de energia total mundial. Os Estados Unidos da América são o país que mais produz energia nuclear no mundo, sendo responsáveis por $30 \%$ da geração total deste tipo de energia, em 2005. Também destacaram-se: França $(16,2 \%)$, Japão $(10,3 \%)$, Alemanha (6\%) e Rússia $(5,2 \%)$. O Brasil foi responsável por $0,44 \%$ da geração de energia por fonte nuclear no mundo, no mesmo ano. (IAEA, 2008).

Assim como outros sistemas de natureza crítica, o Sistema Nuclear foi responsável por acidentes e incidentes que resultaram em ferimentos, mortes ou séria contaminação ambiental desde o seu surgimento. Um dos piores casos foi 0 acidente de Chernobyl em 26 de abril de 1986, que segundo relatos da Organização das Nações Unidas - ONU, ocorreram 56 mortes na data do acidente, e posteriormente cerca de 4.000 mortes com doenças relacionadas com o acidente (ONU, 2008).

As falhas inseguras em módulos que compõem os Sistemas de Controle de Usinas Nucleares representam as principais causas de catástrofes nesses sistemas. As Tomadas de Decisões Estratégicas, centradas na confiança desses módulos durante o projeto podem resultar em aperfeiçoamento dos mecanismos de proteção e evitar, ou ao menos, amenizar os impactos de incidentes e acidentes. 


\subsection{ATRIBUTO CONFIANÇA EM SISTEMA CRÍTICOS}

O termo "Atributo Confiança" é utilizado, nesta Tese, como substituto da palavra em inglês "Dependability", a qual reúne diversos conceitos como confiabilidade, disponibilidade, segurança e mantenabilidade (DHIRAJ, 1996).

No âmbito dos Sistemas Críticos, busca-se enfatizar que a confiabilidade, disponibilidade, segurança e mantenabilidade são atributos extremamente importantes para o pleno funcionamento dos módulos do sistema. Portanto, os conceitos do Atributo Confiança devem ser considerados na concepção, operação e manutenção de Sistemas Críticos.

\subsubsection{Confiabilidade}

O termo "confiabilidade" surgiu na indústria eletrônica dos Estados Unidos, na década de 1950, devido à preocupação com as constantes ocorrências de falhas e consequentes diminuições de disponibilidade dos sistemas eletrônicos, principalmente militares. Tal situação levou o Departamento de Defesa NorteAmericano e as indústrias eletrônicas da época a criarem um grupo de pesquisa para conduzir estudos sobre confiabilidade (VILLEMEUR, 1992).

Confiabilidade é a probabilidade de um sistema executar a função para o qual foi projetado, por um período de tempo específico, e sob determinadas condições (U.S. Department of Defense, 1998 apud MARCONIN e ABACKERLI, 2003).

A operação de um Sistema Crítico remete à probabilidade condicional, considerando o nível de confiança e o tempo que o equipamento irá levar para realizar suas funções, de forma satisfatória ou sem falha. Isto envolve operar dentro dos limites de desempenho especificados, por um dado período de tempo, ou um tempo de missão, quando o sistema for usado nas formas e propósitos pretendidos, enquanto durar a operação (SOMMERVILLE, 2007).

A análise de confiabilidade e segurança de módulos de Sistemas Críticos

fundamenta-se, não somente na necessidade de garantir a operação adequada do 
sistema, mas principalmente na necessidade de evitar falhas inseguras e catastróficas que possam afetar o funcionamento dos módulos do sistema e causar sérios danos ao meio em que este se encontra (SHELDON e JERATH, 2004).

A avaliação da confiabilidade tem papel fundamental na capacidade de identificar falhas em módulos de Sistemas Críticos e evitar o desdobramento destas falhas em transtornos operacionais. É neste contexto que a avaliação da confiabilidade adquire um elevado grau de importância, dado o seu enorme potencial para o aumento de produtividade e melhoria da qualidade de sistemas que requerem especial atenção em seu tempo de vida útil.

O tempo de vida útil dos componentes e módulos de um Sistema Crítico pode ser previsto conforme cálculos de taxas de confiabilidade. Os indicadores de confiabilidade são calculados em testes de durabilidade. Um grande número de amostragens aproxima a estimativa da probabilidade real de falhas, e com isso, proporciona a maior precisão nas estimativas de confiabilidade.

\subsubsection{Medidas de Confiabilidade}

A medida de confiabilidade mais utilizada para itens que podem sofrer reparos é o MTBF (Mean Time Between Failures), conhecido como o tempo médio entre falhas. Tal medida é utilizada para itens onde as falhas são esperadas, podendo ser reparadas antes do desgaste, quebra ou troca definitiva de determinado componente ou o módulo do sistema.

Tem-se como exemplo um veículo comercial que, após sair da fábrica, pode ter um tempo médio entre falhas de $10.000 \mathrm{~km}$. Porém, realizando-se reparos e ajustes, a vida média útil do veículo pode ultrapassar $100.000 \mathrm{~km}$ O tempo médio entre falhas é de grande importância para a manutenção de Sistemas Críticos, diante da necessidade em reparar seus módulos em prazos previamente especificados.

Outra importante medida utilizada para calcular tempo de falha é o MTTF (Mean Time To Failure) ou tempo médio até a falha. Este parâmetro é utilizado para 
estabelecer o tempo médio de operação de um Sistema Crítico, até a ocorrência da falha.

O MTTF pode ser utilizado para planejar o número de peças de reposição e os custos envolvidos com a mão de obra para realizar os reparos, e ainda estabelecer manutenções preditivas, preventivas e corretivas em Sistemas Críticos.

Em Sistemas Metroviários, o índice internacional que mede a confiabilidade dos trens é o MKBF (Mean Kilometer Between Failures) ou quilometragem média entre falhas ou avarias.

Trens mais confiáveis contribuem para que os intervalos entre os trens continuem cada vez mais regulares, o que se observa na Companhia Paulista de Trens Metropolitanos do estado de São Paulo, nos últimos anos. Em 2005, o índice de intervalos realizados em relação aos programados atingiu $91 \%$, contra $90,6 \%$ em 2004 e 89,5\% em 2003 (CPTM, 2008).

Outro exemplo da utilização do indicador MKBF encontra-se na especificação técnica referente à modernização e implantação do sistema de sinalização e controle das Linhas 1 (azul), 2 (verde) e 3 (vermelha) do Sistema Metroviário de São Paulo, no qual indica-se, no processo licitatório, que acoplamentos mecânicos e elétricos como engates, mangueiras e cabos de conexões utilizados nos trens, devem possuir MKBF de 1.000.000 km (METRO, 2009).

Finalmente, destaca-se a medida de confiabilidade MTTR (Mean Time To Repair), ou tempo médio para reparo, medido em horas. O MTTR geralmente engloba todo o período de tempo em que o equipamento está indisponível para utilização e compreende as etapas de: diagnóstico da falha, acesso aos componentes com falhas, substituição do componente, restauração e teste do sistema.

Ainda que os indicadores de MTBF, MTTF, MKBF e MTTR sejam extremamente importantes para projetos em Sistemas Críticos, não está no contexto deste trabalho explorar as expressões utilizadas para calcular esses indicadores, e sim ressaltar a importância de coletar dados, com precisão e qualidade, para subsidiar esses cálculos. 


\subsubsection{Segurança}

A segurança funcional (safety) é a probabilidade de o sistema estar em funcionamento e executar sua função corretamente ou descontinuar suas funções de forma a não provocar danos a outros sistemas ou pessoas a seu redor. Já a segurança informacional (security) é a proteção contra falhas maliciosas, visando privacidade, autenticidade e integridade de dados. No tocante a Sistemas Críticos é importante estudar a segurança funcional e a segurança informacional simultaneamente (CAMARGO JR, 2002).

O limite entre a segurança e a falta desta, está intrinsecamente relacionado com o projeto do sistema que determina a implementação de mecanismos de proteção para os módulos do sistema. A definição em utilizar controles manuais, ou automatizados, pode influenciar, diretamente, a segurança de um Sistema Crítico (REASON, 2000).

Em Sistemas Aeronáuticos ou Metroviários, por exemplo, a utilização de controles automáticos pode auxiliar na ativação de mecanismos de segurança do sistema e evitar acidentes, dada a possibilidade de ocorrência de falhas humanas, muitas vezes ocasionadas por fatores como ausência de treinamento, estresse, fadiga, condições ambientais, entre outros.

Existe uma correlação direta entre o sistema de controle e o sistema controlado, no tocante à segurança. $O$ usuário de um sistema de natureza crítica pode se adaptar a eventuais problemas operacionais oriundos de sistemas de controle, desde que seja devidamente informado e tenha sua integridade física e emocional preservada (SOMMERVILLE, 2007).

Ao longo das últimas décadas, foram criados termos especializados para discutir a segurança em Sistemas Críticos. Os tópicos a seguir resumem algumas definições referentes à segurança propostas por Leveson (1995), e adaptada por Sommerville (2007): 
- Exposição: Uma perda ou dano no sistema computacional que controla o Sistema Crítico pode expô-lo a uma condição insegura, durante um determinado período de tempo.

- Vulnerabilidade: Uma fraqueza no sistema computacional que pode comprometer a segurança do Sistema Crítico.

- Ataque: Uma exploração da vulnerabilidade do sistema computacional e consequentemente do Sistema Crítico.

- Ameaças: A possibilidade de afetar a funcionalidade do sistema computacional e comprometer a segurança do Sistema Crítico.

- Controle: Uma medida de proteção no sistema computacional que pode manter a segurança no Sistema Crítico.

As organizações que provêm Sistemas Críticos vêm desenvolvendo e aprimorando normas para projetar, construir e manter seus módulos seguros, de forma a garantir que as ameaças estejam de acordo com limites considerados seguros para a operação do sistema.

Em 1996, o Instrumentation Society of America (ISA) publicou uma norma para guiar a classificação de sistemas e instrumentos de segurança. Tal norma foi classificada como ANSI/ISA-S84, e definiu o conceito de Nível de Integridade de Segurança (Safety Integrity Level - SIL), para as indústrias de processos dos EUA (ISA, 2008).

Um ano mais tarde a Internacional Electrotechnical Commission, (IEC) publicou a norma IEC 61508 (Functional safety of electrical / electronic / programmable electronic safety-related systems - general requirements) para quantificação do grau de disponibilidade em sistemas elétricos. As duas normas sugerem metodologias para a definição do Nível SIL requerido pelo sistema de segurança, que se traduz no nível de robustez a ser implementado para minimizar os riscos dos processos (IEC, 1997). 
Para a determinação do nível de segurança exigido pelos processos nos Sistemas Críticos, devem ser analisadas, basicamente, a identificação dos perigos envolvidos e a avaliação dos riscos de cada perigo detectado. Neste caso pode-se aplicar metodologias como a HAZOP (Hazard and Operability Study) ou análise de perigo e operabilidade, desenvolvida com o intuito de examinar as linhas de processo, identificando perigos e prevenindo problemas em produtos ou sistemas.

\subsubsection{Análise de Risco}

Pode-se definir o risco como a probabilidade de ocorrer uma operação imprópria do sistema sob análise. Logo, a Análise de Riscos tem por objetivo qualificar e quantificar o impacto dos riscos existentes no ambiente e verificar quais ações de segurança são necessárias para mitigar os riscos inaceitáveis e gerenciar os riscos aceitáveis (CAMARGO JR, 2002).

Há na literatura específica, diferentes abordagens para a análise de risco, como por exemplo, as que focalizam aspectos de segurança e saúde humana, impactos ambientais e ecológicos, valores patrimoniais e financeiros, entre outras.

Sob o aspecto normativo, no que tange à segurança ocupacional, o risco pode ser considerado aceitável quando é reduzido a um nível que pode ser suportado pela organização, levando em conta suas obrigações legais e sua política de segurança ocupacional (BS OHSAS 18001:2007).

$\mathrm{Na}$ indústria crítica, a análise de risco está diretamente relacionada com a confiança do sistema. Portanto, a Análise de Risco visa identificar as vulnerabilidades encontradas no sistema, possibilitando a tomada de decisão em relação às políticas de segurança para eliminá-las, minimizá-las, ou assumi-las.

A Análise de Risco permite identificar, classificar e documentar, de forma organizada, todas as possíveis ameaças que podem comprometer a segurança de um Sistema Crítico. 
Determinados riscos em Sistemas Críticos são aceitáveis, e viabilizam sua operação. O risco deve atingir um nível baixo o suficiente, de forma que reduções maiores não sejam justificáveis dos pontos de vista técnicos e econômicos. Esse princípio é conhecido como ALARP (As Low As Reasonably Possible), conforme a Figura 1

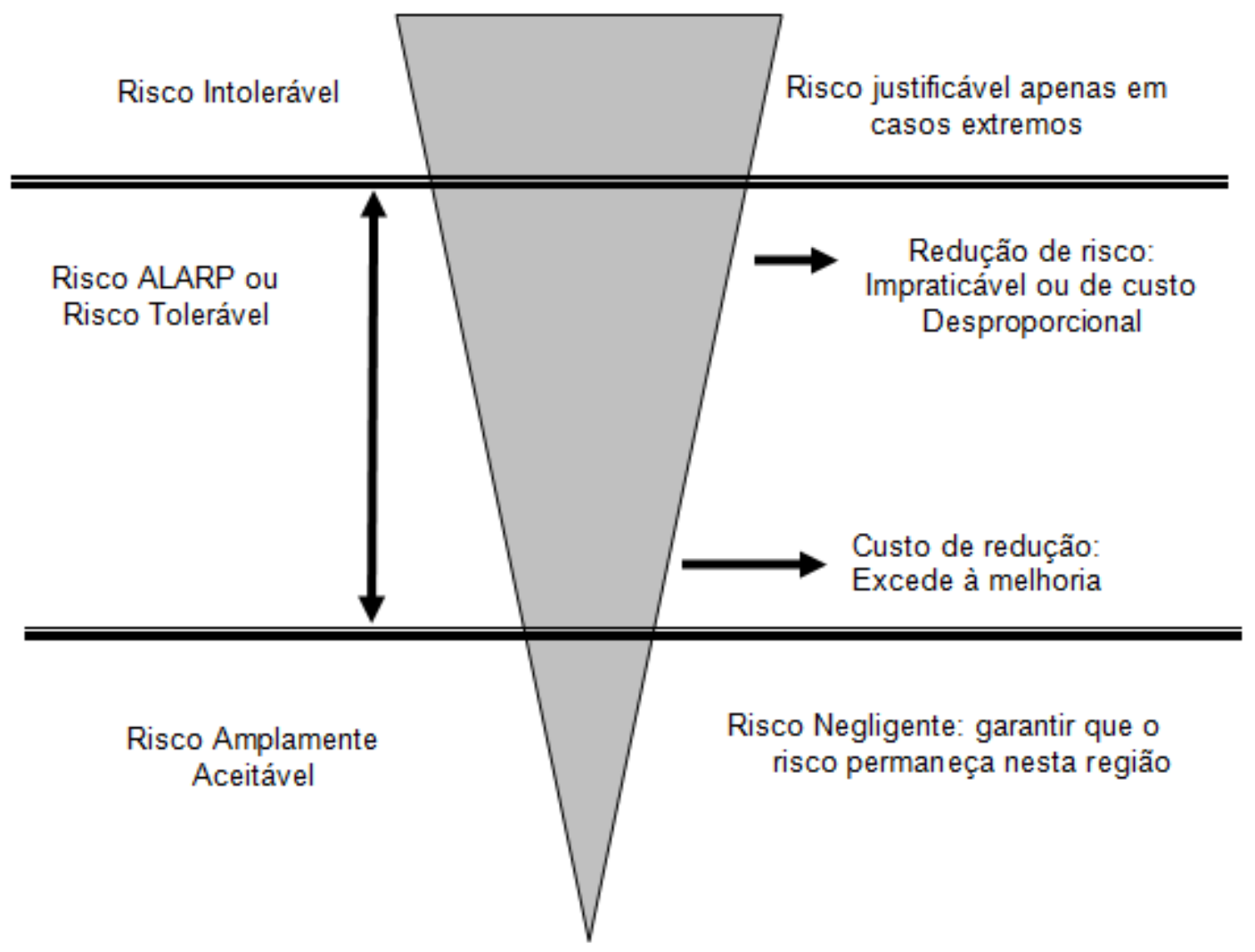

Figura 1 - Princípio ALARP (IEC, 1997)

\subsubsection{Análise de Perigo}

Define-se perigo como a fonte, situação ou ato com o potencial para provocar danos em termos de lesão ou doença de pessoas, ou uma combinação destes (OHSAS, 2007). Nesse sentido, a análise de perigo em Sistemas Críticos deve ter seu início na fase preliminar do projeto, e se estender até a fase de implantação do sistema. Nesta atividade, avalia-se a adequação dos requisitos de segurança do sistema versus as possiveis falhas, tanto em operação normal, quanto em operação degradada (CAMARGO, ALMEIDA, CUGNASCA, 2006). 
Em projetos de sistemas ferroviários, por exemplo, diversos módulos do sistema são analisados e um amplo estudo de perigo é desenvolvido para legitimar as funcionalidades do sistema de acordo com as normas vigentes. (LES, 2006).

A análise de perigo em Sistemas Críticos considera também os aspectos ambientais em que o sistema está inserido, e os possíveis desvios de processo. Para quantificar os processos em termos de consequências danosas faz-se a utilização de técnicas de análise dedutivas ou indutivas.

As técnicas dedutivas partem dos perigos existentes e perceptíveis no ambiente, ou ainda, dos desvios de processos não previstos nas fases de projetos, para propor ações corretivas. Já as técnicas indutivas investigam os possíveis efeitos de um evento danoso, possivelmente abstrato, para propor ações mitigadoras de falhas. (CALIXTO, 2006).

\subsubsection{Disponibilidade}

A disponibilidade de um sistema está diretamente associada ao seu propósito, ou seja, para sistemas que atendem diretamente à população, como os sistemas de transporte de massa, a probabilidade do mesmo estar disponível para operação, quando solicitado, é de extrema importância. Um dos principais indicadores de disponibilidade é a rapidez com que o sistema é reparado quando da ocorrência de uma falha.

No sentido literário, a disponibilidade significa "estar disponível, de forma que, quando o usuário necessitar, possa usar". Logo, a disponibilidade de um sistema pode ser considerada seu estado ativo, conforme a sua especificação funcional. A disponibilidade sistêmica pode ser avaliada de acordo com a transição entre a falha e o reparo (LAFRAIA, 2001).

A redução de falhas é de extrema importância para se alcançar a alta disponibilidade em um Sistema Crítico. A alta disponibilidade não dependente apenas de ações de proteção em módulos isolados, como sistemas computacionais, sistemas de sinalização, sistemas elétricos, entre outros. É necessária uma análise minuciosa das possíveis causas e efeitos das falhas em todos os módulos do sistema. 
Os especialistas que atuam em projetos de Sistemas Críticos devem, periodicamente, analisar as possíveis correlações entre as ocorrências de falhas e o comprometimento da disponibilidade do sistema. Tal análise pode implicar no manuseio de grandes volumes dados de falhas com precisão, rapidez e qualidade condizente com a complexidade do sistema.

Para calcular a disponibilidade em Sistemas Metroviários, por exemplo, devem-se considerar os seguintes conceitos (Metro, 2000):

- Operação Degradada: decorrente de uma falha no sistema que interfere na forma de operação dos trens, que fica prejudicada, não atendendo integralmente aos requisitos operacionais,

- Operação Paralisada: decorrente de uma falha no sistema que não permite a prestação dos serviços de operação.

- Atraso na liberação da via férrea: decorrente da pontualidade da liberação da via férrea para a circulação dos trens.

\subsubsection{Mantenabilidade}

Define-se mantenabilidade como a facilidade de realizar a manutenção em um sistema, ou seja, o tempo que se leva para que um sistema inoperante seja restaurado a um estado operacional. Tal restauração envolve a localização do problema, o reparo e a colocação do sistema em operação (WEBER, 2009).

As ações de mantenabilidade são previstas na fase de projeto de cada módulo do sistema principal. Isso significa que o sistema deve ser projetado na perspectiva de que cada módulo que o constitui, quando do processo de perda da funcionalidade ou mesmo após uma falha da função, seja recuperado para a condição de normalidade, qualquer que seja a ação de manutenção executada: corretiva, preventiva ou preditiva. 
As ações de mantenabilidade, quando focadas em reparos de módulos do sistema, dependem da detecção de falhas ativas e erros latentes, muitas vezes em tempo real. Já as ações preventivas e preditivas têm uma forte dependência de dados históricos de falhas e são planejadas na fase de projeto do sistema.

\subsection{FALHAS EM SISTEMAS CRÍTICOS}

As falhas em Sistemas Críticos estão associadas a estados anormais ou indesejáveis que comprometem o funcionamento de um ou vários módulos do sistema. Na maioria dos casos, essas falhas causam inconvenientes operacionais que comprometem a disponibilidade, mas não a segurança do sistema.

Em outros momentos, as falhas podem se desdobrar em incidentes de segurança, e desencadear acidentes, muitas vezes com danos e perdas irreparáveis ao sistema e ao ambiente em que este está inserido. Por incidentes, entende-se que são eventos que podem dar origem a um acidente ou que tinham o potencial para conduzir a um acidente (OHSAS, 2007).

As ações analíticas preditivas voltadas para identificar, remover, ou ainda, desenvolver mecanismos tolerantes a falhas são fundamentais para a operação segura do sistema. Tais ações iniciam-se na identificação e classificação das possíveis falhas que podem romper as defesas do sistema.

\subsubsection{Classificação das Falhas em Sistemas Críticos}

As falhas sistêmicas são inevitáveis e perceptíveis apenas na sua manifestação física (WEBER, 2009). Desse modo, uma análise minuciosa das falhas manifestadas torna-se extremamente importante para o desenvolvimento de sistemas tolerantes a elas. A Tabela 3 contém uma possível classificação das falhas em Sistemas Críticos. 
Tabela 3 - Classificação dos Tipos de Falhas em Sistemas Críticos

\begin{tabular}{|l|l|}
\hline \multicolumn{1}{|c|}{ Tipo de Falha } & \multicolumn{1}{c|}{ Ocorrência } \\
\hline Desenvolvimento & Na fase de concepção do sistema \\
\hline Operação & $\begin{array}{l}\text { Quando o sistema está executando suas } \\
\text { funcionalidades }\end{array}$ \\
\hline Interna & No contexto interno do sistema \\
\hline Externa & Fora do contexto do sistema \\
\hline Natural & Sem a participação humana \\
\hline Humana & Devido à participação humana \\
\hline Física & Em equipamentos físicos \\
\hline Lógica & Por uma falha na rotina programada \\
\hline Sistêmica & Em processos encadeados \\
\hline Maliciosa & Intencionalmente \\
\hline Acidental & Sem intenção prévia \\
\hline Por Incompetência & Por erro de execução de tarefa \\
\hline Permanente & Por tempo indeterminado \\
\hline Transitória & Por tempo determinado \\
\hline Fonte: Basic concepts and &
\end{tabular}

Fonte: Basic concepts and taxonomy of dependable and secure computing (AVIZIENIS et at., 2004).

$\mathrm{Na}$ classificação apresentada, é importante destacar que é possível haver a combinação entre os tipos de falhas, o que potencializa o problema e demanda especial atenção em todo o ciclo de vida do sistema. Destaca-se como exemplo uma falha na concepção que pode relacionar-se com todas as demais falhas.

Avizienis et al. (2004) propõem ainda uma taxonomia para relacionar, e ao mesmo tempo diferenciar conceitos como defeito (fault), erro (error) e falha (failure) em um sistema. Pode-se afirmar que a especificação de um sistema constitui um dos principais aspectos a serem verificados em Sistemas Críticos.

Nesse sentido, a especificação de um Sistema Crítico deve ter as características de ser completa, consistente e compreensível, não devendo conter ambiguidades. Se o comportamento de um sistema desviar-se do especificado, tem-se a ocorrência de uma falha, a qual refere-se ao comportamento externo inadequado do sistema, comportamento esse resultante de problemas internos. Esses problemas internos recebem a denominação de erros e são, por sua vez, causados por componentes ou 
módulos com defeito. O defeito de um componente ou módulo pode ser causado por problemas mecânicos, elétricos, hidráulicos, entre outros. Na Figura 3 é ilustrado o encadeamento entre o defeito, o erro e a falha (ALMEIDA JR, 2003).

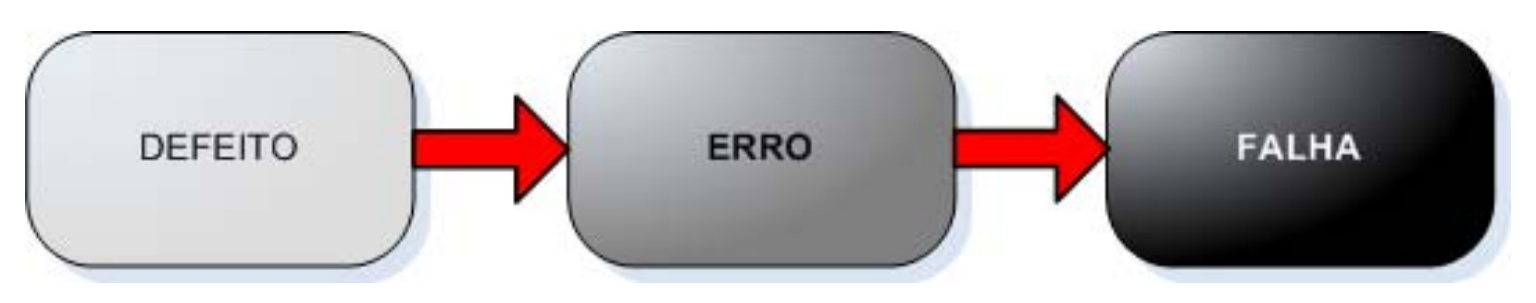

Figura 2 - Desencadeamento da Falha, adaptado (ALMEIDA JR, 2003)

É importante ressaltar que nem todos os defeitos resultam em erros e, da mesma forma, nem todos os erros produzem falhas. Um defeito pode ficar contido, não levando problemas aos módulos ou subsistemas, não provocando erros. De maneira similar, um erro pode permanecer restrito ao módulo ou subsistema, não sendo exteriorizado na forma de uma falha.

\subsubsection{Falhas Ativas Inseguras em Sistemas Críticos}

Falhas ativas inseguras são disfunções externalizadas que, ao ultrapassarem as defesas do sistema, podem causar acidentes. Tem-se como exemplo, uma falha no sistema de sinalização do Sistema Metroviário, no qual a violação da distância mínima entre dois trens seguida de uma segunda falha no sistema de frenagem pode aumentar a probabilidade de colisão entre os trens.

As falhas ativas inseguras são ocasionadas por atos ou atitudes que iniciam processos equivocados no sistema. Muitas vezes são ações cometidas por pessoas que estão em contato direto com o sistema, podendo assumir diferentes formas: deslizes, lapsos, perdas, erros e violações de procedimentos. As falhas ativas inseguras geralmente têm um impacto de curta duração sobre o sistema, porém, ao romperem suas defesas, podem causar acidentes de grandes proporções (REASON, 2000).

A detecção de falhas ativas inseguras em Sistemas Críticos requer especial atenção. $O$ intervalo médio entre a detecção e o reparo da falha deve ser 
previamente especificado na fase de projeto, na qual o foco principal é a segurança. No entanto, outros aspectos como a confiabilidade, a disponibilidade e a mantenabilidade também são importantes para que o sistema possa atingir seus objetivos. A decisão de parar um trem em um sistema Metroviário, por exemplo, pode ser pré-programada no sistema computacional de controle, quando este módulo de controle detectar uma condição insegura no sistema.

Tão importante quanto detectar e acionar mecanismos tolerantes a falhas, são as ações que garantem o registro imediato dessas ocorrências, e viabilizam o acionamento de recursos para análises posteriores e futuras ações corretivas.

\subsubsection{Erros Latentes em Sistemas Críticos}

Erros latentes são anomalias que podem surgir no sistema e não trazer nenhuma consequência imediata. Tais falhas podem permanecer dormentes no sistema por muito tempo, e descobertas apenas quando uma ou mais defesas do sistema falhar. Os erros latentes transformadas em falhas ativas inseguras podem ultrapassar as defesas do sistema e provocar acidentes. A Figura 3 representa a transformação dos erros latentes em falhas ativas inseguras (REASON, 2000).

Nessa figura, os furos atravessados pela seta preta representam o alinhamento entre os eventos de falhas que se tornaram ativos e inseguros, rompendo as defesas do sistema. Já os furos menores, representam os erros latentes, ainda não manifestadas no sistema, portanto, de difícil identificação. Assim, uma atuação fundamental no sentido de aumentar a confiança de um Sistema Crítico está na detecção prévia dessas falhas. 


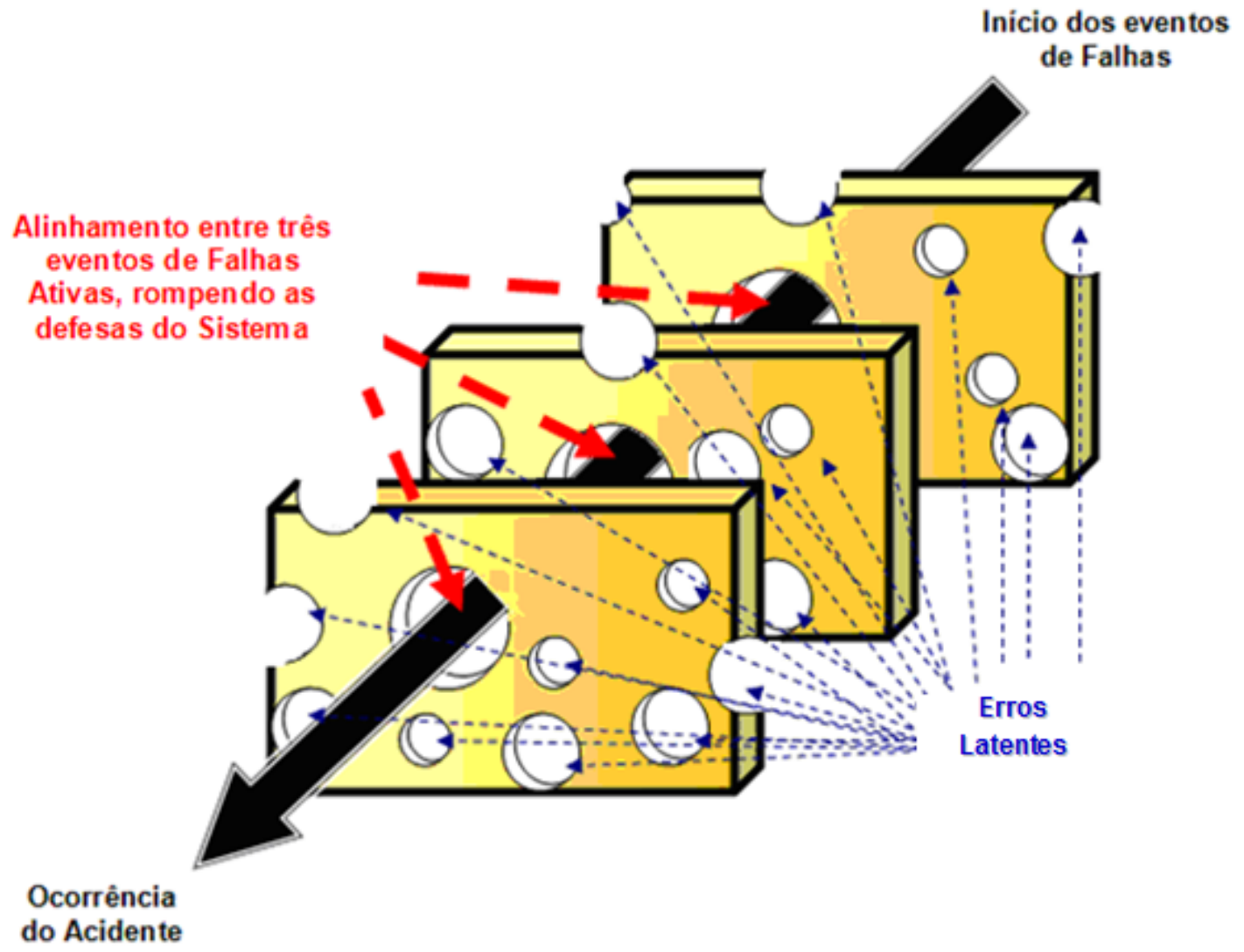

Figura 3 - Alinhamento das Falhas Ativas Inseguras (REASON, 2000)

Um exemplo notável no registro de erros latentes é o da NASA (National Aeronautics and Space Administration), que mantém o centro de pesquisa Ames Research Center em Moffett Field, Califórnia, destinado a receber informações do sistema de aviação, por meio do Aviation Safety Reporting System - ASRS (NASA, 2008).

Nesse sistema os trabalhadores do transporte Aeronáutico comunicam situações críticas vividas no cotidiano do trabalho. Essas informações são analisadas e armazenadas em bancos de dados para apoiar ações estratégicas preditivas.

Por meio do ASRS todos os trabalhadores da aviação são incentivados a registrar eventos críticos ou incidentes. A participação voluntária se dá na perspectiva de se desenvolver ações preditivas e minimizar as probabilidades de acidentes Aeronáuticos. Pilotos, controladores de tráfego, comissários de bordo, mecânicos, inclusive pessoal de terra, são sensibilizados a relatar para a NASA fatos ou situações em que a segurança da aviação possa ser comprometida. 
Toda participação é espontânea, e o sigilo da informação é assegurado por lei. Todas as informações recebidas são analisadas e passam a fazer parte de um banco de dados. Mensalmente um boletim com os casos mais críticos é encaminhado a todos os participantes do sistema, democratizando a informação das ocorrências mais significativas em termos de risco.

O modelo similar brasileiro é o Relatório de Perigo (RELPER), documento que contém o relato de fatos perigosos ou potencialmente perigosos para a segurança de Vôo. O RELPER é uma importante ferramenta da Prevenção de Acidentes Aeronáuticos, pois permite que qualquer pessoa reporte situações perigosas ou potencialmente perigosas observadas, ou que delas teve conhecimento (CENIPA, 2008).

O RELPER destina-se, exclusivamente, a apoiar ações preditivas e preventivas de acidentes aeronáuticos, por intermédio de alerta aos responsáveis pela manutenção das condições de segurança da atividade aérea. Tais alertas são armazenados em sistemas computacionais.

Os sistemas computacionais são essenciais para auxiliar os projetistas especializados em detecção de erros latentes, em especial no que tange à coleta, o armazenamento e análise de registros de falhas, e consequentemente o apoio a decisões preditivas em projetos de tais sistemas.

As equipes de projetos em Sistemas Críticos podem estabelecer cenários para testarem módulos e verificarem como uma falha pode afetar a operação do sistema, e a análise preditiva pode oferecer dados históricos e até dados em tempo real, para auxiliar a detecção de possíveis erros latentes que venham a se manifestar a qualquer momento no sistema.

\subsubsection{Análise Preditiva de Falhas em Sistemas Críticos}

A análise preditiva, como é chamada, é comumente aplicada em setores financeiros para a detecção de fraudes, em operadoras de telecomunicações para monitorar serviços e detectar se existe algum problema em contratos firmados com 
determinado cliente, e se esse problema pode ter impacto nos serviços acordados com o cliente.

$\mathrm{Na}$ indústria, é comum o emprego do termo "Manutenção Preditiva", termo este associado a "predizer", ou seja, prever as falhas em equipamentos ou sistemas por meio do acompanhamento dos diversos parâmetros, antes das intervenções no sistema em operação. (OTANI e MACHADO, 2008).

A análise preditiva pode oferece vantagens estratégicas para projetos em Sistemas Críticos, no que tange à descoberta de condições inseguras no sistema. Estrategicamente, a análise preditiva pode fornecer bases qualitativas $e$ quantitativas para identificar e avaliar problemas, e buscar, antecipadamente, possíveis soluções.

Organizações especializadas em análise e manutenção preditiva na indústria convergem para a necessidade estratégica de coleta de dados que possibilitem a análise de tendências de falhas em equipamentos, se possível em operação, com o mínimo de interferência no sistema.

Esses dados que se originam de módulos do sistema, são coletados e transformados em informações e aferidos com técnicas analíticas, que geram modelos para a classificação, segmentação, previsão, reconhecimento de padrões, detecção de seqüências, entre outras condições associadas a falhas.

A utilização de técnicas analíticas preditivas tem como objetivo antever o grau de degradação que um módulo de um sistema atinge, ou se aproxima do limite previamente especificado. Isto permite uma preparação prévia do serviço de manutenção, além de outras decisões operacionais, táticas e estratégicas para manter o sistema. Seguem alguns exemplos de técnicas utilizadas para análise preditiva na indústria (OTANI e MACHADO, 2008).:

- Termografia em instalações elétricas: Detecta equipamentos defeituosos ou com mau contato.

- Ensaios Elétricos: Avalia corrente elétrica, tensão, perdas e/ou rigidez e espectro de corrente ou tensão. 
- Análise de Temperatura: Mede a temperatura de barramentos e conexões elétricas.

- Análise de Interferência de Sinal: Avalia ruídos e interrupções no envio e recebimento de sinais.

A combinação dos métodos de análise preditiva com a experiência dos projetistas resulta em conhecimento para subsidiar decisões críticas, como por exemplo, substituição de determinados módulos, e até mesmo a troca de fornecedores.

A análise preditiva pode subsidiar ações estratégicas, táticas e operacionais na concepção, operação e manutenção de Sistemas Críticos. Estrategicamente, a análise preditiva fornece subsídios qualitativos e quantitativos para, rapidamente, identificar, avaliar e implementar ações de melhoria no sistema. Taticamente, a análise preditiva pode ser um importante recurso para identificar erros latentes e orientar as equipes de projeto. Já no aspecto operacional, a análise preditiva deve ser utilizada para evitar falhas inseguras e possíveis incidentes e acidentes de grandes proporções.

Diante dos pontos observados no decorrer do Capítulo 2, enfatiza-se que a proposta para análise inteligente de falhas apresentada nesse trabalho, contextualiza-se no âmbito estratégico das organizações provedoras de Sistemas Críticos. Tal contextualização não considera aspectos táticos e operacionais de análise e decisão em tempo real. 


\section{SISTEMAS DE INFORMAÇÃO E INTELIGÊNCIA EMPRESARIAL}

Neste capítulo são apresentados os fundamentos teóricos dos Sistemas de Informação e da Inteligência Empresarial. Ambos os conceitos envolvem um conjunto de técnicas e ferramentas destinadas ao agrupamento e a transformação de dados em informações relevantes para apoiar atividades estratégicas nas organizações (WATSON e WIXOM, 2007).

As ferramentas utilizadas em Sistemas de Informação e Inteligência Empresarial podem gerar receitas, reduzir despesas e até mesmo impulsionar novas estratégias de negócio. Em pesquisa realizada pelo instituto Interactive Data Corporation (IDC) no início de 2006 com 372 empresas de grande porte (com mais de 500 funcionários), constatou-se que para $80 \%$ das empresas as soluções de Sistemas de Informação, em particular a Inteligência Empresarial, seriam prioridades de investimentos para aquele ano. Os mesmos resultados foram apurados em estudo realizado junto a 311 empresas de médio porte, de 100 a 499 funcionários (IDC, 2006).

Em 2007, em uma pesquisa realizada pelo Edge Group, empresa especializada em analisar impactos da tecnologia nos negócios do Brasil, constatou que $98 \%$, de 60 grandes organizações brasileiras utilizavam ferramentas de Sistemas de Informação e de Inteligência Empresarial em segmentos administrativos. As áreas que mais utilizam os recursos, segundo o estudo, eram a Comercial $35 \%$, seguidas pela Financeira 19\% e pela de Logística 14\% (EDGE GROUP, 2007).

Segundo o Gartner Group em 2008 os Sistemas de Informação, dentre eles os sistemas de Inteligência Empresarial, estavam no topo das prioridades tecnológicas de executivos de $\mathrm{Tl}$ em todo o mundo. Em 2011, o faturamento mundial do setor deve atingir sete bilhões de dólares. Até lá, o segmento deve crescer por volta de $9 \%$ ao ano. Em países como Brasil e México, que ficam um pouco atrás na curva de adoção, o Gartner Group acredita em investimentos maiores e crescimento acima de 10\% ao ano (GARTNER GROUP, 2008). 


\subsection{CONSIDERAÇÕES INICIAIS}

O conceito de Inteligência Empresarial, ou ainda de Inteligência nos Negócios, conduz muitas vezes o leitor a associar esse conceito apenas às atividades administrativas e de negócio nos segmentos comerciais e financeiros, ainda que já existam indicações de seu uso em outros setores do mercado (MATHEUS, R. e PARREIRAS, 2004).

Tal como acontece com muitos conceitos genéricos, Inteligência Empresarial também pode incorrer um alto grau de ambiguidade. Muitos autores consideram que Inteligência Empresarial trata da visualização inteligente de dados com o uso de recursos computacionais (BARBIERI, 2001), já outros descrevem Inteligência Empresarial como uma ferramenta de auxilio no gerenciamento estratégico empresarial, por intermédio da tecnologia da informação (AZVINE et al. 2006).

Nesse sentido é importante considerar a inter-relação entre dados, informação e conhecimento. Os dados são elementos brutos, sobre os quais não há, previamente, a atribuição de um significado. Já a informação advém da contextualização e processamento dos dados. Por fim, o conhecimento é a informação processada cognitivamente pelos indivíduos. O grande desafio dos tomadores de decisão é implementar recursos adequados para auxiliar os indivíduos no processo de transformação de dados em informação e de informação em conhecimento. (ANGELONI, 2003).

Quando se traça um paralelo entre as atividades estratégicas de negócio e as atividades de projetos em Sistemas Críticos, nota-se importante semelhança na necessidade em obter conhecimento, no menor tempo possível, para identificar tendências, antever problemas e evitar futuros desdobramentos negativos em todas as fases de projeto de um Sistema Crítico.

Na Figura 4 são apresentados dois cenários decisórios, o cenário $A$, no qual se toma decisões sem o auxílio do recurso de Sistemas de Informação e Inteligência Empresarial, e o cenário $\mathrm{B}$, no qual se toma decisões com o auxilio de tais recursos. 
Cenário A : sem Sistemas de Informação e Inteligência empresarial $\Delta \mathrm{t}_{1}+\Delta \mathrm{t}_{2}+\Delta \mathrm{t}_{3}+\Delta \mathrm{t}_{4}+\Delta \mathrm{t}_{5}=\mathrm{Td}$ (Tempo da Decisão)

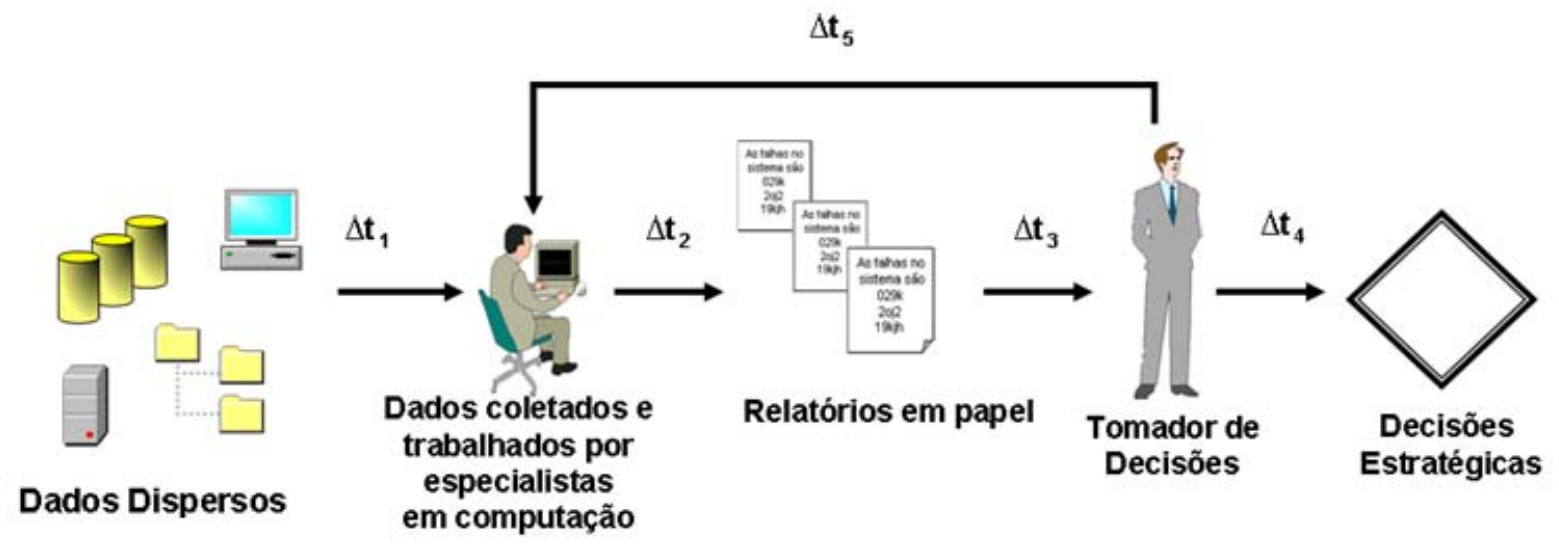

Cenário B : com Sistemas de Informação e Inteligência empresarial $\Delta \mathrm{t}_{1 \mathrm{a}}+\Delta \mathrm{t}_{2 \mathrm{a}}+\Delta \mathrm{t}_{3 \mathrm{a}}=\mathrm{Td}$ (Tempo da Decisão)

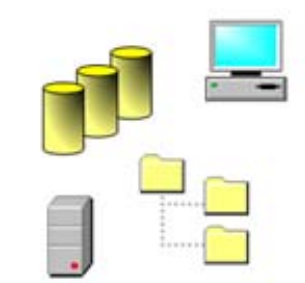

Dados Dispersos

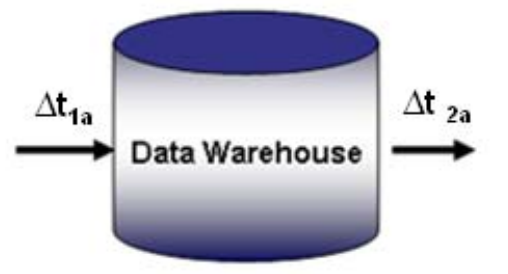

Informações coletadas e Tomador de armazenadas em Depósito de Decisões Dados devidamente modelados

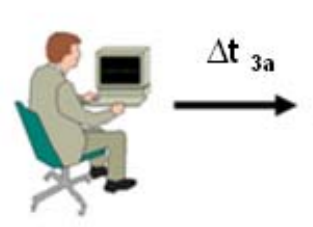

Decisões Estratégicas

\section{Figura 4 - Cenários de Tomada de Decisões com e sem recursos de Sistema de Informação e Inteligência Empresarial}

No cenário $A$, destacam-se cinco intervalos de tempo no processo decisório, são eles: $\Delta t_{1}$ é o tempo para um especialista em computação coletar os dados dispersos nas ambientes operacionais, $\Delta \mathrm{t}_{2}$ é o tempo para gerar relatórios em papel, $\Delta \mathrm{t}_{3}$ é o tempo para o decisor analisar os dados, $\Delta \mathrm{t}_{4}$ é o tempo gasto para a tomada das decisões, e finalmente, $\Delta t_{5}$ é o tempo para eventual solicitação de mais dados.

Já no cenário $B$, os intervalos representam, com alto grau de abstração, apenas três intervalos de tempo, sendo: $\Delta \mathrm{t}_{1 \mathrm{a}} \mathrm{O}$ tempo gasto na coleta e armazenamento dos dados com ferramentas computacionais, $\Delta \mathrm{t}_{2 \mathrm{a}} \mathrm{o}$ tempo de análise dos dados na base 
de dados previamente modelada e, finalmente $\Delta t_{3 a} \circ$ tempo de tomada de decisão. Considerando-se os avanços da computação, admite-se a que a base de dados utilizada no cenário B é capaz de armazenar todas as informações disponíveis na organização.

Comparando-se os dois cenários, pode-se afirmar que a economia de tempo no cenário $B$, com relação ao cenário $A$, é bastante significativa, proporcionando um tempo maior para as fases de análise e tomada de decisões, extremamente críticas a qualquer que seja a área envolvida.

\subsection{PERSPECTIVAS DE SISTEMAS DE INFORMAÇÃO E DE INTELIGÊNCIA EMPRESARIAL}

As iniciativas de Sistemas de Informação e de Inteligência Empresarial surgiram como uma resposta natural da computação às necessidades organizacionais de acessar e analisar, simultaneamente, dados contidos em diferentes sistemas operacionais. A esse respeito, o advento da computação revolucionou o conceito de agrupar dados para transformá-los em informação, em intervalos de tempo expressivamente menores do que os atingidos pelo ser humano.

\subsubsection{Perspectiva Organizacional}

As organizações modernas são fortemente dependentes de informações que utilizam com vistas ao desenvolvimento de suas ações estratégicas. Neste sentido, pode-se dizer que Sistemas de Informação são utilizados na perspectiva da Inteligência Empresarial e consistem na criação de meios para sistematização dos processos de coleta, tratamento e análise de informações sobre diferentes aspectos dos ambientes internos e externos da organização tais como: concorrentes, mercado, parceiros ou aliados, fabricantes, clientes, governos, entre outros. (TERRA, 2001).

$\mathrm{Na}$ perspectiva organizacional as iniciativas de Sistemas de Informação e Inteligência Empresarial têm como objetivo permitir que os tomadores de decisão das organizações antecipem-se às tendências dos mercados de interesse e avaliem 
as oportunidades e ameaças de negócio com informações mais precisas. (TAFNER e BERNHARDT, 2007)

Quando essas informações são colocadas em um único sistema, responsável pela criação de significado, as mesmas são transformadas em conhecimento pelos colaboradores da organização, detectando possibilidades de inovação, ameaças ou oportunidades (CHOO, 2003).

Sob o aspecto conceitual, são várias as finalidades da aplicação de Sistemas de Informação e Inteligência Empresarial, dentre as quais se destacam (BARBIERI, 2001):

- Maior eficácia na implementação de ações estratégicas;

- Aumento na detecção de oportunidades e ameaças;

- Mais agilidade no acesso a dados para tomada de decisão;

- Melhor avaliação do perfil do cliente;

- Melhor avaliação de parceiros e fornecedores.

Já no âmbito de Sistemas Críticos busca-se transpor os fundamentos aplicados em segmentos mercadológicos e agregar valores tangíveis nas decisões relativas à concepção, operação e manutenção de tais sistemas.

\subsubsection{Perspectiva Sistêmica de Inteligência Empresarial}

Nas últimas quatro décadas surgiram importantes iniciativas sistêmicas em torno da temática "Apoio à Tomada de Decisão", que antecederam, e, de certa forma, estão intrínsecas nas técnicas e ferramentas de Sistemas de Informação (LAUDON e LAUDON, 2007), são elas:

- Sistema de Informações Gerenciais - SIG (Management Information Systems - MIS): O objetivo de um SIG é fornecer informações para a tomada de decisões no âmbito gerencial da organização. São implementados para 
receberem dados operacionais e produzirem informações quantitativas e qualitativas para o nível gerencial.

- Sistema de Apoio Executivo - SAE (Executive Information System - EIS): O SAE é uma categoria de SIG destinada ao corpo de executivos da organização. O uso de recursos gráficos e até mesmo áudio visuais é comum nas soluções de SAE. São implementados para receberem dados dos ambientes internos e externos, e apresentarem para os executivos de alto escalão indicadores de desempenhos nos negócios.

- Sistemas de Apoio à Decisão - SAD (Decision Support Systems - DSS): Um SAD recebe, como entrada, alternativas para solução de um problema e responde com as conseqüências para cada alternativa. Assim o administrador pode avaliar qual é a melhor alternativa. A diferença para o SIG é que um SAD oferece recursos interativos para simular situações decisivas com o usuário. São implementados para receberem dados sumarizados e apoiarem os especialistas com simulações e aferições diversas.

- Sistemas de Apoio a Decisões Colaborativas - SDC (Collaborative Decision Making - CDM): O CDM é um conjunto de aplicativos que visa melhorar as operações de vôo mediante o crescente envolvimento dos operadores de aeronaves e de aeroportos no processo de gerenciamento de tráfego aeronáutico (ZANGISKI e LIMA, 2007).

A correta utilização de um Sistema de Informações implementado com os recursos anteriormente apresentados, pode prover vantagem competitiva e aumentar a eficácia empresarial, diminuindo o nível de risco nas decisões estratégicas, táticas e operacionais nas organizações (OLIVEIRA, 2008).

\subsection{DATA WAREHOUSE}

O conceito Data Warehouse foi introduzido por Bill Inmon no início da década de 1980 como um armazém de dados corporativo não volátil, crescente no tempo, 
integrado e orientado ao negócio para dar suporte à tomada de decisões (INMON, 2005).

O uso de Data Warehouse viabiliza o armazenamento, a integração e o acesso aos dados de várias áreas da organização. Tais dados são selecionados de acordo com o tipo de decisões a serem tomadas pelos estrategistas. O Data Warehouse é a fonte de dados para consulta das principais informações da organização (KIMBALL, 1996).

Por concepção, os dados em um Data Warehouse não estão, normalmente, tão atualizados quanto os dados do ambiente operacional. Tal problema ocorre devido à periodicidade de atualização dos dados no Data Warehouse. Existem estudos acadêmicos que defendem o uso do Data Warehouse como uma solução de acesso a informações em tempo real (NGUYEN et al. 2005). Contudo, tal recurso não está no escopo deste trabalho.

Uma das formas de apresentação do Data Warehouse é feita por Bill Inmon, sob o título de "Fábricas de Informações Corporativas" (INMON, 2007). Na Figura 5 exemplifica-se esse ambiente.

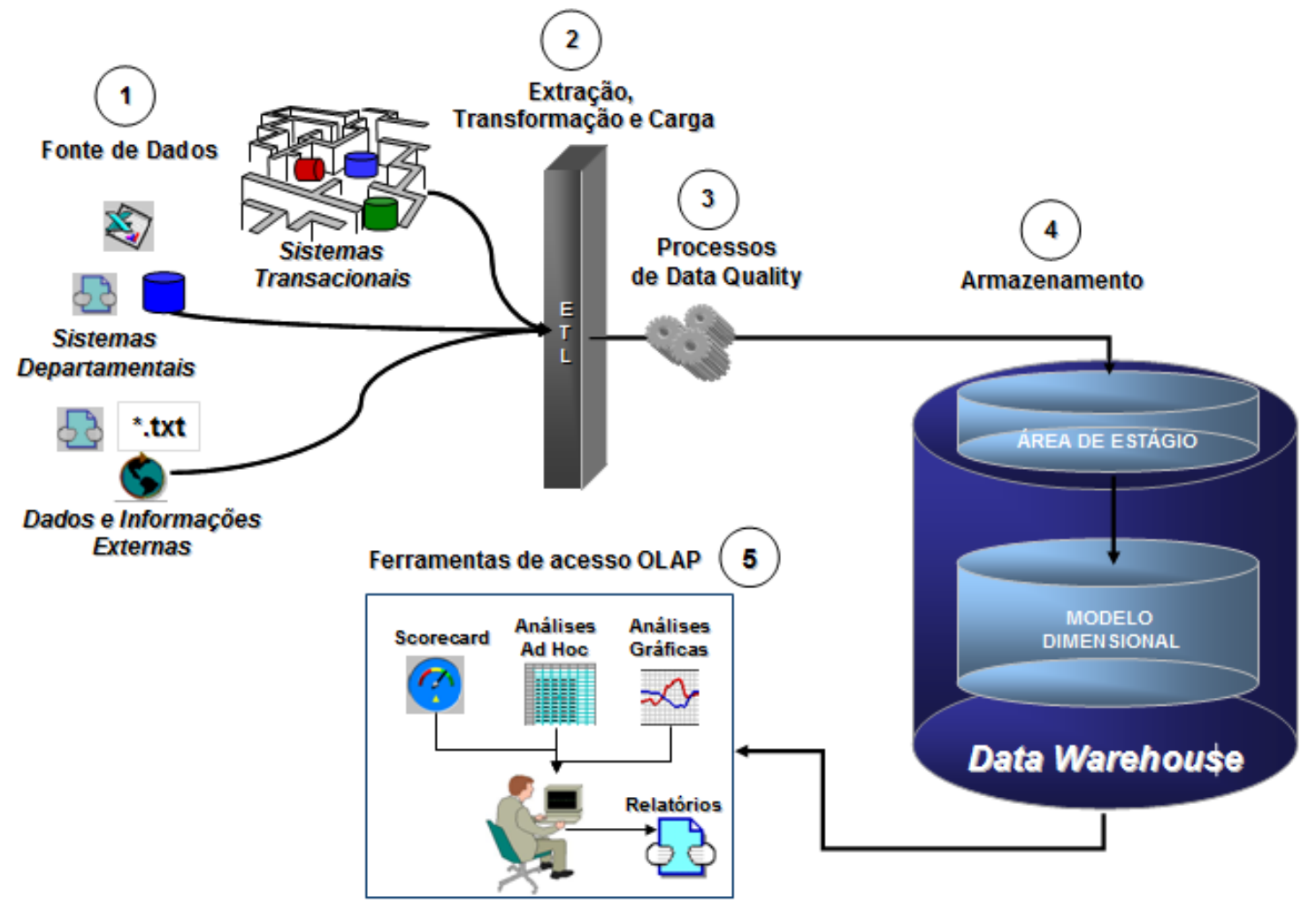

Figura 5 - Corporate Information Factory (INMON, 2007) 
Na Fábrica de Informações Corporativa, nota-se a existência de fontes de dados compostas por sistemas transacionais corporativos, sistemas departamentais, dados e informações externas, armazenados em documentos de texto, planilhas eletrônicas (1).

Em seguida, os dados passam pelos processos de extração, transformação e carga (Extract, Transform and Load - ETL) e Qualidade de Dados (2 e 3), antes de serem armazenados no Data Warehouse (4). Eventualmente, um ambiente de Data Warehouse pode conter ainda uma área para o armazenamento de dados replicados do ambiente operacional, tal área é comumente conhecida como Área de Estágio (Operational Data Storange - ODS).

Após o tratamento e a transferência dos dados já preparados para o Data Warehouse (4), os dados são disponibilizados para o acesso com ferramentas analíticas (5), também conhecidas como ferramentas OLAP (Online Analytical Process).

A questão que se coloca é porque montar um ambiente distinto do ambiente operacional, considerando todas as questões relativas à necessidade de mais recursos computacionais e de pessoas. A resposta está ancorada, principalmente, em três aspectos:

- Não atrapalhar as operações cotidianas e que dão sustento à empresa, por meio da realização de consultas nas bases de dados operacionais, que poderiam congestionar tal ambiente computacional, paralisando as operações da empresa;

- Poder armazenar grandes históricos de dados, relativos a grandes períodos de tempo, o que não é factível, na prática nas bases de dados operacionais, principalmente por questões de desempenho;

- Concentrar os dados úteis à análise em um ambiente centralizado, provendo, ainda, a qualidade necessária aos dados, que sofrem, normalmente, de falta de padronização entre as diversas bases de dados operacionais. 


\subsubsection{Modelagem Dimensional}

A proposta de modelagem dimensional foi introduzida por Ralph Kimball em 1997 e tornou-se praticamente um sinônimo de modelagem de dados para apoiar decisões em ambientes de Sistemas de Informação e Inteligência Empresarial. Ao contrário da modelagem tradicional de dados, como a modelagem entidade-relacionamento, na qual o objetivo é criar uma estrutura normalizada de banco de dados para apoiar as operações rotineiras de uma organização como: Vendas, Compras, Folha de Pagamento, Financeiro, Manutenção, etc.

A normalização visa, basicamente, eliminar redundâncias de dados que possam existir em bancos de dados. Nesse sentido, o principal meio utilizado para eliminar redundâncias é por meio da divisão ou fragmentação de tabelas, o que acaba por produzir bancos de dados de entendimento mais complexo.

Já no modelo dimensional há uma tabela dominante no centro do diagrama com múltiplas junções conectando-a as outras tabelas (KIMBALL, 1996). O modelo dimensional (ou modelo estrela) deve ser iniciado pela definição do Data Warehouse, isto é, definição do principal assunto a ser modelado. Por exemplo: pedidos de compra, vendas, entregas, empregados, entre outros. Em seguida a granularidade dos fatos a serem armazenados deve ser definida. O grão é o nível de detalhe com que os fatos serão armazenados no Data Warehouse (KIMBALL et al.1998)

Recomenda-se armazenar os fatos no maior nível de detalhes disponível nos sistemas transacionais de origem, mas a prática registra muitas situações de armazenamento já sumarizado dos dados, em virtude de restrições de espaço para armazenamento dos dados (KIMBALL et al.1998).

No modelo entidade-relacionamento a normalização é uma preocupação constante dos projetistas. Na modelagem dimensional, voltada para aumentar o desempenho das consultas e compreensão do usuário, a normalização não é uma prática recomendada (BARBIERI, 2001).

Uma eventual normalização, no modelo dimensional, explicita hierarquias entre dimensões, mas pode prejudicar o desempenho de consultas e a compreensão dos 
usuários, ao tornar o modelo mais complexo. O modelo dimensional clássico é apresentado na Figura 6.

Nesse modelo todas as tabelas dimensão relacionam-se, por meio dos atributos chaves primárias (Primary Key - PK), diretamente com a tabela fato, localizada no centro da figura, a qual contém a chave primária PK composta por chaves estrangeiras de relacionamento (Foreing Key - FK) com as tabelas dimensões. A tabela fato contém os valores numéricos, ou medidas dos fatos consultados.

Tabelas Dimensão

\begin{tabular}{|c|c|c|}
\hline PKDimensäo 1 & Tabela Fato & PK Dimensäo 3 \\
\hline $\begin{array}{l}\text { Atributo } 1.1 \\
\text { Atributo } 1.2 \\
\ldots \\
\text { Atributo } 1 . n\end{array}$ & $\begin{aligned} & \text { Dimensäo } 1(\mathrm{FK}) \\
& \mathrm{P} \text { Dimensäo } 2(\mathrm{FK}) \\
& \mathrm{k} \text { Dimensäo } 3 \text { (FK) } \\
& \text { Dimensão N (FK) }\end{aligned}$ & $\begin{array}{l}\text { Atributo } 3.1 \\
\text { Atributo } 3.2 \\
\text { Atributo } 3 . n\end{array}$ \\
\hline PK Dimensăo 2 & & PK Dimensão N \\
\hline $\begin{array}{l}\text { Atributo } 2.1 \\
\text { Atributo } 2.2 \\
\ldots \\
\text { Atributo } 2 . n\end{array}$ & $\begin{array}{l}\text { Fato } 2 \\
\text { Fato } 3 \\
\ldots \\
\text { Fato } \mathrm{N}\end{array}$ & $\begin{array}{l}\text { Atributo N.1 } \\
\text { Atributo N.2 } \\
\text { Atributo N.n }\end{array}$ \\
\hline
\end{tabular}

Figura 6 - Modelo Dimensional

Já a Figura 7 exemplifica um modelo dimensional que poderia ser utilizado no segmento comercial. O modelo dimensional exemplificado nessa figura reúne uma tabela fato, com quatro tabelas dimensões.

A tabela fato refere-se ao assunto Vendas e é formada por um conjunto de dados, que correspondem às métricas do negócio. Cada fato pode representar uma determinada transação ou evento de negócio ocorrido em um determinado contexto obtido por meio da interseção de todas as dimensões. $O$ fato é o elemento central do modelo dimensional e contém os campos de relacionamento com as tabelas de dimensão e campos com valores numéricos.

Neste caso, a granularidade implementada é a de vendas por loja, tempo, produto e tipo de cliente. 
Dimensầo Tempo

Dimensäo Produto

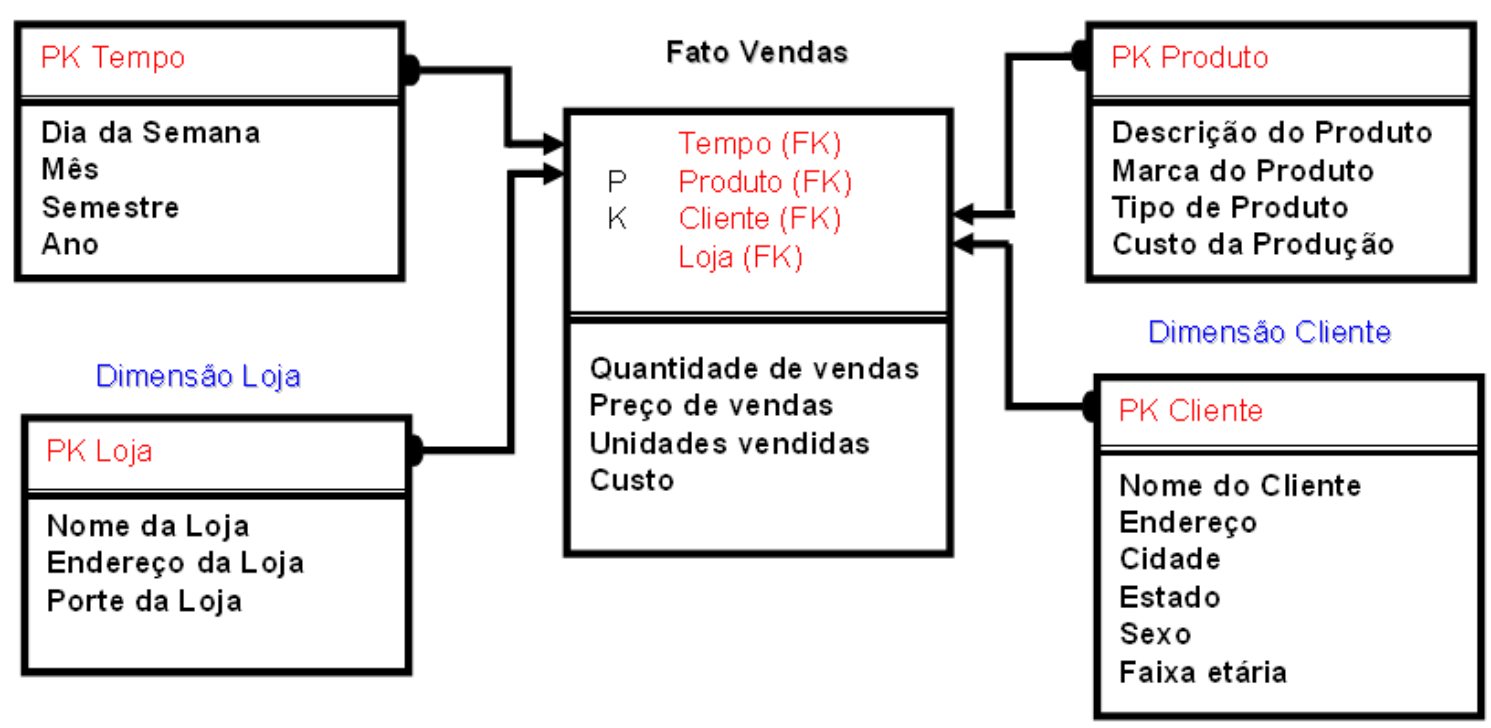

Figura 7 - Modelo Dimensional de Vendas

As tabelas dimensionais Tempo, Produto, Loja e Cliente, armazenam informações descritivas. As dimensões atuam como índices na identificação dos valores das vendas. As tabelas de dimensão são os principais eixos de análise das métricas. Os atributos das tabelas de dimensão configuram-se como o principal fator de restrição às consultas efetuadas no modelo dimensional. As tabelas de dimensão especializam o contexto do fato.

A utilização de um modelo dimensional do tipo estrela para os processos de consultas pode trazer benefícios significativos em relação a uma estrutura relacional (POE, KLAUER e BROBST, 1998). Destacam-se, como exemplo, os seguintes benefícios :

- Redução do tempo de resposta nas consultas complexas;

- Adequação dos dados às reais necessidades do tomador de decisão;

- Simplicidade no entendimento e navegação entre os dados;

- Adaptação a um número maior de ferramentas OLAP;

- Ameniza os impactos de novas implementações;

- Maior flexibilidade na implementação de novas dimensões;

- Menor tempo nos processos de ETL. 
A partir do Data Warehouse podem ser projetados Data Marts, conforme a Figura 8. Os Data Marts constituem-se em porções especializadas dos dados contidos no Data Warehouse. Tal especialização pode ser feita, por exemplo, por região geográfica, produto, departamento, entre outros. Um Data Mart pode ser montado por simples filtros lógicos, ou mesmo pela replicação dos dados do Data Warehouse, entre outros servidores.

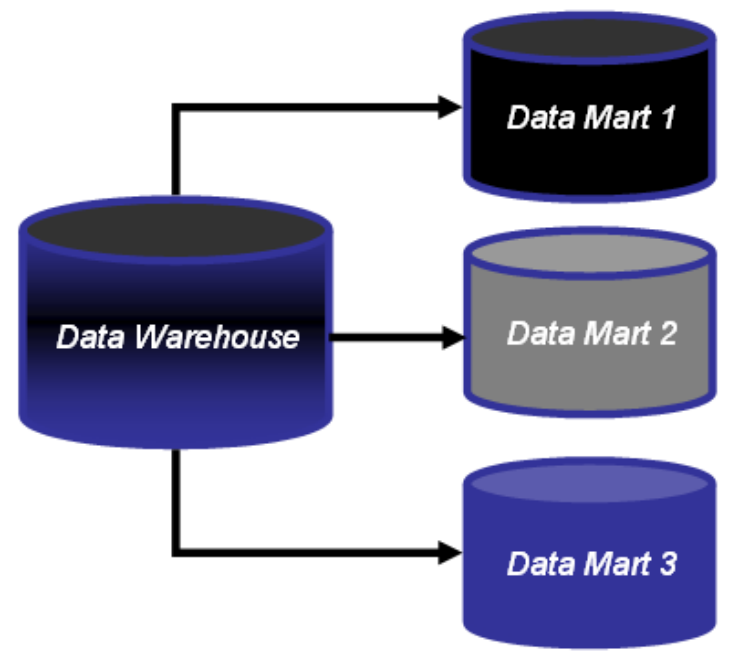

Figura 8 - Data Marts

\subsubsection{Extração, Transformação e Carga de Dados - ETL}

A etapa de Extração, Transformação e Carga de Dados (Extract, Transform and Load - ETL) é imprescindível para o Data Warehouse.

Para a extração de dados devem ser identificadas as fontes de dados, tanto do ambiente operacional, quanto de dados externos à empresa. Em boa parte dos casos haverá dados dispersos em diversos bancos de dados operacionais, podendo haver dados distintos com mesmos nomes, ou ainda dados com nomes distintos, porém representando fatos comuns.

A Figura 9 simboliza um processo de ETL, no qual os dados de medidas, moedas e sexo são coletados nos ambientes operacionais, transformados em valores padronizados e carregados em formatos únicos nos depósitos de dados de destino. 


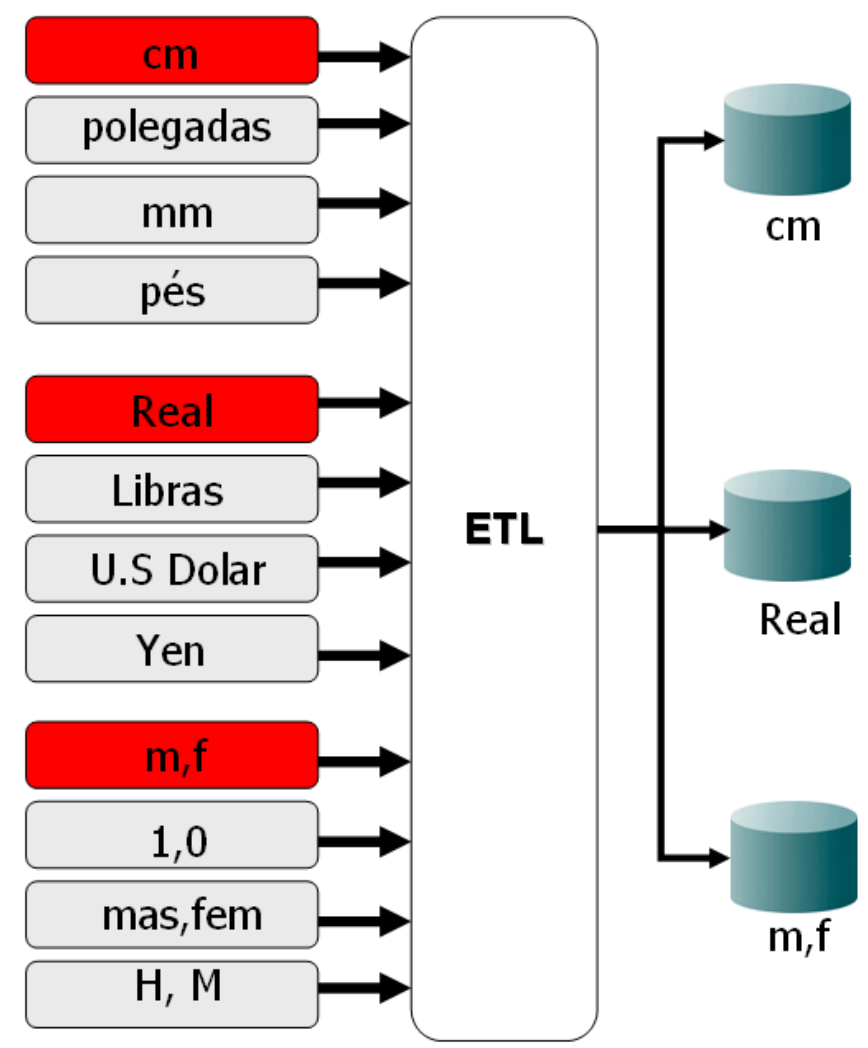

Figura 9 - Extração Transformação e Carga de Dados

Além disso, normalmente, há falta de padronização. Por exemplo, caso típico são unidades de medida, podendo haver valores em centímetros, metros ou milímetros para um mesmo produto. Assim, é necessária a etapa de transformação, que visa padronizar e dar qualidade necessária aos dados. É na etapa de transformação que se obtém a qualidade necessária para os dados a serem armazenados no Data Warehouse.

A qualidade de dados é um fator crítico para o sucesso de um ambiente de Data Warehouse. Se os dados possuírem qualidade insuficiente, os usuários da informação que consultam o Data Warehouse não poderão confiar nos resultados.

Finalmente, vem a etapa de carga, que consiste no armazenamento dos dados já transformados para o Data Warehouse. Sempre há uma carga inicial, no início de funcionamento do ambiente de Data Warehouse, seguida por cargas periódicas dos dados, sendo que tal periodicidade é especificada em função do tipo de atividade, podendo ser diária, semanal, etc. 


\subsubsection{Ferramentas OLAP - Online Analytical Process}

Define-se OLAP como um recurso computacional utilizado para apoiar consultas no Data Warehouse ou Data Mart. O termo OLAP refere-se a um conjunto de ferramentas voltadas para acesso e análise de dados, com o objetivo final de transformar dados em informações, de maneira amigável, flexível e tempo hábil para o tomador de decisão (KIMBALL, 1996).

Uma das características exigidas de ferramentas OLAP é a capacidade de permitir, a geração de consultas ad-hoc, ou seja, consultas personalizadas, feitas conforme haja a necessidade por informação por parte de cada analista. Normalmente as ferramentas de acesso aos dados possibilitam também aumentar ou diminuir o nível de detalhes das consultas sobre os dados disponíveis, como (DWBRASIL OLAP, 2008):

- Drill Down: aumentar o nível de detalhes de uma consulta. Por exemplo, em uma consulta por países, pode ser detalhada por estado, cidade, etc.

- Drill Up: é o inverso de Drill Down, ou seja, apresentar os dados em um nível mais elevado. Por exemplo, em uma consulta a dados diários, pode-se subir para os níveis semanal, mensal, etc.

Uma forma de se melhorar o desempenho das consultas a um Data Warehouse consiste na execução de uma consulta e o armazenamento dos resultados de tal consulta, nos chamados cubos de dados multidimensionais. Assim, qualquer nova consulta relativa a tal assunto pode ser feita diretamente no cubo, sem a necessidade de refazer todo o processamento.

A tecnologia OLAP pode ser implementada de diversas formas. A seguir são descritos os principais modelos (INMON, 2005):

- ROLAP (Relational Online Analytical Process): todas as consultas são feitas diretamente no modelo dimensional. 
- MOLAP (Multidimensional Online Analytical Process): todas as consultas são feitas diretamente nos cubos pré-armazenados no servidor.

- DOLAP (Desktop Online Analytical Process): todas as consultas são feitas diretamente nos cubos pré-armazenados no cliente.

- HOLAP (Hybrid Online Analytical Process): As consultas podem ser feitas tanto no modelo dimensional, quanto nos Cubos multidimensionais.

\subsection{GESTÃO DO CONHECIMENTO}

A gestão do conhecimento, na perspectiva organizacional, surgiu no início de 1990, e não é mais fruto de pensamentos abstratos, estando difundida na estratégia da organização (SVEIBY, 1998). Sob essa perspectiva, o conhecimento é natural e deve ser interpretado como uma prática que gera valores intangíveis, relacionados com as atividades estratégicas de negócio, envolvendo assim muito mais do que processos e tecnologias. O conhecimento é resultado da compreensão de uma determinada situação real (ALVESSON e KARREMAN, 2001).

Autores contemporâneos, normalmente, interpretam a gestão do conhecimento de duas formas. A primeira forma trata conhecimento como objetos que podem ser identificados e tratados por meio de Sistemas de Informação, forma esta adotada neste trabalho (MURRAY, 2006). A segunda vertente identifica a gestão do conhecimento como gestão de pessoas, sendo o conhecimento entendido como processo que leva ao aprendizado organizacional e à criação de competências (CHOO, 2003).

O conhecimento deriva da informação assim como esta, dos dados. Nesse sentido, acredita-se que os Sistemas de Informação e Inteligência Empresarial podem ajudar as organizações a conhecerem melhor os ambientes internos e externos por meio da aquisição, coleção, análise, interpretação e exploração da informação (CHUNG, CHEN e NUNAMAKER, 2003). 
A construção do conhecimento, no contexto sistêmico, é representada no modelo SECI (NONAKA e TAKEUCHI, 1997), no qual se sugere um espiral para simbolizar a conversão de conhecimento tácito em explicito e de conhecimento explicito em conhecimento tácito. Na Figura 10 é ilustrado um esboço desse espiral.

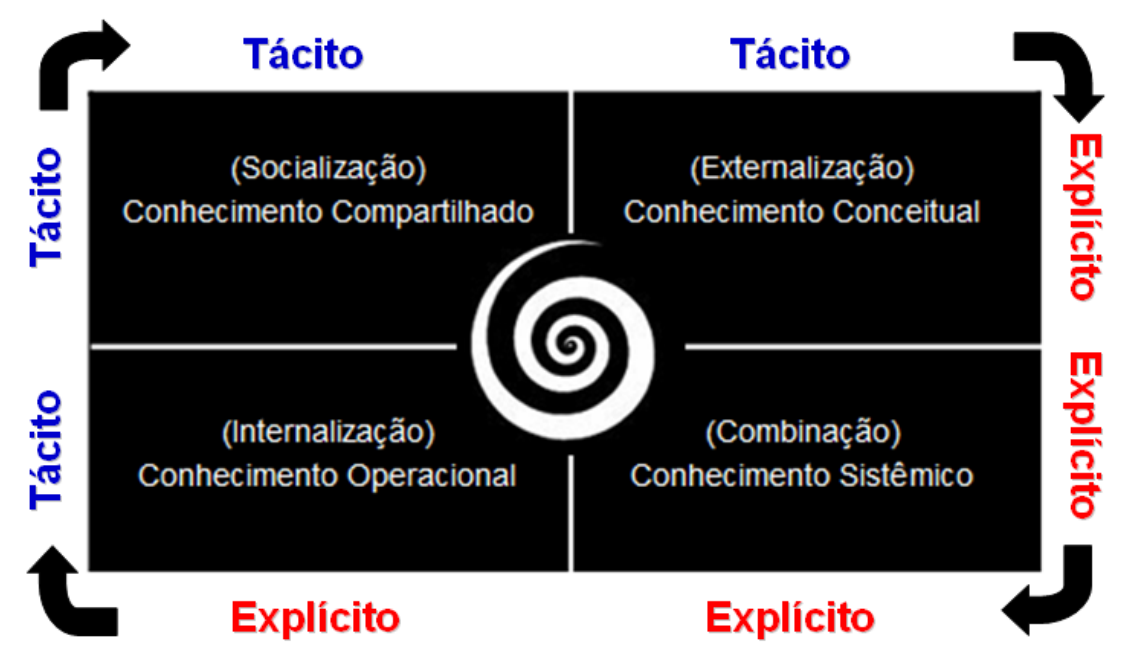

Figura 10 - Modelo SECI (NONAKA e TAKEUCHI, 1997)

Os quadrantes do espiral do conhecimento simbolizam, no primeiro quadrante, a Socialização como o compartilhamento do conhecimento tácito, por meio da observação, imitação ou prática (tácito para tácito). No segundo quadrante, simboliza-se a Externalização como a conversão do conhecimento tácito em explícito e sua comunicação ao grupo (tácito para explícito). No terceiro quadrante, simboliza-se a Combinação como a padronização do conhecimento externalizado na elaboração de manuais ou guias de trabalho (explícito para explícito). Finalmente, no quarto quadrante, simboliza-se a Internalização como a criação de novos conhecimentos explícitos, possivelmente compartilhados na organização entre as pessoas. (explícito para tácito).

Os fundamentos teóricos observados no decorrer do Capítulo 3 são de relevada importância para a construção da proposta de Análise Inteligente de Falhas como subsídio para Apoiar a Tomada de Decisões Estratégicas em Projetos de Sistemas Críticos, apresentada no Capítulo 5. Antes, porém, faz-se necessário correlacionar tais fundamentos com fundamentos de Sistemas Críticos, observados no Capítulo 2, os quais destacam o contexto de aplicação da referida proposta. 
No próximo Capitulo, busca-se correlacionar as necessidades de Análise Inteligente de Falhas em Sistemas Críticos, enfatizando o Sistema Metroviário, com fundamentos da Teoria da Tomada de Decisão, implementada com recursos de Sistemas de Informação e Inteligência Empresarial. 


\title{
4 ANÁLISE INTELIGENTE DE FALHAS E A TOMADA DE DECISÕES ESTRATÉGICAS EM SISTEMAS METROVIÁRIOS
}

\begin{abstract}
A Análise Inteligente de Falhas para a Tomada de Decisões Estratégicas em Projetos de Sistemas Críticos, com as especificidades de Sistemas Metroviários, escora-se em dois princípios. O primeiro é a necessidade de amplo conhecimento das reais condições de funcionamento dos módulos de um Sistema Crítico. O segundo escora-se na relação entre o tempo dispendido para a obtenção dos dados necessários e o tempo disponível para a tomada de decisões. Quanto maior for o intervalo de tempo disponível para decidir, maiores serão as possibilidades de desenvolver ações de melhoria para o sistema.
\end{abstract}

\subsection{CONSIDERAÇÕES INICIAIS}

A verdadeira inteligência do homem consiste em tornar sua sociedade inteligente. Exprime-se em mensagens, linguagens e tecnologias de aperfeiçoamento, combinação e melhoramento das práticas de trabalho. A tecnologia, não é autosuficiente, é uma extensão da inteligência humana, contudo, a escolha da tecnologia adequada é fundamental para aprimorar processos decisórios que vão muito além da intuição (LABROSSE e LÉVY, 1999).

No contexto de Sistemas Metroviários, é importante considerar que uma decisão estratégica inadequada pode resultar em impactos negativos de grande vulto ao sistema, e consequentemente ao ambiente em que este está inserido.

\subsection{A TOMADA DE DECISÃO}

Os fundamentos da Tomada de Decisão foram introduzidos pelo economista Herbert Alexander Simon, ganhador do Prêmio Nobel de Economia em 1978, pelo seu conjunto de pesquisas realizadas na área de tomada de decisão organizacional, as quais escoraram-se em fundamentos do comportamento humano diante de complexos sistemas decisórios (NOBELPRIZE, 2009). 
As decisões organizacionais dividem-se em duas categorias, as decisões programadas, caracterizadas pela rotina e repetitividade, e as decisões não programadas, caracterizadas basicamente pela novidade (SIMON, 1959).

Nas decisões programadas os tomadores de decisão devem contar com dados já adequados e normalmente repetitivos, condições estáticas e alto grau de certeza. As decisões são programadas à medida que são repetitivas e rotineiras e que se desenvolveu um método com foco direto no problema, por meio de processos previamente especificados pelas organizações. Essas decisões podem ser instrumentadas pela análise de sistemas, análise matemática, processamento de dados, pesquisa operacional e modelos estatísticos.

Um exemplo de decisão programada de negócio é o processamento de dados de uma Folha de Pagamento, uma ação que demanda dados frequentemente repetitivos, e grande confiança no tocante à relação causa e efeito.

Por outro lado, as decisões não programadas normalmente advêm de situações dinâmicas, nas quais os tomadores de decisão deparam-se, muitas vezes, com dados inadequados e alto grau de subjetividade. São as decisões novas e não estruturadas. Como tais não têm um método determinado para a abordagem do problema, ou porque este problema não surgiu antes, ou porque é complexo e extremamente importante.

Uma decisão não programada de negócio, exemplifica-se normalmente no enfrentamento de uma crise econômica, e impõe aos tomadores de decisão a necessidade de coletar o maior número de dados possível para subsidiar ações estratégicas com maiores probabilidades de acerto.

No processo decisório organizacional, existem, pelo menos, seis elementos que participam diretamente do ciclo de vida da decisão. Tais elementos são interdependentes, porém, mantêm características que os tornam diferentes uns dos outros (CHIAVENATO, 2003). São eles:

- Tomador de decisão: é a pessoa que deve fazer uma escolha.

- Objetivos: representam os alvos que o tomador de decisão pretende alcançar .. 
- Preferências: constituídas pelos critérios que o tomador de decisão usa para fazer a escolha.

- Estratégia: compreende o caminho que o decisor escolhe para melhor atingir o objetivo.

- Situação: é caracterizada pelos aspectos ambientais que envolvem o Tomador de Decisão.

- Resultado: exprime a conseqüência das decisões tomadas no processo decisório.

A Tomada de Decisão, constitui parte importante para a melhor compreensão da proposta deste trabalho. Contudo, ressalta-se que, em projetos de Sistemas Metroviários, os elementos da decisão descritos escoram-se em processos analíticos subsidiados por recursos computacionais, os quais diferem da abordagem da teoria comportamental da administração que destaca, especificamente, o comportamento das pessoas no processo decisório, deixando em segundo plano, os recursos utilizados por essas pessoas.

\subsection{LIMITAÇÕES COGNITIVAS E TECNOLÓGICAS NO PROCESSO DECISÓRIO EM SISTEMAS METROVIÁRIOS}

Os tomadores de decisões estratégicas atuam de maneira inteligente quando, a partir do potencial informacional da organização, conseguem estruturar fluxos de informações para superar limitações cognitivas e tecnológicas, e tomar decisões com maior precisão, no enfrentamento de problemas do cotidiano (GONÇALO, 2005).

No aspecto organizacional, as limitações cognitivas podem comprometer a criação e o desenvolvimento de competências organizacionais e dificultar a gestão do conhecimento e tomada de decisões estratégicas (ZANGISKI, et al, 2009). Da mesma forma, existem as limitações tecnológicas que dificultam a interação dos indivíduos com tecnologias da informação e impõem um alto grau de dependência 
de pessoas que dominam essas tecnologias. A informação passa a ser um ativo exclusivo dos detentores da informação que, muitas vezes, são provedores indiretos de conhecimento.

As limitações tecnológicas e cognitivas estão presentes no dia-a-dia de todas as organizações. O que não é diferente no Sistema Metroviário, no qual tomadores de decisões estratégicas são, eventualmente, afetados por limitações cognitivas e tecnológicas na tomada de decisões em projetos de concepção, operação e manutenção do sistema.

Na Figura 11 há um fluxograma que representa as possíveis interferências causadas por limitações cognitivas e tecnológicas no fluxo de análise de falhas, durante um processo decisório.

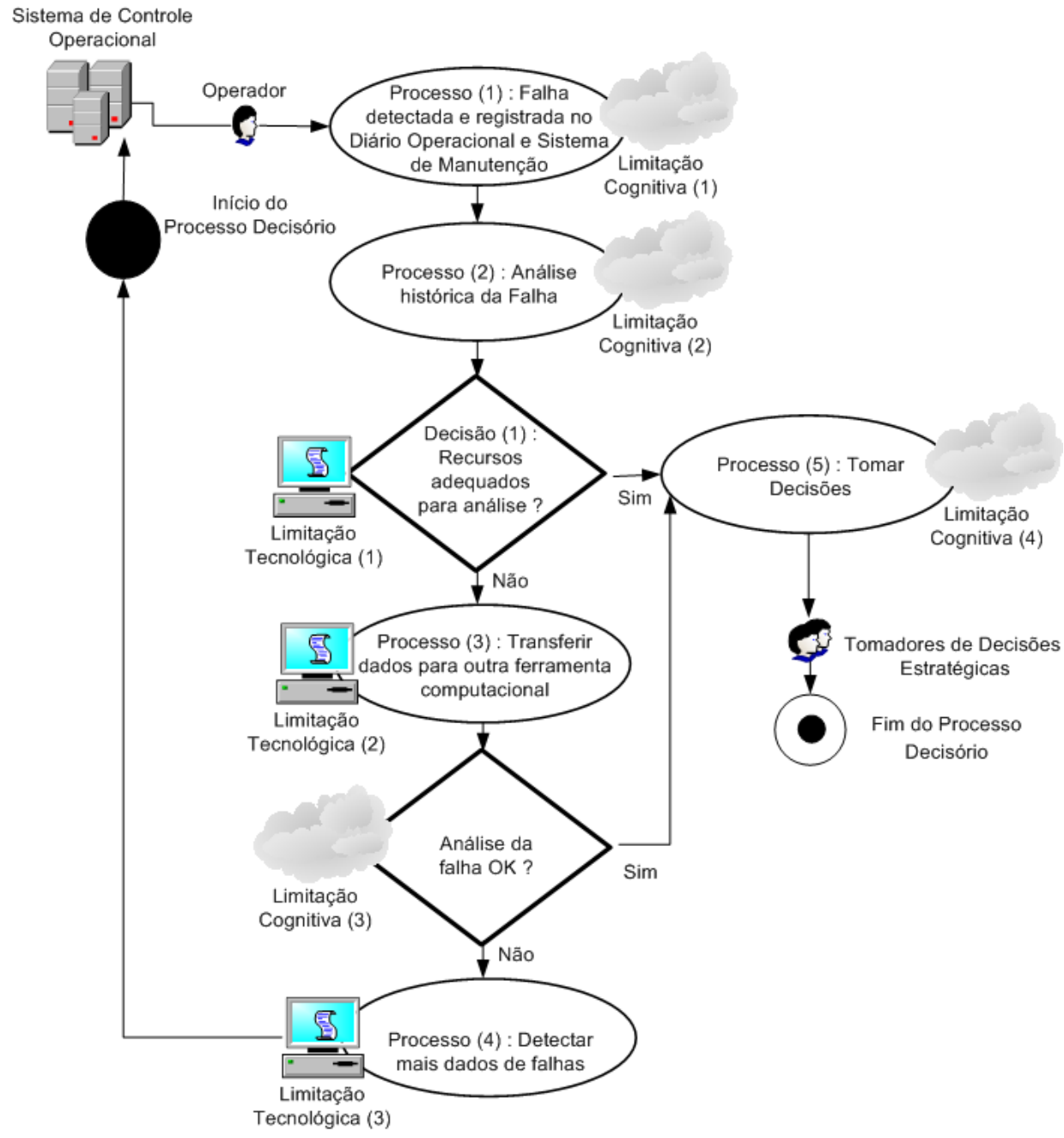

Figura 11- Limitações no Fluxo de Informações de Falhas 
O processo inicia-se com a detecção da falha pelo Sistema de Controle Operacional, em seguida a falha é registrada pelo operador no Sistema Diário Operacional e Sistema de Manutenção (Processo 1), posteriormente analisa-se a falha (Processo 2). Tal análise demanda de uma decisão no tocante a recursos adequados para a análise (Decisão 1). Se houver condições de analisar a falha segue-se para a tomada de decisão (Processo 5), caso contrário, transferem-se os dados para outra ferramenta computacional (Processo 3).

Após o Processo 3 verifica-se a possibilidade de analisar adequadamente a falha (Decisão 2), se possível, segue-se para a tomada de decisão (Processo 5), caso contrário, inicia-se uma nova detecção de falhas (Processo 4) e o fluxo é reiniciado.

A complexidade existente no fluxo da informação de falhas no Sistema Metroviário ocorre, principalmente, em função das eventuais limitações cognitivas e tecnológicas apresentadas na Figura 17, nas quais se destacam as seguintes características:

\section{- Limitações Cognitivas}

1. Possibilidade de interpretação incorreta da falha;

2. Impossibilidade de analisar falhas históricas por falta de informação;

3. Dificuldade de análise, devido à falta de indicadores;

4. Tomada de decisões com as informações disponíveis, com possível incerteza,

\section{- Limitações Tecnológicas}

1. Ausência de tecnologias adequada para a análise de falhas;

2. Dificuldade em transferir dados para outras tecnologias computacionais;

3. Impossibilidade em detectar indicadores de falhas com precisão.

As limitações cognitivas e tecnológicas são fenômenos presentes no cotidiano das organizações. No entanto, com o advento de Sistemas de Informação e Inteligência Empresarial, busca-se amenizar os impactos causados por tais fenômenos em processos decisórios. 


\subsection{A NFORMAÇÃO EM PROJETOS DE SISTEMAS METROVIÁRIOS}

Um projeto consiste num esforço temporário com um objetivo previamente especificado, definido e claro, seja para criar um novo produto, um serviço, ou um processo. Deve ter início, meio e fim bem definidos, duração e recursos limitados, numa seqüência de atividades relacionadas (PMI, 2008).

A informação conduz ao controle. O controle favorece o planejamento e a segurança nas decisões. A informação permite saber onde se está dispendendo energia ou materiais desnecessariamente e é ela que ajuda a coordenar esforços e atingir objetivos (DRUCKER, 1993).

A falta de informação é hoje um dos grandes problemas enfrentados pelas organizações, o que não difere de indústrias com Sistemas Críticos que também enfrentam problemas de descentralização das informações em diferentes unidades de negócio. A ausência de sistemas de informação pode comprometer, sensivelmente, o desenvolvimento de projetos e decisões estratégicas em sistemas de qualquer natureza.

Assim como em segmentos comerciais, as organizações que operam Sistemas Críticos, como Sistemas Metroviários, possuem uma grande quantidade de dados, dos quais, em sua maioria podem ser extraídas informações. Dados transformam-se em informação, quando previamente contextualizados (LAUDON e LAUNDON, 1999).

Em Sistemas Metroviários as fontes de informações são oriundas dos processos de concepção, operação e manutenção dos módulos do sistema. Em linhas gerais tais fontes dividem-se em:

- Estruturadas: Compostas por banco de dados estruturados, alimentados por sistemas computacionais e sistemas de engenharia.

- Não-Estruturadas: Compostas por manuais de fabricantes, normas técnicas e procedimentos operacionais e de manutenção. 
Assim, os dados estruturados de falhas, confrontados com os dados não estruturados tornam-se um importante recurso para apoiar ações analíticas preditivas e implementar melhorias no funcionamento de Sistemas Críticos.

Contudo, não basta ter dados estruturados, é preciso transformá-los em informação, sendo esta essencial para promover o conhecimento homogêneo das reais condições do sistema.

Iniciativas como as do GAIN (Global Aviation Information Network) um sistema de compartilhamento de informações sobre segurança aérea, mantido pelas principais entidades do meio aeronáutico, exemplifica o processo de transformação de dados em informação, ao armazenar e compartilhar, entre seus participantes, informações referentes às condições inseguras na aviação (GAIN, 2004).

Já no Sistema Metroviário do Estado de São Paulo, os dados registrados pelo Sistema de Controle Operacional podem servir para manter a segurança e a disponibilidade do sistema. O problema é que tais dados podem ficar parcialmente inacessíveis, ou mesmo quando disponibilizados, são de difícil interpretação, exigindo, das equipes de projeto, tempo em demasia para a análise quantitativa e qualitativa de ocorrências de anomalias no sistema.

A informação é composta por dados convertidos em contextos com significados definidos. Para converter dados em informação em Sistemas Críticos, os processos são idênticos aos encontrados em áreas administrativas das organizações, ou seja, os dados oriundos dos sistemas operacionais ou transacionais devem ser acessados, transformados em informação e recuperados conforme as necessidades de compreender determinadas situações e subsidiar a tomada de decisões estratégicas.

Para compreender situações que exigem a tomada de decisões estratégicas, é necessário dispor de recursos capazes de dar significado aos dados de interesse e convertê-los em informação. O significado só é atingido se a informação, por sua vez, atender a determinados requisitos básicos da compreensão humana (LAUDON e LAUDON, 2007), conforme segue: 
- Clareza: Apresentar o fato com clareza e objetividade.

- Precisão: Deve ter um alto padrão de precisão e nunca apresentar termos como: "por volta de", "a cerca de", "mais ou menos".

- Rapidez: Chegar ao ponto de decisão em tempo hábil para que gere efeito na referida decisão.

- Foco: Chegar ao tomador de decisões, com foco em resultados previamente especificado na organização.

Um grande desafio imposto aos tomadores de decisões estratégicas em Sistemas Críticos, como Sistemas Metroviários, é o de ter informações com clareza, precisão, rapidez e foco, para projetar e implementar ações de melhorias nas perspectivas da concepção, operação e manutenção do sistema.

\subsection{A ARQUITETURA DA INFORMAÇÃO DECISÓRIA EM SISTEMAS METROVIÁRIOS}

Sem uma arquitetura compreensível a Informação pode ter a sua propagação comprometida na organização, e dificultar decisões estratégicas, táticas e operacionais. Ter um fluxo controlado de informação, não é apenas ter tecnologia, e sim processos estruturados que garantam que a informação chegue a seu destino (LAUDON e LAUDON, 2007).

A informação necessita de meios para propagar-se em momentos e setores distintos. No Sistema Metroviário a informação precisa de meios para propagar-se entre o nível estratégico, tático e operacional. A informação pode propagar-se verticalmente entre níveis hierárquicos e horizontalmente pelos setores.

$\mathrm{Na}$ Figura 12 ilustram-se os fluxos da informação em uma pirâmide organizacional, com a especificidade de um Sistema Metroviário. 


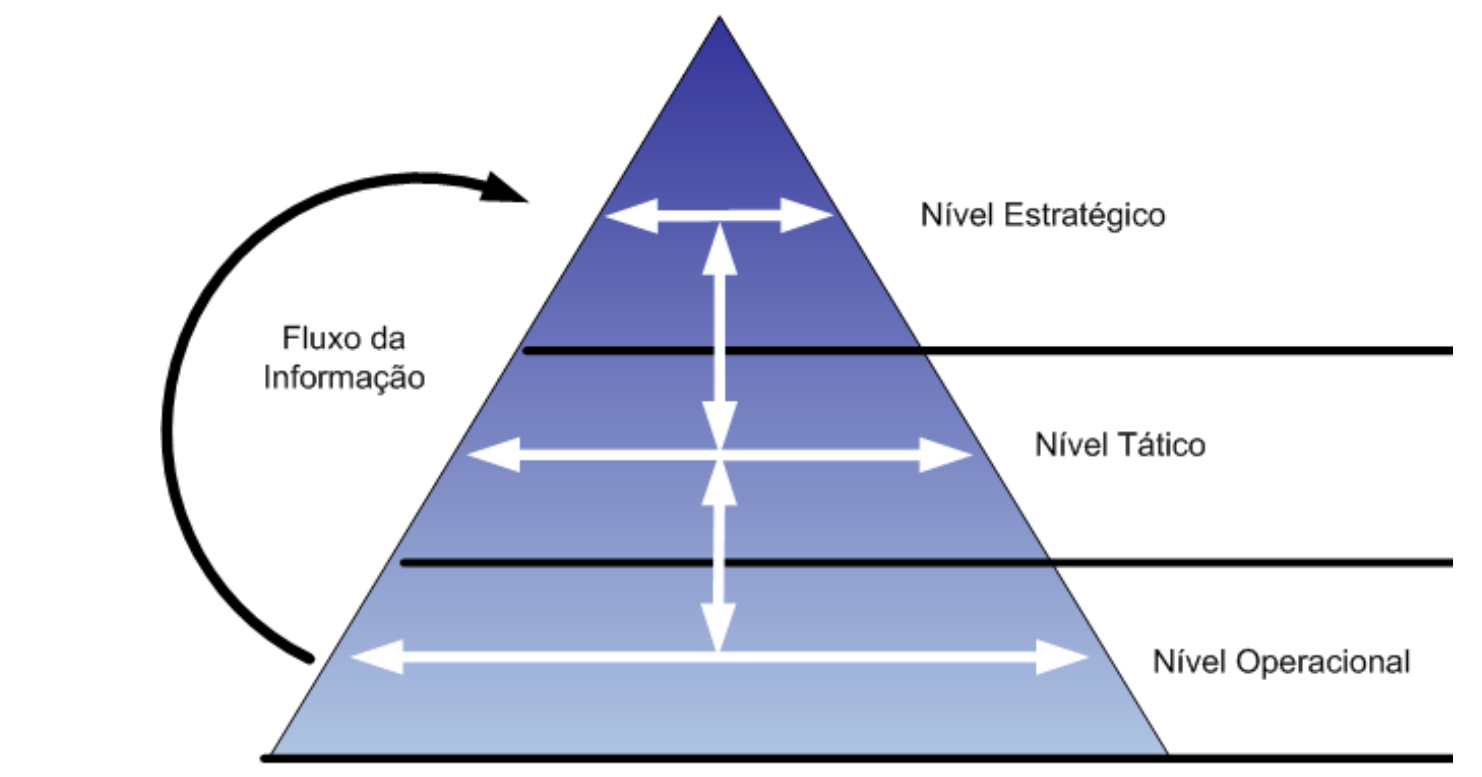

Figura 12 - Pirâmide da Informação Organizacional no Sistema Metroviário, adaptado de (LAUDON e LAUDON, 2007)

É importante destacar que o fluxo da informação pode ser influenciado por processos existentes nos diferentes níveis da organização. Qualquer interrupção no fluxo natural da informação pode favorecer a criação de fluxos alternativos e comprometer a tomada de decisões estratégicas.

Os processos decisórios são horizontalmente autônomos e verticalmente dependentes. O sucesso nos processos decisórios influencia diretamente o sucesso e o desempenho organizacional (DAVIS, MACDONALD e MARASHI, 2007).

Para identificar as necessidades informacionais para a Tomada de Decisões Estratégicas em projetos em Sistemas Metroviários é fundamental dividir as informações em três grupos, sendo:

- Informações Estratégicas: São oriundas de informações operacionais, muitas vezes sintetizadas em indicadores chave para apoiar processos decisórios. As informações estratégicas são produzidas, periodicamente, com a finalidade de prover subsídios para os tomadores de decisões definirem estratégias que vão desde ações estratégicas preditivas, preventivas e corretivas, a possíveis mudanças na concepção do sistema. 
- Informações Táticas: São oriundas de ações preditivas, preventivas e corretivas, muitas vezes previstas em normas técnicas e manuais de fabricantes. Os dados que compõem as informações táticas são registrados e analisados, na maioria das vezes, por ferramentas de engenharia de confiabilidade, e possibilitam a análise sistêmica de falhas em cenários previamente definidos.

- Informações Operacionais: São oriundas de transações rotineiras. Os dados que compõem as informações operacionais são coletados, na maioria das vezes, por sistemas de controle computadorizados e replicados para sistemas de manutenção.

As informações estratégicas, táticas e operacionais são de extrema importância para subsidiar as fases de concepção, operação e manutenção de Sistemas Metroviários. Com a evolução dos computadores é comum que ações operacionais repetitivas que não demandem intervenções cognitivas, ou humanas, sejam atribuídas a computadores, como, por exemplo, a operação automática no Sistema Metroviário.

Entende-se por cognição o conjunto de atividades e processos pelo qual o ser humano adquire informação e desenvolve conhecimento. (HAYES e ALLINSON, 1994).

\subsection{CICLO DE VIDA DAS INFORMAÇÕES EM SISTEMAS METROVIÁRIOS}

É importante considerar a relevância da dinâmica no ciclo de vida das informações que subsidiam projetos e Sistemas Metroviários. Na Figura 13 é simbolizado um ambiente computacional, no qual destaca-se um ciclo de vida da informação em projetos de Sistemas Metroviários.

No ambiente representado nessa figura exemplificam-se a camada de dados composta por normas técnicas e dados históricos de concepção, operação e manutenção do Sistema Metroviário (1). Posteriormente, na camada da informação, conhecimento e decisão, encontram-se as etapas da informação consolidada, na qual é possível obter informações sobre as condições do sistema (2). Em seguida, representa-se a análise das informações (3) e a tomada de decisões estratégicas 
(4). Sugere-se ainda, que os dados das ações de melhoria sejam realimentados com melhorias contínuas no sistema.

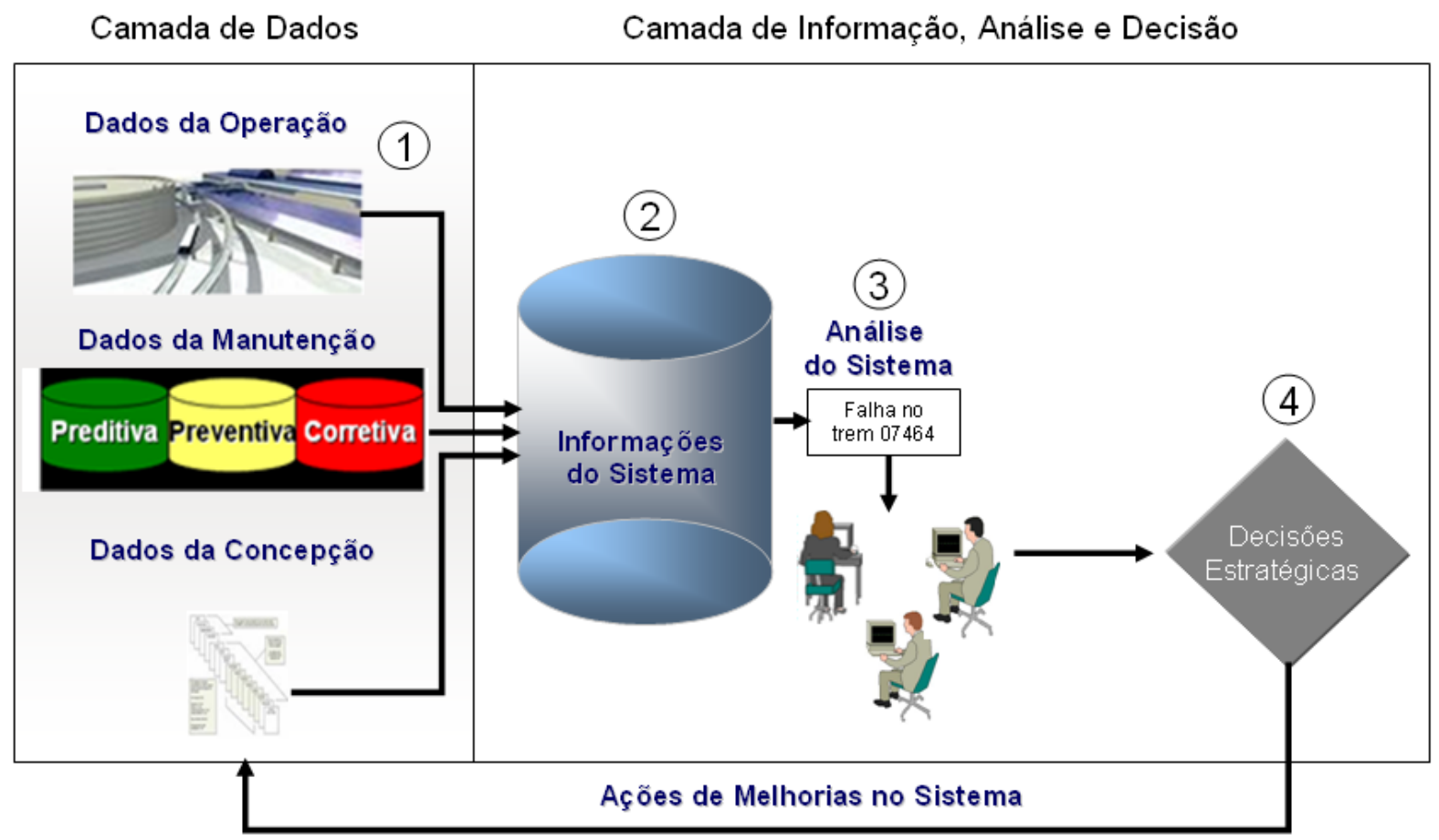

Figura 13 - Ciclo de vida da informação em Sistemas Metroviários

No que se refere a projetos de Sistemas Metroviários, nas perspectivas da concepção, operação e manutenção do sistema, uma abordagem conceitual consiste em elucidar a preocupação em criar e manter fluxos de informação dinâmicos, capazes de suportar a demanda por informações precisas, em intervalos de tempo aceitáveis para suportar processos decisórios.

Para exemplificar a importância da dinâmica no fluxo de informação nas organizações com Sistemas Críticos, nas Figuras 14 e 15 são apresentados resultados de ensaios realizados no Sistema Metroviário, no qual buscou-se avaliar o tempo para a obtenção de informações de falhas, para subsidiar decisões estratégicas (OLIVEIRA e ALMEIDA JR, 2008).

Na Figura 14, é simbolizada a detecção de uma falha no Sistema de Controle Operacional (1). Dez minutos depois, a falha é registrada no Sistema de Manutenção (2). Posteriormente, os dados do Sistema de Manutenção são 
replicados para uma base de dados temporária (3). Em seguida, representa-se o processo de análise de dados com softwares utilitários como planilhas, editores de texto, entre outros (4), sendo que tal processo demandou aproximadamente dez dias. Após essas etapas, as informações básicas para apoiar decisões estratégicas são processadas em aproximadamente um dia (5). Havendo necessidade de mais informações, o processo é reiniciado (6).

Com os recursos convencionais (Figura 14), constatou-se um tempo médio de 12 dias para obter a informação e 1 dia para tomar decisões e completar um ciclo básico de análise de Falhas para subsidiar processos decisórios relacionados com o Atributo Confiança do sistema. O tempo poderia ter sido estendido se houvesse a necessidade de informações complementares, o que não foi considerado.

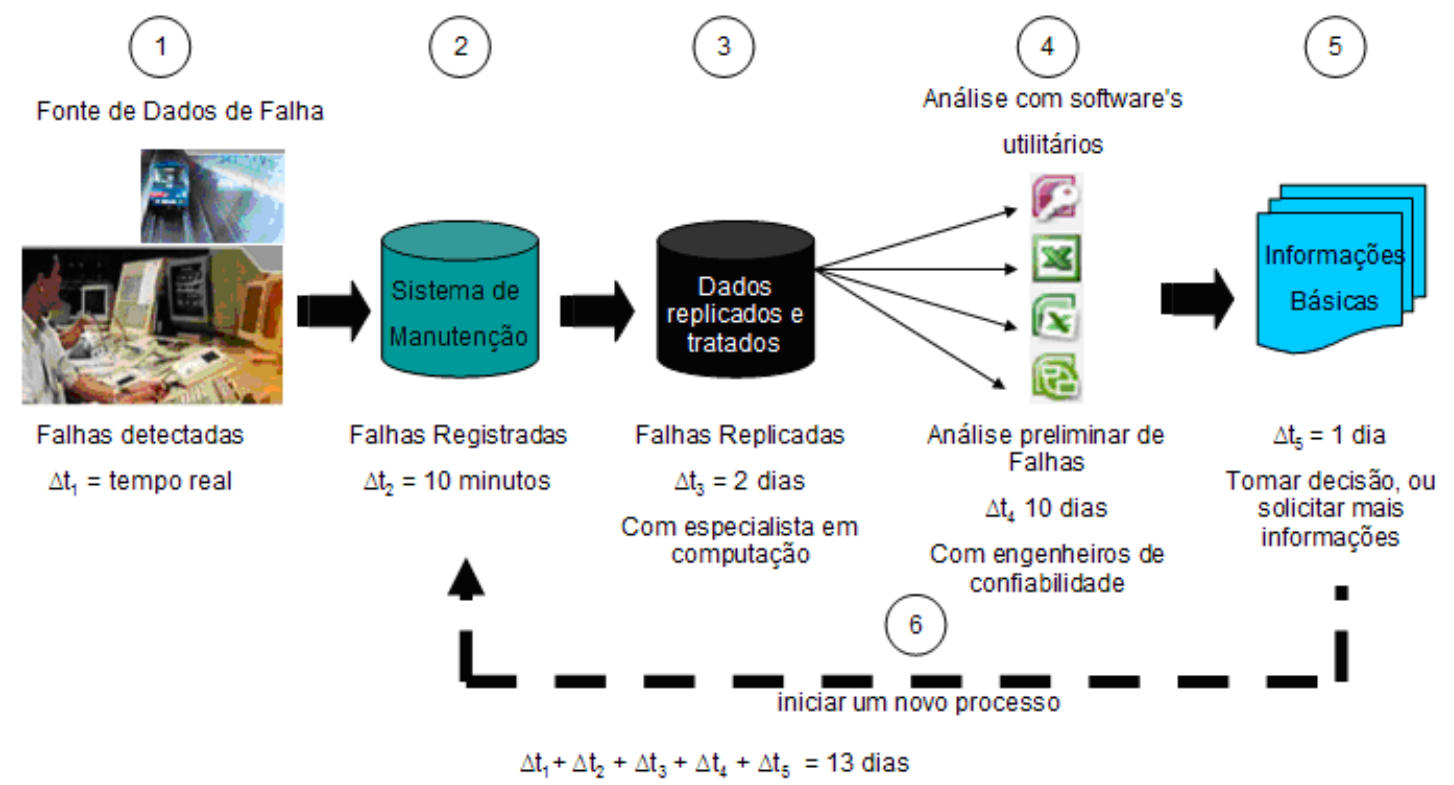

Figura 14 - Fluxo Padrão de Análise de Falhas em um Sistema Metroviário

É importante ressaltar que o ambiente apresentado na Figura 14 considerou apenas o fluxo da informação para apoiar decisões estratégicas em projetos na perspectiva da manutenção do Sistema Metroviário. Contudo, admite-se que o problema enfrentado com o tempo para obtenção de dados poderia ser potencializado se o objetivo estivesse centrado em decisões estratégicas nas perspectivas da concepção do sistema, as quais demandariam informações mais abrangentes, armazenadas em diferentes fontes de dados. 
Já na Figura 15 é ilustrado o fluxo das informações suportado por recursos previstos na proposta deste trabalho. O ambiente viabilizou o acesso às mesmas informações de falhas e consequentemente à tomada de decisão 24 horas após a identificação de tais falhas pelo Sistema de Controle Operacional.

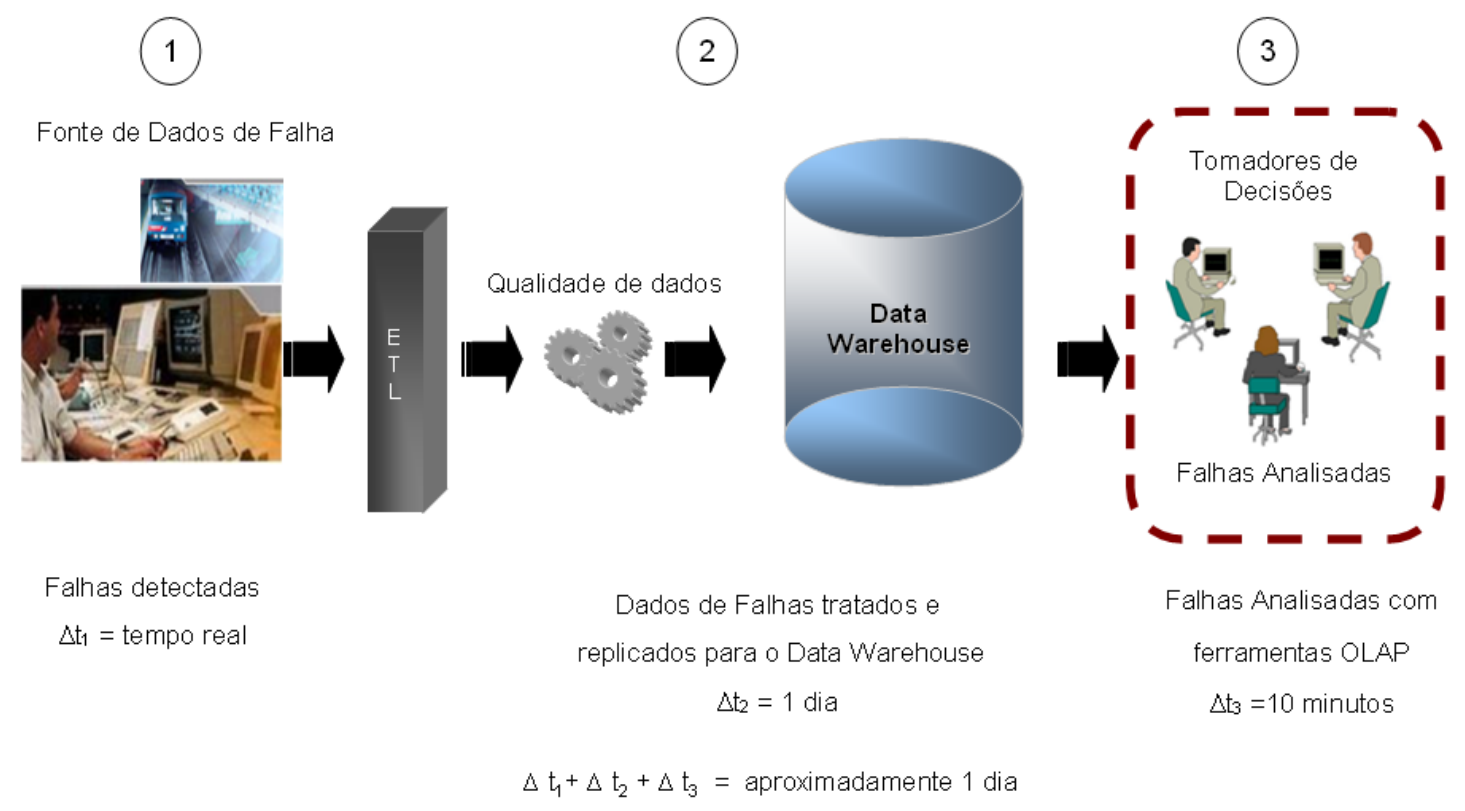

Figura 15 - Fluxo informacional proposto para o Sistema Metroviário

Os dados são obtidos do ambiente operacional (1). Posteriormente, os dados são extraídos, tratados pelas ferramentas de ETL (Extract Transform and Load) e replicados para o Data Warehouse (2). Finalmente os dados ficam disponíveis para análise e apoio a decisões estratégicas (3).

\subsection{PERSPECTIVAS DE PROJETOS NO SISTEMA METROVIÁRIO}

Projetos em Sistemas Críticos, e especificamente em Sistemas Metroviários podem abranger desde ações de grande impacto na concepção do sistema, até a elaboração de planos de operação e manutenção dos módulos do sistema já implantados.

No Sistema Metroviário, objeto do estudo, entre diversas perspectivas como a financeira, atendimento a cliente, logística, comercial, entre outras, destacam-se três 
perspectivas diretamente ligadas com o Atributo Confiança, ou seja, concepção, operação e manutenção, descritas nos próximos itens.

A Figura 16 ilustra o ciclo de vida de um projeto no Sistema Metroviário, considerando as perspectivas da concepção, operação e manutenção do sistema.

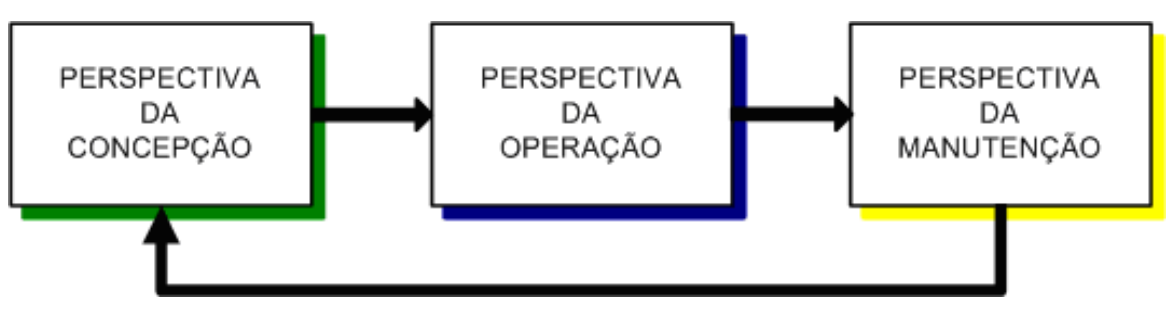

Figura 16 - Perspectiva de um Projeto no Sistema Metroviário

Nota-se na Figura 16 uma inter-relação entre as três perspectivas de projetos, as quais provocam estímulos e respostas de informações entre si, de maneira cíclica.

\subsubsection{Perspectiva da Concepção}

A perspectiva da concepção em projetos de Sistemas Metroviários tem como principal objetivo estabelecer as diretrizes básicas para subsidiar o desenvolvimento, a expansão e a modernização do sistema. Tal perspectiva responde pela sondagem de soluções técnicas, pela elaboração dos procedimentos de testes de engenharia e pela qualificação técnica de empresas fornecedoras de sistemas elétricos, eletromecânicos, material rodante e demais suprimentos para o Sistema Metroviário (METRO, 2001).

Entre as principais diretrizes estratégicas eminentes na perspectiva da concepção, e com estreita relação com o Atributo Confiança, destacam-se:

- Segurança: Analisar indicadores de falha em sistemas já implantados e definir estratégias para a aquisição e implantação de novos sistemas seguros, possivelmente mais eficazes.

- Confiabilidade: Analisar a sazonalidade de falhas históricas em sistemas já implantados e especificar indicadores MTBF, MTTF, MKBF e MTTR (termos já 
descritos no Capítulo 2) em novos projetos de aquisição e implantação de módulos do sistema.

- Disponibilidade: Analisar as taxas de falhas históricas dos módulos do sistema já implantados, confrontá-las com as taxas de falhas previamente especificadas, e elaborar novos requisitos de disponibilidade para a aquisição de novos módulos para o sistema.

- Mantenabilidade: Analisar as ocorrências de falhas históricas nos módulos do sistema já implantado, e confrontá-las com normas técnicas de manutenção preditiva, preventiva e corretiva, especificadas por equipes técnicas e fornecedores do sistema na época da contratação e, consequentemente, apresentar novos requisitos de mantenabilidade.

\subsubsection{Perspectiva da Operação}

A perspectiva da operação em projetos de um Sistema Metroviário tem como principal objetivo buscar, constantemente, a eficácia operacional, considerando as normas vigentes, atendendo às reais necessidades e anseios da sociedade. Tal perspectiva contextualiza-se ainda na provisão de transporte metroviário com segurança, confiabilidade, disponibilidade e responsabilidade socioeconômica na região em que o sistema opera (METRO, 1994).

Entre as principais atribuições contextualizadas na perspectiva da operação, e com estreita relação com o Atributo Confiança, destacam-se:

- Segurança: Analisar indicadores históricos de falha, e especificar mecanismos de proteção contra incidentes e acidentes operacionais no sistema.

- Confiabilidade: Monitorar, periodicamente, indicadores de falha, avaliar a confiabilidade operacional dos módulos do sistema e identificar situações de não conformidade com as taxas de falhas previstas em projetos de operação.

- Disponibilidade: Medir a disponibilidade operacional dos módulos do sistema e estabelecer diretrizes estratégicas para definir a oferta e o intervalo entre trens 
(headway) durante os horários e dias da semana de maior e menor movimento, bem como estabelecer as estratégias operacionais para disponibilizar o serviço de transporte a população usuária do sistema.

- Mantenabilidade: Monitorar a aplicação de procedimentos operacionais afetos aos sistemas de sinalização, alimentação elétrica, equipamentos auxiliares e materiais rodantes.

\subsubsection{Perspectiva da Manutenção}

A perspectiva da manutenção em projetos de Sistemas Metroviários tem como principal objetivo assegurar a confiabilidade, segurança e disponibilidade do sistema e seus módulos conforme padrões previamente especificados, e executar, quando demandadas, complementações ou modificações para a sua readequação (METRO, 2000).

Entre as principais atribuições contextualizadas na perspectiva da manutenção, e com estreita relação com o Atributo Confiança, destacam-se:

- Segurança: Analisar indicadores históricos de falha e especificar métricas de manutenção para assegurar a segurança do sistema com testes préoperacionais.

- Confiabilidade: Monitorar equipamentos potencialmente falhos e especificar parâmetros para a Manutenção Centrada na Confiabilidade, (Reliability Centred Maintenance - RCM), possibilitando a seleção de tarefas adequadas de manutenção direcionada para os modos de falhas identificados no sistema.

- Disponibilidade: Aferir a demanda operacional versus a disponibilidade dos componentes do sistema, e desenvolver estudos e projetos de equipamentos auxiliares de manutenção, ferramentas, técnicas e recursos humanos especiais para otimizar o restabelecimento do sistema após eventos de falha. 
- Mantenabilidade: Analisar indicadores históricos de falha e especificar procedimentos técnicos de manutenção preditiva, preventiva e corretiva nos módulos do sistema.

As perspectivas da concepção, operação e manutenção que permeiam projetos no Sistema Metroviário demandam tomadas de decisões estratégicas, as quais devem ser subsidiadas por informações integradas e comuns às três perspectivas. Tais informações são de extrema importância, tanto do ponto de vista da decisão em si, quanto de prazos e pontos de controle capazes de avaliar a eficácia nos resultados do projeto.

\subsection{A TOMADA DE DECISÕES ESTRATÉGICAS EM PROJETOS DE SISTEMAS METROVIÁRIOS}

Diante dos aspectos da Tomada de Decisão, anteriormente citados, ao considerar que um Sistema Metroviário está contido em uma estrutura organizacional, as decisões estratégicas de concepção, operação e manutenção do sistema assemelham-se às decisões estratégicas em processos de negócios, nas quais os tomadores de decisões podem provocar grande mudanças estruturais na organização. Espera-se que decisões estratégicas em projetos de Sistemas Metroviários possam privilegiar a confiabilidade, a segurança, a disponibilidade, a mantenabilidade, entre outros aspectos do Atributo Confiança do sistema. 


\subsubsection{Decisões em Projetos de Sistemas Metroviários}

Conforme descrito no Item 4.2, as decisões estratégicas dividem-se em programadas e não programadas. Em Sistemas Metroviários, as decisões programadas são, normalmente, definidas como decisões amparadas por normas técnicas e procedimentos de engenharia destinados a orientar ações preventivas e corretivas nos módulos do sistema. Por outro lado, as decisões incertas ou não programadas são as decisões tomadas em decorrência de situações novas ou desconhecidas para os tomadores de decisões.

A incerteza em decisões não programadas pode refletir-se nos resultados atingidos, muitas vezes contrários aos esperados. Tal condição se dá, entre outros fatores, pela ausência de variáveis informacionais, ou ainda, por erro de compreensão dos dados que compõem essas variáveis. Tal incerteza pode resultar em situações adversas às idealizadas no projeto e colocar o sistema em situação de alto risco operacional (WICKENS e HOLLANDS, 1999).

As decisões programadas no Sistema Metroviário permeiam, entre outras, as perspectivas da concepção, operação e manutenção do sistema, conforme os seguintes exemplos:

- Perspectiva da Concepção: A aquisição de um novo sistema de sinalização. Neste caso, utiliza-se como método decisório a prospecção de fornecedores;

- Perspectiva da Operação: Uma ocorrência de falsa ocupação em um Sistema Metroviário, ou seja, a sinalização indevida da presença de um trem em determinado local na via férrea. Neste caso, utilizam-se procedimentos operacionais para interromper, temporariamente, o fluxo de trens até a correção da falha.

- Perspectiva da Manutenção: Manutenção preventiva no Sistema de Freio de um trem. Neste caso, utilizam-se procedimentos de manutenção preventiva especificados pelos fabricantes dos módulos em questão. 
Assim como as decisões programadas, as decisões não programadas em um Sistema Metroviário também abrangem as perspectivas da concepção, manutenção e operação do sistema, conforme os seguintes exemplos:

- Perspectiva da Concepção: A exclusão de um fornecedor do catálogo corporativo de fornecedores. Neste caso, utiliza-se de embasamentos legais de não conformidades previstas em contratos de fornecimentos de módulos e serviços. Para subsidiar tal decisão, necessita-se de levantamentos de dados históricos que comprovem a situação apontada.

- Perspectiva da Operação: A existência de um ruído anormal em uma máquina de chaveamento de via, durante o horário de pico. Neste caso, utilizam-se ações intuitivas para alertar os operadores de trens que transitam no local e registra-se a ocorrência de falha no Sistema de Manutenção. Para subsidiar ações preditivas, necessita-se de levantamento de dados históricos que indiquem, por exemplo, a presença de uma possível falha latente no equipamento com ruído anormal.

- Perspectiva da Manutenção: Uma ocorrência de falha não prevista na programação da manutenção. Neste caso, utilizam-se dados históricos para averiguação de falhas anteriores que indiquem não conformidades referentes aos cálculos de confiabilidade do fornecedor.

Assim como outros Sistemas Críticos, as decisões não programadas em Sistemas Metroviários podem induzir ações intuitivas de solução de problemas, julgamentos, deduções e criatividade, ou seja, condições adversas em relação às condições previstas nas decisões programadas. Neste caso, uma alternativa plausível pode estar no acesso a informações históricas armazenadas em bases de dados, para a identificação de situações semelhantes vividas anteriormente, tornando mais embasada a utilização de métodos já experimentados para a resolução de problemas semelhantes, o que aproximaria a decisão não programada, à decisão programada. 


\subsubsection{Elementos da Decisão em Projetos de Sistemas Metroviários}

Ao transpor os elementos decisórios, Item 4.2, para o âmbito de Sistema Metroviário evidenciam-se complexidades semelhantes às encontradas nos segmentos de negócio. A capacidade de tomar decisões precisas, claras e no tempo certo é uma importante característica do modelo de gestão organizacional. O tipo de decisão, porém, varia conforme as circunstâncias. Por isso, é preciso sempre fazer uma análise da situação e de possíveis implicações, com o máximo de elementos possíveis, para que, ao menos, as decisões possam ser tomadas com embasamento de conhecimento.

Nesse sentido, ressalta-se que, enquanto uma decisão inadequada pode acarretar perdas financeiras no âmbito dos negócios, em Sistemas Metroviários, por exemplo, decisões inadequadas podem ocasionar grandes catástrofes.

Utilizando-se os elementos de decisão organizacional descritos no Item 4.2, é possível transportar tais elementos para o ambiente metroviário. Dessa forma, o papel do Tomador de Decisão é realizado pela Equipe de Projeto, e os demais elementos assumem outras características, conforme descrito a seguir:

- Equipe de Projeto: responsável pela tomada de decisões do projeto, composta por especialistas em transporte Metroviário.

- Objetivos: são representados pela concepção, operação e manutenção do sistema, mantendo o Atributo Confiança do mesmo.

- Preferências: são constituídas por critérios para o projeto dos módulos do sistema, visando eliminar os perigos e reduzir os riscos a níveis aceitáveis.

- Estratégia: compreende o estabelecimento da arquitetura do sistema, considerando as diretrizes tecnológicas, buscando mitigar falhas ativas e antever erros latentes. 
- Situação: caracteriza-se pela tomada de decisões programadas na concepção, operação e manutenção do sistema metroviário.

- Resultado: tem como alvo final prover transporte público com rapidez, segurança, confiabilidade e sustentabilidade ambiental.

\subsubsection{Ações Preditivas em Sistemas Metroviários}

Uma grande variedade de decisões estratégicas em Sistemas Metroviários relaciona-se com ações preditivas, e podem, por exemplo, serem utilizadas para reduzir ações preventivas e corretivas de manutenção nos módulos do sistema.

Neste trabalho, define-se como predição, ações que se embasam em informações previamente aferidas. As informações são obtidas por meio do processamento de quantidades significativas de dados previamente preparados para subsidiar decisões estratégicas.

A obtenção de dados históricos para subsidiar ações preditivas em projetos de Sistemas Metroviários pode advir de técnicas que identificam erros latentes ao realizar inspeções em módulos do sistema, ou ainda, de históricos de falhas ativas nos componentes do sistema. Em ambos os casos, as ações preditivas podem subsidiar a Tomada de Decisões Estratégicas em projetos de Sistemas Metroviários, escorando-se nos seguintes pontos::

- Identificação das fontes primárias de dados de falhas:, identificar as fontes de dados de falhas do sistema.

- Seleção dos dados: selecionar os dados adequados, registrados nos sistemas operacionais fontes.

- Coleta e Tratamento dos dados: coletar e tratar os dados selecionados para evitar distorções dos significados originais.

- Acesso aos dados: implementar ferramentas e processos analíticos para auxiliar os tomadores de decisões nas consultas de indicadores estratégicos. 
- Tomada de decisão estratégica: escolher as melhores alternativas e reavaliar, periodicamente, as alternativas escolhidas.

- Realimentação: conceber novos modelos e recursos para o sistema e operar e manter os atuais, tendo como referência as práticas de sucesso.

Os aspectos conceituas descritos no presente Capítulo são de grande relevância para orientar a aplicação da proposta deste trabalho, apresentada no Capítulo 5 


\section{PROPOSTA DE ANÁLISE INTELIGENTE DE FALHAS EM SISTEMAS METROVIÁRIOS}

Neste capítulo é apresentada a proposta de Análise Inteligente de Falhas para Apoiar Decisões Estratégicas em Projetos de Sistemas Críticos, enfatizando-se o Sistema Metroviário. Tal proposta reúne um conjunto de processos implementados com recursos computacionais específicos para viabilizar o acesso a todas as fontes potenciais de dados de falha, coletar esses dados e transformá-los em informação para apoiar decisões estratégicas em projetos de concepção, operação e manutenção do Sistema Metroviário.

Para analisar a viabilidade técnica e funcional da referida proposta foi desenvolvido um estudo de caso no Sistema Metroviário de São Paulo, no qual buscou-se implementar, metodicamente, as etapas necessárias para a Análise Inteligente de Falhas, utilizando recursos computacionais como ETL, Data Warehouse e ferramenta OLAP, conforme ilustrado na Figura 17.

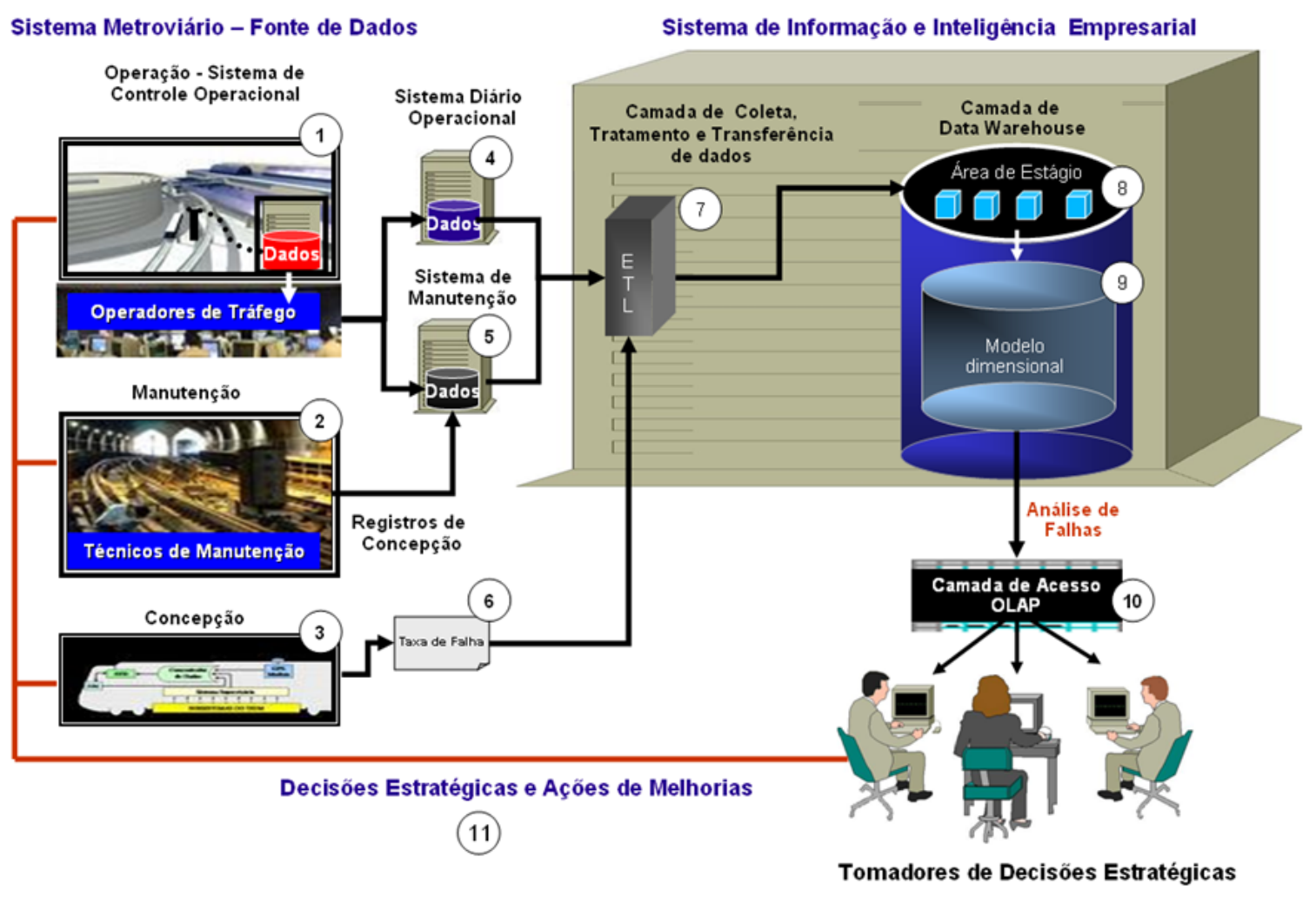

Figura 17 - Ambiente Computacional para a Análise Inteligente de Falhas no Sistema Metroviário 
A Figura 17 ilustra o ambiente computacional utilizado para implementar a proposta deste trabalho, na qual a inteligência na análise de falhas para apoiar processos decisórios deve ser vista como uma ação humana amparada por Sistemas de Informação e Inteligência Empresarial, implementados com base nos seguintes processos:

- Processo de Identificação das Fontes Potenciais de Falhas: As fontes potenciais de dados de falhas foram identificadas no Sistema de Controle Operacional (1), no Sistema Diário Operacional (4) e Sistema de Manutenção (5). Já as falhas registradas na concepção (3), contêm informações técnicas, com base em manuais de fornecedores. No entanto, estes últimos dados não foram utilizados por não estarem registrados em sistemas computacionais estruturados, embora tenham sido representados na figura para indicar uma possível fonte potencial de falha em projetos futuros.

- Processo de Registro de Falhas: As ocorrências de falhas operacionais identificadas no Sistema de Controle Operacional (1) não foram acessadas diretamente, tendo em vista que esse sistema é inacessível pela rede convencional, por tratar-se de um sistema de missão crítica e controlar o Sistema Metroviário em tempo real. Contudo, as falhas detectadas Sistema de Controle Operacional (1) são registradas pelos operadores do Centro de Controle Operacional (CCO), no Sistema Diário Operacional (4), como Ocorrência Operacional e no Sistema de Manutenção (5), como Ordem de Serviço para futura Manutenção Corretiva. Já as falhas detectadas na manutenção pelas equipes técnicas também são registradas no Sistema de Manutenção (5) como Ordem de Serviço para futura Manutenção Corretiva.

- Processo de Coleta, Tratamento e Transferência de Dados: A coleta, tratamento e transferência dos dados do Sistema Diário Operacional (4) e Sistema de Manutenção (5) são feitos, periodicamente, pelas ferramentas de ETL (7), que asseguram que esses dados sejam corretos, precisos, consistentes, completos, íntegros e aderentes às necessidades decisórias dos projetistas tomadores de decisões estratégicas. 
- Processo de Armazenamento: Após a coleta e o tratamento, os dados são armazenados em uma área intermediária do servidor de Data Warehouse denominada Área de Estágio (8). Tal área armazena os dados dos sistemas transacionais (fontes de dados) e, após a execução de processos internos desenvolvidos com recursos do gerenciador de banco de dados, os dados são selecionados e inseridos no modelo dimensional do Data Warehouse (9).

- Acesso e Análise de Dados: Com os dados disponíveis no Data Warehouse (9), os tomadores de decisões estratégicas passam a contar com recursos para executarem consultas OLAP no Data Warehouse (9).

- Processos de Realimentação: Após as aferições analíticas na camada OLAP (10) espera-se que as decisões estratégicas sejam tomadas (11), e sejam executadas ações de melhorias no sistema.

O ambiente computacional implementado para a análise de falhas no Sistema Metroviário possibilita, viabilizou executar, ciclicamente, ensaios de processos analíticos e decisórios, em intervalos de tempo bastante reduzidos. Estima-se, especificamente para este estudo de caso, que o intervalo de um dia para atualização das informações do ambiente analítico atenda às expectativas dos tomadores de decisões estratégicas do Sistema Metroviário.

\subsection{ESTUDO DE CASO NO SISTEMA METROVIÁRIO DE SÃO PAULO}

O estudo de caso relatado neste Item foi realizado no Sistema Metroviário de São Paulo e teve como base situações que requerem a Tomada de Decisões Estratégicas em projetos de concepção, operação e manutenção do sistema estudado,

As informações institucionais e os resultados de caráter privado foram parcialmente omitidos para não incorrer em interpretações equivocadas que pudessem comprometer a imagem da organização. 
Um dos requisitos para o desenvolvimento do estudo de caso foi estabelecer um roteiro estruturado em seis etapas. É altamente recomendado estabelecer um roteiro estruturado para orientar o desenvolvimento de soluções computacionais (PRESSMAN, 2006). Desta forma, os próximos subitens descrevem as etapas do roteiro especificado para a construção do ambiente protótipo e o desenvolvimento do estudo de caso no Sistema Metroviário de São Paulo. A Figura 18 ilustra a sequência de tais etapas.

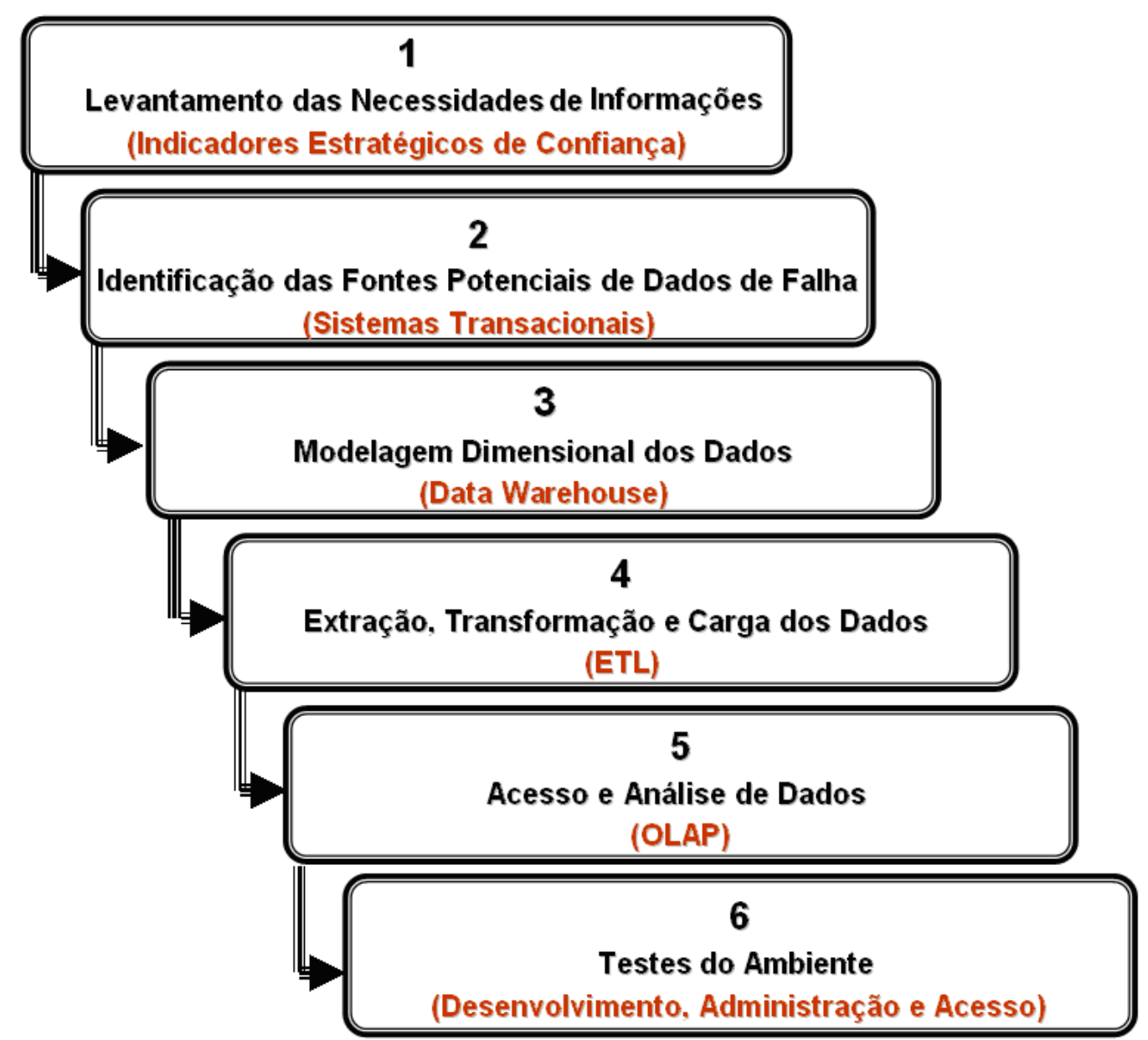

Figura 18 - Etapas do Estudo de Caso no Sistema Metroviário

\subsubsection{Etapa 1: Levantamento das Necessidades de Informações}

O levantamento das necessidades informacionais feito no sistema estudado partiu da identificação dos Indicadores Estratégicos de Confiança (IEC), sendo o termo Confiança originado da expressão Atributo Confiança, conforme descrito no Item 2.3. 
O conceito "Indicadores Estratégicos de Confiança (IEC)", baseia-se na terminologia "Indicadores-Chave de Desempenho" do acrônimo em inglês KPI (Key Performance Indicator), utilizados na metodologia de Balanced Scorecard (KAPLAN e NORTON, 1996).

Ressalta-se, que os Indicadores Estratégicos de Confiança aqui apresentados são específicos deste trabalho e foram preparados para o desenvolvimento do estudo de caso no Sistema Metroviário de São Paulo. Em casos reais de Sistemas Metroviários, ou em outros sistemas de natureza crítica seria possível levantar muitos outros indicadores estratégicos, diante da complexidade de Sistemas Críticos, como, por exemplos, sistemas aeronáuticos, nucleares, petroquímicos, entre outros.

A Figura 19 apresenta os Indicadores Estratégicos de Confiança (IEC) utilizados para aferir situações de falhas e apoiar decisões estratégicas em projetos no Sistema Metroviário, nas perspectivas da concepção, operação e manutenção do sistema. Nota-se, que os indicadores 1,2, 3, 4, 5 e 6 são comuns às três perspectivas citadas, enquanto que os indicadores 7 e 8 relacionam-se, exclusivamente, às perspectivas da concepção e manutenção respectivamente.

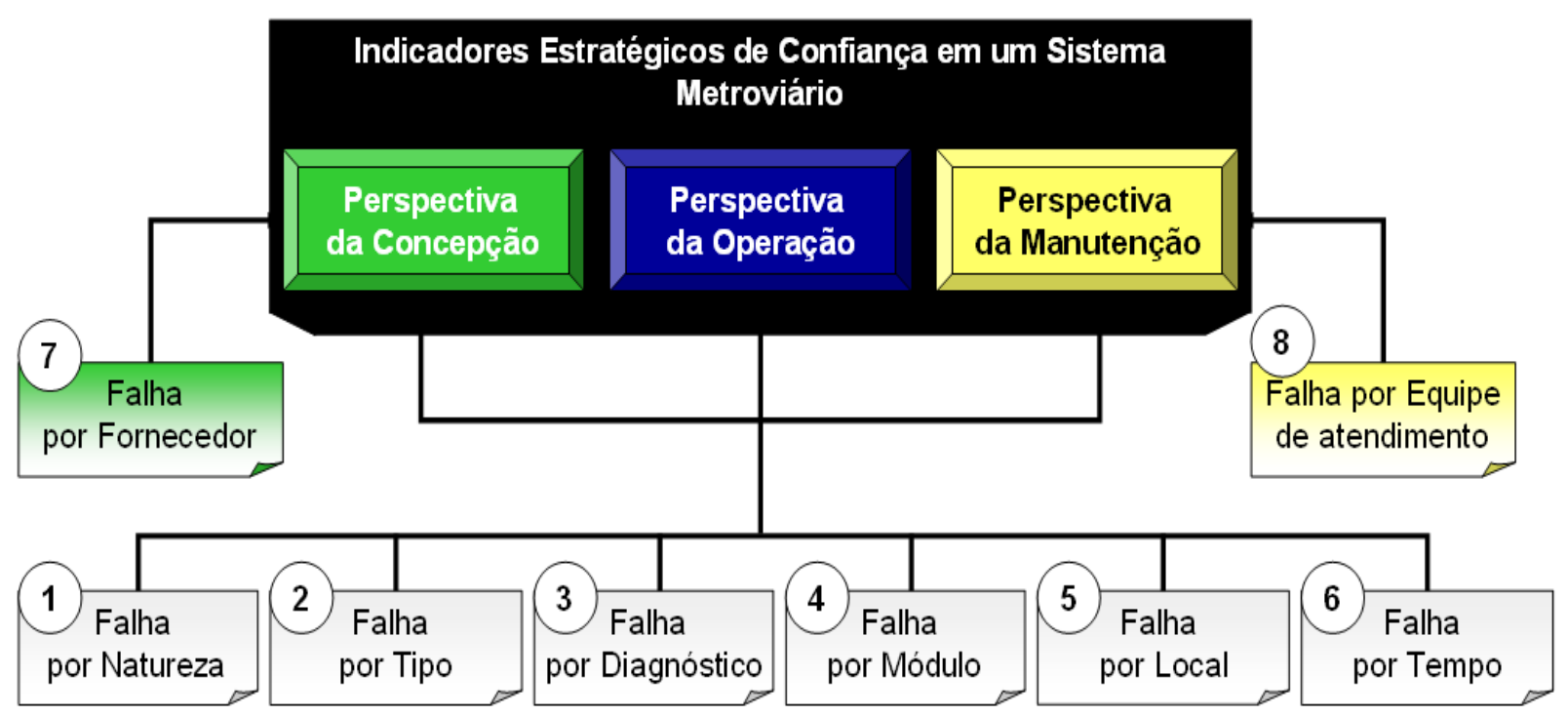

Figura 19 - Indicadores Estratégicos de Confiança no Sistema Metroviário 
$\mathrm{Na}$ perspectiva da concepção estabelecem-se as diretrizes tecnológicas para a aquisição, implantação, expansão e modernização dos módulos do sistema. $\mathrm{Na}$ perspectiva da manutenção definem-se as estratégias de mantenabilidade e confiabilidade dos equipamentos e instalações do sistema. Já na perspectiva da operação verifica-se se a segurança e a disponibilidade estão em conformidade com as diretrizes operacionais do sistema.

A seguir é apresentada uma descrição sucinta dos Indicadores Estratégicos de Confiança (IEC) sugeridos para o estudo de caso do Sistema Metroviário de São Paulo:

- Indicador de Falha por Natureza (1): Indica a origem das falhas (equipamentos fixos, materiais rodantes e estações elétricas retificadoras), e seu grau de severidade ( 1 - remota, 2 - baixa, 3 - moderada, 4 - alta e 5 - muito alta), considerando os módulos e os aspectos operacionais do sistema.

- Indicador de Falha por Tipo (2): Indica os tipos de falhas (elétricas, mecânicas, hidráulicas, computacionais e humanas), suas categorias (urgente e não urgente) e seu status (aberta, fechada e suspensa).

- Indicador de Falhas por Diagnóstico (3): Indica os diagnósticos das falhas (abertura inadequada, agente externo, causa não identificada, consequência de outra falha, fortuidade natural, manutenção indevida, operação indevida, parâmetro técnico inadequado, sintoma não identificado e vandalismo), os seus sintomas (trepidação anormal, ruído anormal, fumaça, perda de sinal, perda de pressão, sinalização indevida, aquecimento anormal e resfriamento anormal), o grau de risco (intolerável, tolerável e aceitável), e o tipo de perigo envolvido (físico, elétrico, químico, biológico e ergonômico).

- Indicador de Falhas por Módulos (4): indica os tipos dos módulos falhos (módulos de trem, via férrea permanente, sistema elétrico, sistema de controle automático - ATO, sistema de proteção - ATP e outros) e suas categorias (fixo e rodante). 
- Indicador de Falhas por Local (5): Indica as características dos locais geográficos das falhas (linhas, pátios de manobras, subestações elétricas retificadoras, estações, outros).

- Indicador de Falha por Tempo (6): Indica o ano, mês, dia e hora da abertura das falhas e o ano, mês, dia e hora de seus encerramentos.

- Indicador de Falha por Fornecedores (7): Indica as características dos fornecedores de módulos falhos (nome e CNPJ) as especialidades (equipamento fixo e material rodante) e o tempo de relacionamento (data de cadastro).

- Indicador de Falha por Equipe de Atendimento (8): Indica as características das equipes técnicas que atenderam as falhas, o turno das equipes (matutino, vespertino e noturno) e os seus responsáveis.

\subsubsection{Etapa 2: Identificação das Fontes Potenciais de Dados de Falha}

A identificação das fontes potenciais de dados de falha partiu da premissa conceitual de Sistemas de Informação e Inteligência Empresarial que considera como fonte potencial o ambiente computacional que dá origem aos dados operacionais. Os dados selecionados para o desenvolvimento do ambiente protótipo tiveram como origem a base de dados do Sistema Diário Operacional, no qual as falhas são registradas pelo operador, após a detecção pelo Sistema de Controle Operacional, e a base de dados do Sistema de Manutenção, na qual a falha é tratada como ordem de serviço de manutenção.

Os cenários ilustrados na Figura 20 referem-se à detecção e registros de falhas na operação e manutenção do Sistema Metroviário. As falhas operacionais (1) são identificadas no Sistema de Controle Operacional e registradas pelos operadores no Sistema Diário Operacional e no Sistema de Manutenção. As falhas de manutenção são identificadas nas rotinas de manutenção e registradas por técnicos de manutenção no Sistema de Manutenção (2). 


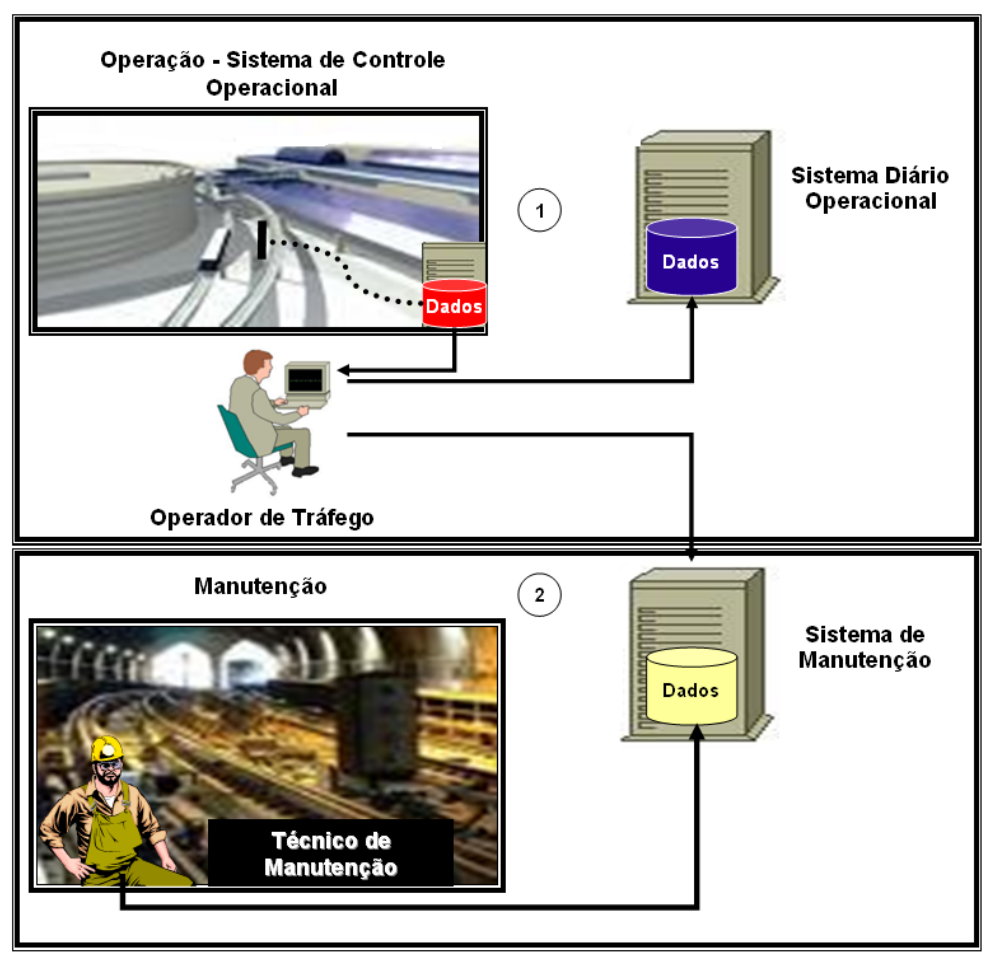

Figura 20 - Fontes Potenciais de Dados

Foram selecionados para este estudo cerca de 8 mil registros de falhas identificadas no Sistema Diário Operacional e Sistema de Manutenção que se correlacionam, ou seja, uma falha no módulo de freio de um trem, por exemplo, é registrada no Sistema Diário Operacional como ocorrência operacional, e posteriormente registrada no Sistema de Manutenção como ordem de serviço para manutenção corretiva. Nesse momento, os dados correspondentes são registrados no Sistema de Manutenção (código, descrição, etc.).

Os 8 mil registros selecionados para o estudo de caso correspondem ao período de 2003 a 2008 e referem-se a falhas em equipamentos fixos, materiais rodantes e estações elétricas retificadoras. O período de tempo dos registros selecionados foi uma opção. Os demais registros (290 mil, correspondentes ao período de 1990 a 2002 e 2009, os quais, além das informações contidas nas amostras selecionadas contêm registros de falhas abertas para manutenção preventiva em equipamentos de estações de embarque e desembarque do Sistema Metroviário) foram desconsiderados por não estarem no escopo deste estudo.

Na Figura 21 ilustram-se as bases de dados operacionais, com tabelas e atributos de dados extraídos do Sistema Diário Operacional e Sistema de Manutenção. As 
tabelas ilustradas na figura foram utilizadas para o desenvolvimento do estudo de caso proposto. Tais tabelas armazenam os dados necessários para subsidiar os Indicadores Estratégicos de Confianças (IEC) descritos no Item 5.1.1.

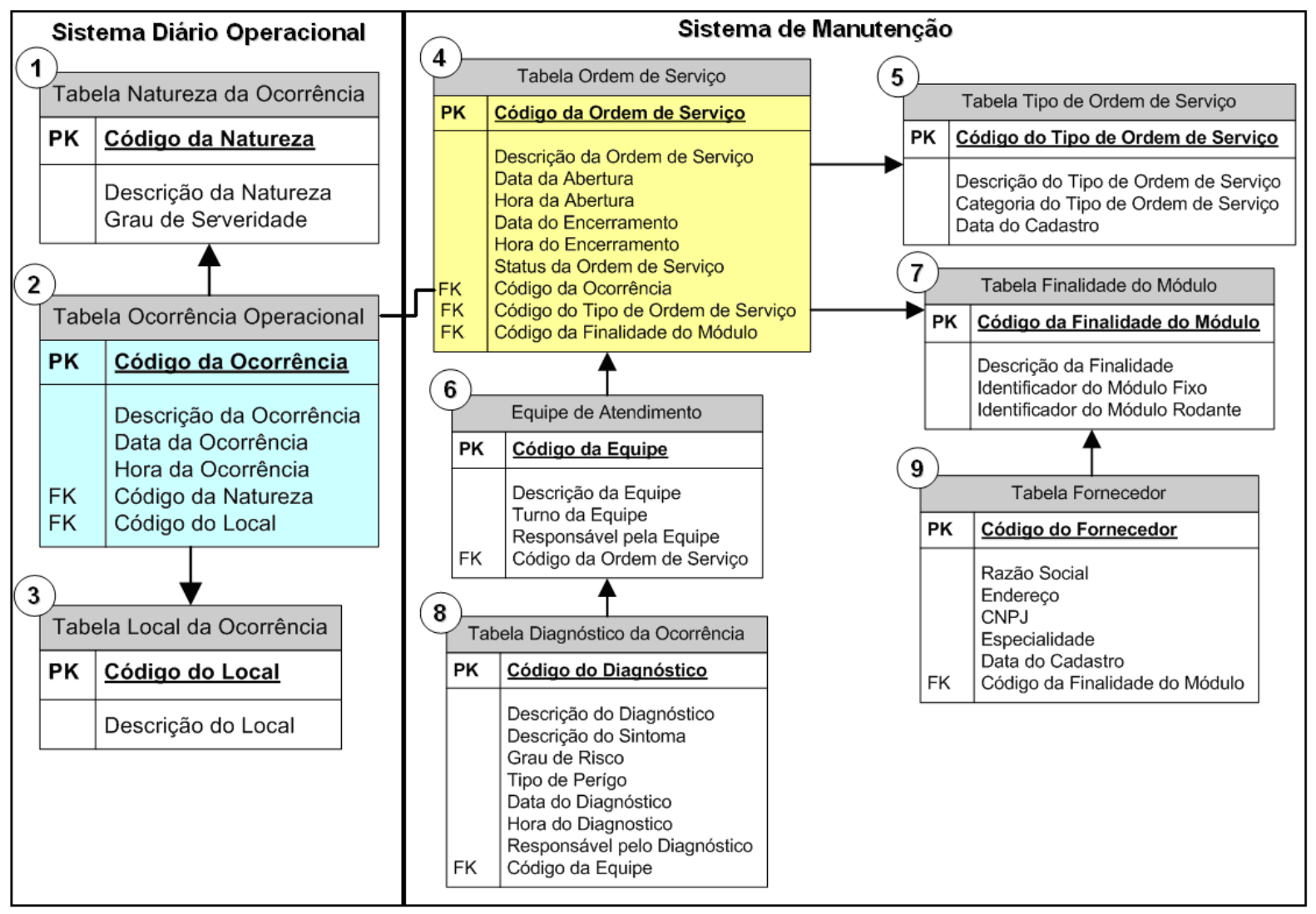

Figura 21 - Mapeamento de Dados dos Sistemas Fonte

Uma descrição sucinta das tabelas resultantes do mapeamento das fontes potenciais de dados é a seguinte:

- Tabela Natureza da Ocorrência (1): Armazena os dados referentes à Descrição da Natureza e ao Grau de Severidade da ocorrência

- Tabela Ocorrência Operacional (2) Armazena os dados complementares da ocorrência como Data e Hora da Ocorrência.

- Tabela Local da Ocorrência (3): Armazena os dados referentes à Descrição do Local geográfico da ocorrência. 
- Tabela Ordem de Serviço (4) Armazena os dados complementares do Tipo de Falha, como a Descrição e Status da Ordem de Serviço, a Data e Hora da Abertura, a Data e a Hora do Encerramento da Ordem de Serviço. E armazena o Código da Ocorrência registrado no Sistema Diário Operacional

- Tabela Tipo de Ordem de Serviço (5): Armazena a Descrição do Tipo de Ordem de Serviço, sua Categoria e a Data do Cadastro.

- Tabela Equipe de Atendimento (6): Armazena a Descrição, o Turno e o Responsável pela Equipe de manutenção.

- Tabela Finalidade do Módulo (7): Armazena a Descrição da Finalidade, o Identificador do Módulo Fixo e o Identificador do Módulo Rodante.

- Tabela Diagnóstico da Ocorrência (8): Armazena a Descrição do Diagnóstico, a Descrição do Sintoma, o Grau de Risco, o Tipo de Perigo, a Data, Hora e o Responsável pelo Diagnóstico.

- Tabela Fornecedor (9): Armazena a Razão Social, o Endereço, o CNPJ, a Especialidade e a Data do Cadastro do fornecedor do sistema.

Após a identificação das fontes potenciais de dados de falhas, a próxima etapa para a construção do ambiente protótipo é a modelagem dimensional dos dados.

\subsubsection{Etapa 3: Modelagem Dimensional dos Dados}

A modelagem dimensional do ambiente protótipo considerou os dados disponíveis nas fontes potenciais versus as necessidades informacionais apontadas nos Indicadores Estratégicos de Confiança (IEC) no Sistema Metroviário estudado. As dimensões selecionadas para o modelo foram diretamente extraídas de tais indicadores, descritos no Item 5.1.1.

Para desenvolver o modelo dimensional optou-se, previamente, pela criação de uma Matriz de Barramentos para identificar os modelos dimensionais necessários para o estudo de caso. A criação da Matriz de Barramento é uma técnica que orienta o desenvolvimento de Data Warehouse (KIMBALL e ROSS 2002). 
Na Figura 22, ao se criar a Matriz de Barramento para o estudo de caso constatouse que seriam necessários três modelos dimensionais para atender às necessidades informacionais do estudo. Contudo, ao considerar a afinidade entre as perspectivas da concepção, operação e manutenção do Sistema Metroviário, optou-se, especificamente, neste estudo, por criar um único modelo dimensional.

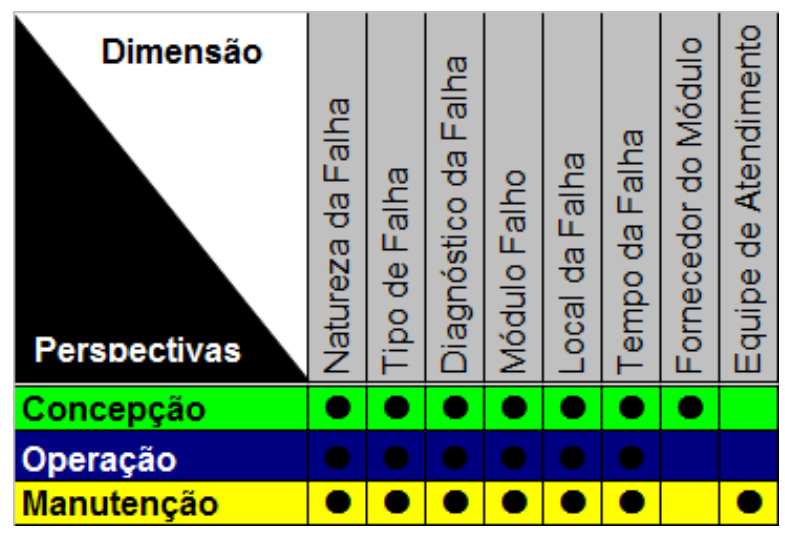

Figura 22 - Matriz de Barramento nas três Perspectivas do Sistema Metroviário

Observa-se que a grande maioria dos assuntos relacionados à falha no Sistema Metroviário é de interesse comum às três perspectivas indicadas na Matriz de Barramento, exceto as informações referentes às Equipes de Atendimento à Falha, de interesse exclusivo na perspectiva da Manutenção e Fabricante do Módulo Falho, de interesse exclusivo na perspectiva da concepção.

Ao verificar-se a possibilidade do desenvolvimento de um único modelo dimensional no estudo de caso, optou-se pela implementação da tabela Fato Falha e tabelas Dimensões Natureza da Falha, Tipo de Falha, Diagnóstico da Falha, Módulo Falho, Local da Falha, Tempo da Falha, Fornecedor do Módulo e Equipe de Atendimento.

A Figura 23 ilustra o modelo dimensional proposto para o Sistema Metroviário estudado. 


\begin{tabular}{|c|c|c|}
\hline Dimensão Natureza da Falha & & Dimensão Local da Falha \\
\hline Chave Natureza da Falha (PK) & & Chave Local da Falha (PK) \\
\hline $\begin{array}{l}\text { Código da Natureza da Falha } \\
\text { Descrição da Natureza da Falha } \\
\text { Grau de Severidade } \\
\text { Código da Ocorrência da Falha } \\
\text { Descrição da Ocorrência da Falha }\end{array}$ & Fato Falha & $\begin{array}{l}\begin{array}{l}\text { Código do Local } \\
\text { Descrição do Local }\end{array} \\
\text { Dimensão Tempo da Falha } \\
\end{array}$ \\
\hline Dimensão Tipo de Falha & Chave Natureza da Falha (FK) & Chave Tempo da Falha (PK) \\
\hline Chave Tipo de Falha (PK) & Chave Tipo de Falha (FK) & $\begin{array}{l}\text { Ano da abertura da Falha } \\
\text { Mês da abertura da Falha }\end{array}$ \\
\hline $\begin{array}{l}\text { Código do Tipo de Falha } \\
\text { Descrição do Tipo de Falha } \\
\text { Categoria do Tipo de Falha } \\
\text { Código da Falha } \\
\text { Status da Falha } \\
\text { Descrição da Falha }\end{array}$ & $\begin{array}{ll}\mathbf{P} & \text { Chave Diagnóstico da Falha (FK) } \\
\mathbf{K} & \text { Chave Módulo Falho (FK) } \\
\text { Chave Local da Falha(FK) } \\
\text { Chave Tempo da Falha(FK) } \\
\text { Chave Fornecedor do Módulo(FK) }\end{array}$ & $\begin{array}{l}\text { Dia da abertura da Falha } \\
\text { Hora da abertura da Falha } \\
\text { Ano do Encerramento da Falha } \\
\text { Mês do Encerramento da Falha } \\
\text { Hora do Encerramento da Falha } \\
\text { Dia do Encerramento da Falha } \\
\text { Hora do Encerramento da Falha }\end{array}$ \\
\hline Dimensão Diagnóstico da Falha & Chave Equipe de Atendimento(FK) & Dimensão Fornecedor do Módulo \\
\hline Chave Diagnostico da Falha (PK) & \multirow{3}{*}{$\begin{array}{l}\text { Quantidade de Falha } \\
\text { Custo da Manutenção } \\
\text { MKBF do Material Rodante } \\
\text { MTTR do Material Rodante e Fixo } \\
\text { MTBF do Material Rodante e Fixo } \\
\text { MTTF do Material Rodante e Fixo }\end{array}$} & Chave Fornecedor do Módulo (PK) \\
\hline $\begin{array}{l}\text { Código do Diagnóstico } \\
\text { Descrição do Diagnóstico } \\
\text { Descrição do Sintoma } \\
\text { Grau de Risco } \\
\text { Tipo de Perigo } \\
\text { Responsável pelo Diagnóstico }\end{array}$ & & $\begin{array}{l}\text { Código do Fornecedor } \\
\text { Razäo Social do Fornecedor } \\
\text { CNPJ do Fornecedor } \\
\text { Especialidade do Fornecedor } \\
\text { Data de Cadastro do Fornecedor }\end{array}$ \\
\hline $\begin{array}{l}\text { Dimensão Módulo Falho } \\
\text { Chave Módulo Falho (PK) }\end{array}$ & & Dimensão Equipe de Atendimento \\
\hline \multirow[b]{2}{*}{$\begin{array}{l}\text { Código do Módulo } \\
\text { Descrição do Módulo } \\
\text { Categoria do Módulo } \\
\text { ld. Módulo Fixo } \\
\text { ld. Módulo Rodante } \\
\text { Taxa de Falha }\end{array}$} & & Chave Equipe de Atendimento (PK) \\
\hline & & $\begin{array}{l}\text { Código da Equipe } \\
\text { Descrição da Equipe } \\
\text { Turno da Equipe } \\
\text { Responsável pela Equipe } \\
\text { Valor hora da Equipe }\end{array}$ \\
\hline
\end{tabular}

Figura 23 - Modelo Dimensional Proposto para o Sistema Metroviário

O modelo dimensional proposto é composto por uma tabela Fato contendo uma chave primária composta de oito chaves estrangeiras, originárias das tabelas dimensionais, com seis medidas que representam, numericamente, o Fato Falha. Já as tabelas dimensionais armazenam os dados descritivos do Fato Falha. $O$ significado dos atributos numéricos da tabela Fato é :

- Quantidade de Falhas: quantidade de falhas para cada evento dimensional.

- Custo da Manutenção: soma dos valores horários da Equipe de Atendimento.

- MKBF do Material Rodante: indicador de falha por quilometragem dos Módulos Rodantes.

- MTTR do Material Rodante e Fixo: indicador de tempo de reparo de falhas dos Módulos Fixos e Rodantes. 
- MTBF do Material Rodante e Fixo: indicador de tempo entre falhas dos Módulos Fixos e Rodantes.

- MTTF do Material Rodante e Fixo: indicador de tempo para falhas dos Módulos Fixos e Rodantes.

Ressalta-se, contudo, que os atributos da tabela Fato Falha : Custo da Manutenção, MKBF do Material Rodante e MTTR , MTBF e MTTF do Material Rodante e Fixo, assim como os atributos: Taxa de Falha da tabela Dimensão Módulo Falho e Valor Hora da Equipe, da tabela Dimensão Equipe de Atendimento, não foram implementados neste estudo devido à ausência dos dados nos sistemas fontes

Considerando-se a não implementação de tais atributos e medidas, o modelo implementado está ilustrado na Figura 24.

Dimensão Natureza da Falha

\begin{tabular}{|c|c|c|}
\hline Chave Natureza da Falha (PK) & & Chave Local da Falha (PK) \\
\hline $\begin{array}{l}\text { Código da Natureza da Falha } \\
\text { Descrição da Natureza da Falha } \\
\text { Grau de Severidade } \\
\text { Código da Ocorrência da Falha } \\
\text { Descrição da Ocorrência da Falha }\end{array}$ & Fato Falha & $\begin{array}{l}\begin{array}{l}\text { Código do Local } \\
\text { Descrição do Local }\end{array} \\
\text { Dimensão Tempo da Falha }\end{array}$ \\
\hline Dimensão Tipo de Falha & Chave Natureza da Falha (FK) & nave lempo da ralna( $r$ \\
\hline Chave Tipo de Falha (PK) & Chave Tipo de Falha (FK) & $\begin{array}{l}\text { Ano da abertura da Falha } \\
\text { Mês da abertura da Falha }\end{array}$ \\
\hline $\begin{array}{l}\text { Código do Tipo de Falha } \\
\text { Descrição do Tipo de Falha } \\
\text { Categoria do Tipo de Falha } \\
\text { Código da Falha } \\
\text { Status da Falha } \\
\text { Descrição da Falha }\end{array}$ & $\begin{array}{l}\text { P Chave Diagnóstico da Falha (FK) } \\
\text { K Chave Módulo Falho (FK) } \\
\text { Chave Local da Falha(FK) } \\
\text { Chave Tempo da Falha (FK) } \\
\text { Chave Fornecedor do Módulo(FK) }\end{array}$ & $\begin{array}{l}\text { Dia da abertura da Falha } \\
\text { Hora da abertura da Falha } \\
\text { Ano do Encerramento da Falha } \\
\text { Mês do Encerramento da Falha } \\
\text { Hora do Encerramento da Falha } \\
\text { Dia do Encerramento da Falha } \\
\text { Hora do Encerramento da Falha }\end{array}$ \\
\hline$\frac{\text { Dimensão Diagnóstico da Falha }}{\text { Chave Diagnostico da Falha }(\mathrm{PK})}$ & Chave Equipe de Atendimento(FK) & Dimensão Fornecedor do Módulo \\
\hline Códiao do Diaanóstico & Quantidade de Falha & Chave Fornecedor do Módulo(PK) \\
\hline $\begin{array}{l}\text { Descrição do Diagnóstico } \\
\text { Descrição do Sintoma } \\
\text { Grau de Risco } \\
\text { Tipo de Perigo } \\
\text { Responsável pelo Diagnóstico }\end{array}$ & & $\begin{array}{l}\text { Código do Fornecedor } \\
\text { Razão Social do Fornecedor } \\
\text { CNPJ do Fornecedor } \\
\text { Especialidade do Fornecedor } \\
\text { Data de Cadastro do Fornecedor }\end{array}$ \\
\hline $\begin{array}{l}\text { Dimensão Módulo Falho } \\
\text { Chave Módulo Falho (PK) }\end{array}$ & & Dimensão Equipe de Atendimento \\
\hline \multirow[b]{2}{*}{$\begin{array}{l}\text { Código do Módulo } \\
\text { Descrição do Módulo } \\
\text { Categoria do Módulo } \\
\text { Id. Módulo Fixo } \\
\text { ld. Módulo Rodante }\end{array}$} & & Chave Equipe de Atendimento(PK) \\
\hline & & $\begin{array}{l}\text { Código da Equipe } \\
\text { Descriçấo da Equipe } \\
\text { Turno da Equipe } \\
\text { Responsável pela Equipe }\end{array}$ \\
\hline
\end{tabular}


Para maior compreensão do modelo dimensional implementado no estudo de caso do Sistema Metroviário, segue uma descrição sucinta das tabelas e atributos contidos no modelo.

- Fato Falhas: relaciona-se com todas as tabelas Dimensões por meio das chaves estrangeiras $(F K)$ e armazena os dados numéricos referentes à quantidade de falhas. A medida quantidade de Falha sempre terá o valor 1 (um) para cada evento, indicando a quantidade de falhas para cada uma das combinações possíveis no modelo.

- Dimensão Natureza da Falha: corresponde ao IEC Falha por Natureza e seus dados principais referem-se à origem, grau de severidade, código e descrição da ocorrência da falha.

- Dimensão Tipo de Falha: corresponde ao IEC Falha por Tipo e seus dados principais referem-se ao código, descrição, categoria e status da falha.

- Dimensão Diagnóstico da Falha: corresponde ao IEC Falha por Diagnóstico e seus principais dados referem-se ao código, descrição, sintoma, grau de risco, tipo de perigo e responsável pelo diagnóstico da falha.

- Dimensão Módulo Falho: corresponde ao IEC Falha por Módulo e seus principais dados referem-se ao código, descrição, categoria, identificador $r$ categoria do módulo.

- Dimensão Fornecedor do Módulo: corresponde ao IEC Falha por Fornecedor e seus principais dados referem-se ao código, razão social, CNPJ, especialidade e data de cadastro do fornecedor.

- Dimensão Local da Falha: corresponde ao IEC Falha por Local e seus principais dados correspondem ao código e descrição do local geográfico da falha.

- Dimensão Tempo da Falha: corresponde ao IEC Falha por Tempo e seus principais dados referem-se ao ano, mês, dia e hora da abertura e encerramento da falha. 
- Tabela Dimensão Equipe de Atendimento: corresponde ao IEC Falha por Equipe de Atendimento e seus principais dados correspondem ao código, descrição, turno e responsável pela equipe de atendimento da falha.

A criação de um modelo dimensional, conforme descrito do capitulo 3 deste trabalho, tem como principal objetivo apoiar a análise de grandes volumes de dados e extrair informações de forma direta e intuitiva. A modelagem dimensional utilizada em projetos de Data Warehouse favorece a consulta a informações de diferentes fontes, o que em muitos casos se torna uma tarefa complexa para ser realizada em uma base de dados operacionais (KIMBALL e ROSS, 2002).

O fator que orientou a construção do modelo dimensional apresentado na Figura 25 foi a necessidade de prover informações para cada Indicador Estratégico de Confiança (IEC) apresentado no Item 5.1.1. A Figura 25 ilustra a relação entre os IECs (Figura 19), as tabelas operacionais (Figura 21) e as tabelas dimensionais (Figura 24).

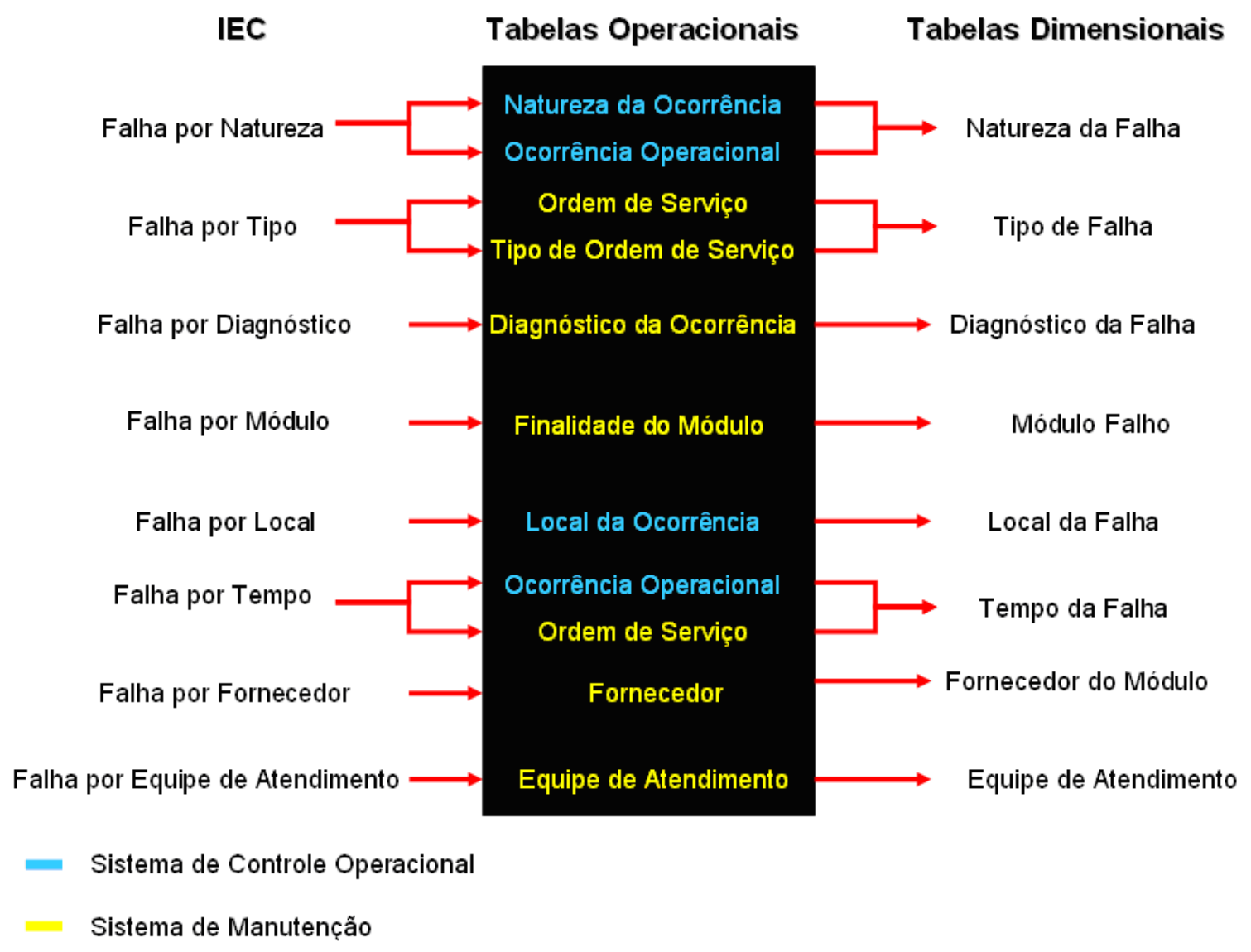

Figura 25 - Relação entre IECs, Tabelas Operacionais e Tabelas Dimensionais 


\subsubsection{Etapa 4: Processo de ETL}

Os processos de ETL foram implementados em 3 etapas que visaram a extração dos dados do ambiente operacional, a transformação e tratamento desses dados e, finalmente, a carga desses dados na Área de Estágio do Data Warehouse. Tais processos dividiram-se em :

- Extração dos Dados: A extração dos dados foi implementada para selecionar e copiar os dados do Sistema Diário Operacional, armazenados em um Gerenciador de Banco de Dados Oracle 9i. Já os dados do Sistema de Manutenção foram selecionados e coletados de um Gerenciador de Banco de Dados IBM DB2, por meio de consultas SQL (Structured Query Language).

- Transformação: Diante da excelente consistência e integridade das bases de dados operacionais, o processo de transformação e qualidade de dados teve como tarefa básica a alteração de formato e alguns atributos. No Sistema Diário Operacional (base Oracle 9i) os dados textuais, numéricos e de tempo encontravam-se no formato NUMBER, VARCHAR e DATE respectivamente. No Sistema de Manutenção (base DB2) os dados alfanuméricos e de tempo encontravam-se no formato VARCHAR e TIMESTAMP. Em ambos os casos os dados numéricos foram convertidos para o formato NUMERIC, os dados textuais foram convertidos para o formato CHARACTER VARYING e os dados de tempo foram convertidos para o formato TIMESTAMP.

- Carga dos Dados: Após os dados serem transformados, finaliza-se o processo de ETL com a carga dos dados na Área de Estágio do Data Warehouse. O método de carga utilizado para no estudo de caso foi a carga completa (full), no qual todos os dados selecionados nos ambientes operacionais foram carregados no ambiente destino. No entanto, sugere-se, em uma eventual implementação real, que o método de carga seja o incremental, ou seja, selecionam-se apenas os dados alterados nos ambientes operacionais e carregam-se esses dados no ambiente de destino, sem excluir os dados existentes. Um dos principais benefícios da carga incremental é a preservação dos dados históricos no Data Warehouse, independente do ambiente origem. 
Os processos de ETL são de grande importância, pois asseguram que os dados sejam efetivamente carregados, com qualidade, no Data Warehouse. Volumes crescentes de dados podem requerer processos de ETL com diferentes escalas de processamento que vão de minutos a horas para serem concluídos.

Com relação à melhora da qualidade dos dados, ainda que não tenha sido explorado neste estudo, poderia ser utilizado para identificar e corrigir erros de digitação de dados, dar significados compreensíveis a termos técnicos, para o pleno entendimento dos tomadores de decisões, criar dados padrão para o preenchimento de campos vazios, como por exemplo dados de fornecedores que eventualmente não são cadastrados, entre outras funcionalidades inerentes ao recurso.

Os processos de ETL foram implementados com a ferramenta Oracle Data Integration (ODI). Os dados foram extraídos dos Sistemas Gerenciadores de Bancos de Dados (SGBD) Oracle e DB2, e carregados no Data Warehouse que está implementado sob o Sistema de Gerenciador de Banco de Dados (SGBD) Postgresql.

Figura 26 ilustra, em alto nível de abstração, os recursos utilizados para extrair, transformar, e carregar os dados de falhas dos ambientes de origem para o Data Warehouse do ambiente protótipo.

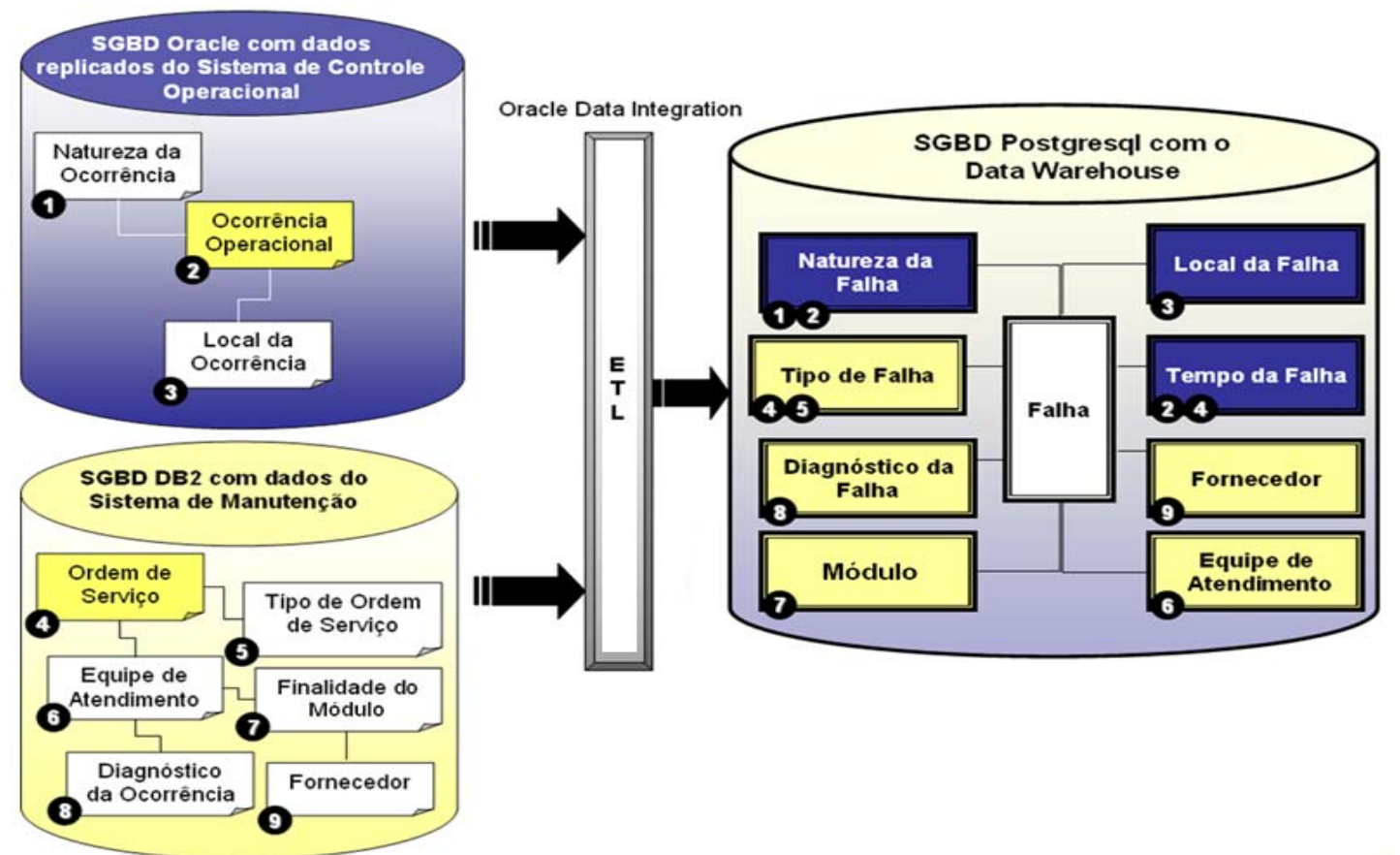

Figura 26 - llustração do Processo de ETL 


\subsubsection{Etapa 5: Camada de Acesso OLAP}

A camada de acesso OLAP foi implementada por intermédio do software TDBI e privilegiou a fácil interatividade de navegação na ferramenta, objetivando-se viabilizar a análise de dados pelos próprios tomadores de decisões estratégicas.

Uma das principais vantagens no uso da ferramenta OLAP é possibilitar a visualização dos dados sem a necessidade de conhecimentos técnicos sobre o modelo dimensional, ou a dependência de profissionais de computação para extrair tais dados. Nesse sentido, o tomador de decisões tem apenas que lidar com termos que já está habituado. A ferramenta OLAP implementada possibilita ainda salvar consultas executadas com frequência no Data Warehouse.

Na Figura 27, exemplifica-se uma consulta OLAP quantitativa, na qual optou-se por selecionar o total de falhas por módulos de quatro fornecedores de material rodante (trem). Tais amostras tornaram-se um importante instrumento para indicar a quantidade de módulos falhos por fornecedores.

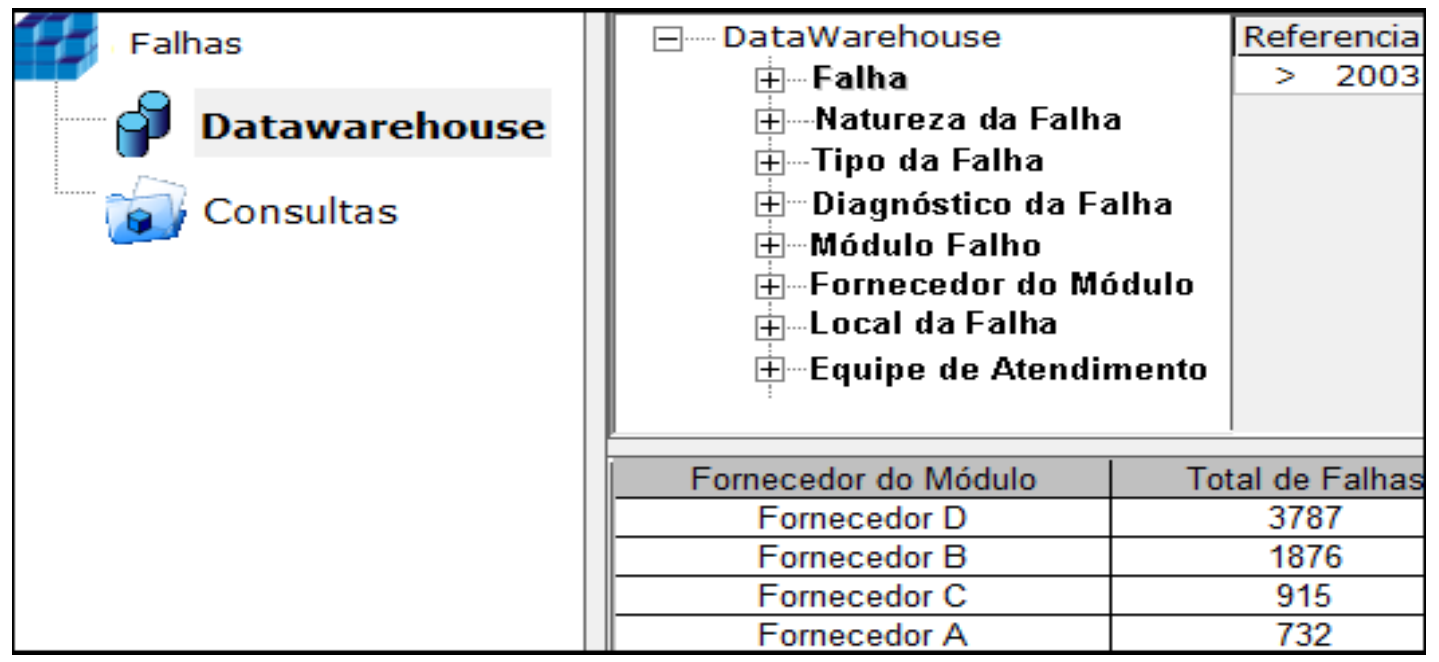

Figura 27 - Interface de Consulta OLAP Quantitativa

As consultas OLAP quantitativas auxiliaram as pesquisas totalizadoras ao indicarem cenários sumarizados que permitiram mensurar a grandeza dos eventos de falha, com a precisão e rapidez dificilmente alcançadas com recursos diferentes dos propostos neste trabalho. 
Já na Figura 28, exemplifica-se uma consulta OLAP qualitativa, na qual optou-se por selecionar uma falha elétrica como Tipo de Falha, o Módulo Falho, e o Ano da falha no Sistema Metroviário.

\begin{tabular}{|c|c|c|c|}
\hline Falhas & Tipo de Falha & Módulo Falho & \begin{tabular}{|l|} 
Ano \\
2005
\end{tabular} \\
\hline Datawarehouse & \multirow{6}{*}{ Elétrica } & DISJUNTOR/CONTATOR UNIPOLAR & $\begin{array}{l}2006 \\
2007\end{array}$ \\
\hline \multirow{5}{*}{ Consultas } & & & 2005 \\
\hline & & FUSIVEL DE LAMINA - COL 3.TR & \begin{tabular}{|l|}
2006 \\
2007 \\
2008 \\
\end{tabular} \\
\hline & & EQUIP. DESENERG. EMERG. SPAP & 2008 \\
\hline & & ESCOVA - MOTOR - GMG & 2005 \\
\hline & & DISJUNTORES EM GERAL & $\begin{array}{l}2006 \\
2008 \\
\end{array}$ \\
\hline
\end{tabular}

Figura 28 - Interface de Consulta OLAP Qualitativa

Após executar a consulta qualitativa nota-se que o módulo Fusível de Lâmina apresentou falhas entre os anos de 2005 a 2008. Neste caso, um dos recursos disponíveis na camada OLAP é a execução de uma consulta do tipo drill down, ou seja, uma consulta para aumentar o nível de detalhe na informação selecionada. A Figura 29 ilustra a execução da consulta drill down, a qual indica a persistência da falha apresentada, sugerindo, a necessidade de readequação dos procedimentos de manutenção preventiva, ou ainda, a substituição efetiva do módulo.

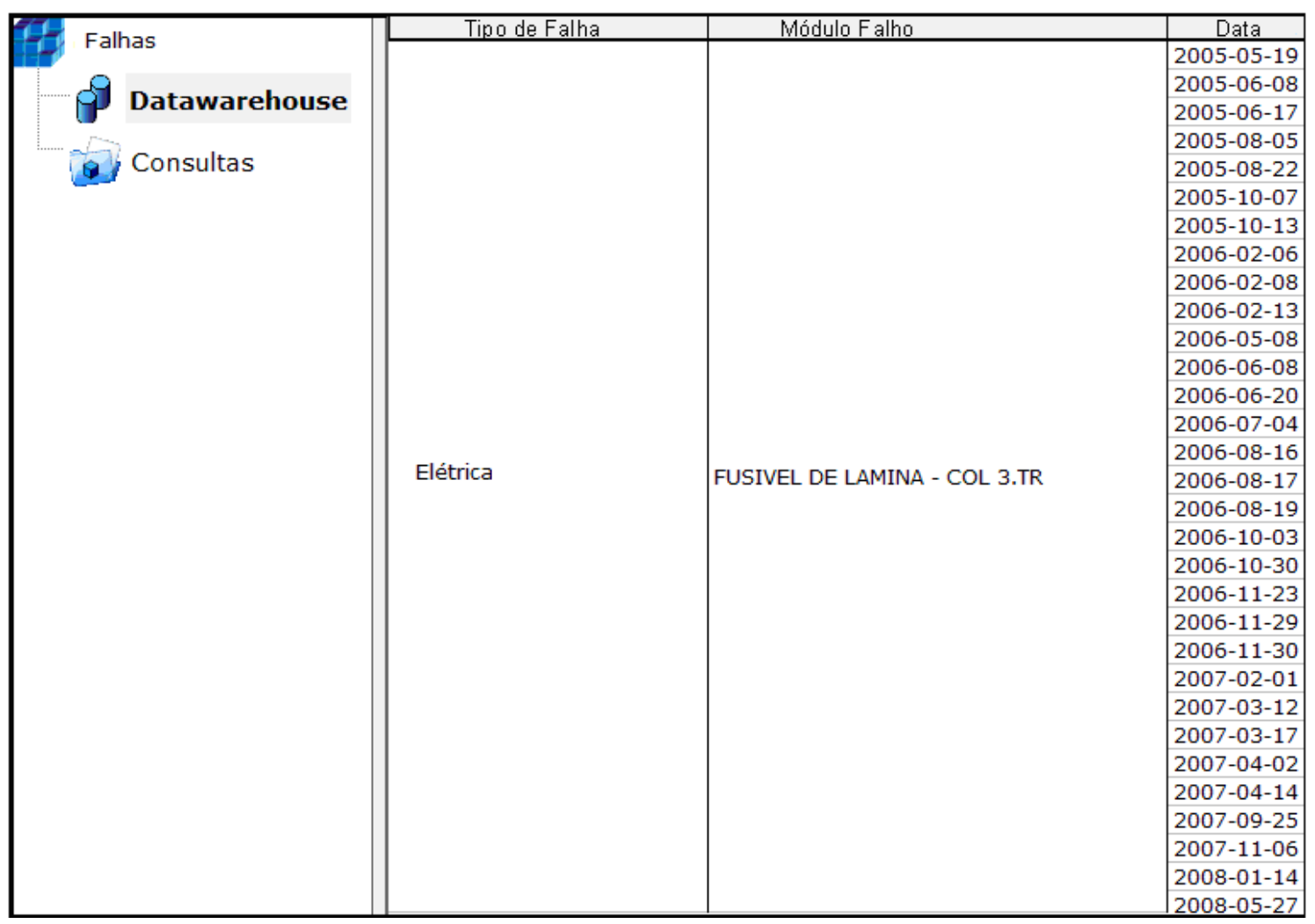

Figura 29 - Interface de Consulta OLAP com Drill Down 
Após executar as consultas, exemplificadas, no protótipo construído para o estudo de caso no Sistema Metroviário, evidenciaram-se diversas possibilidades de análise de informações relevantes para aferir os Indicadores Estratégicos de Confiança (IEC) e apoiar decisões estratégicas nas perspectivas da concepção, operação e manutenção do sistema.

\subsubsection{Etapa 6: Teste do Ambiente Protótipo}

Os testes do ambiente foram realizados com usuários do recurso do protótipo, Neste caso recomenda-se o envolvimento de tomadores de decisões estratégicas no Sistema Metroviário.

O ponto mais relevante para validar a utilização do ambiente protótipo foi a facilidade de executar consultas OLAP do tipo ad-hoc no ambiente, e, consequentemente, a rapidez na elaboração de pesquisas de Indicadores Estratégicos de Confiança (IEC). A homologação do ambiente protótipo considerou ainda a facilidade de implementação do modelo proposto em um ambiente real, utilizando-se das mesmas tecnologias aplicadas no protótipo, conforme segue:

- Tecnologia de ETL: Software Oracle Data Integration (ODI), produto proprietário da empresa Oracle Corporation.

- Área de Estágio (Stage Area) e Data Warehouse: Software Gerenciador de Banco de Dados (SGBD) Postgresql, produto não proprietário de código aberto (Opensource).

- Camada de Acesso Olap : Software TDBI, produto proprietário da empresa TotalData Informática e Tecnologia Ltda.

- Ferramenta de Construção da Camada Olap: Software Tddesigner, recurso específico para implementar scripts de SQL (Structured Query Language), produto proprietário da empresa TotalData Informática e Tecnologia Ltda 
- Ferramenta de Administração e Controle de Acesso: Software TDmanager, produto proprietário da empresa TotalData Informática e Tecnologia Ltda.

- Ambiente Operacional : Sistema Operacional Linux Debian, produto não proprietário de código aberto (Opensource).

A Figura 30 representa, parcialmente, o ambiente proposto, destacando-se as tecnologias empregadas para o desenvolvimento de tal ambiente, o qual reúne, especificamente neste estudo, um servidor (hardware), composto pelo conjunto de tecnologias anteriormente descrito. A comunicação com o servidor é feita remotamente pelos tomadores de decisões, por meio da camada de acesso OLAP, pelo administrador do ambiente com a camada de administração e pelo desenvolvedor com a camada de construção OLAP.

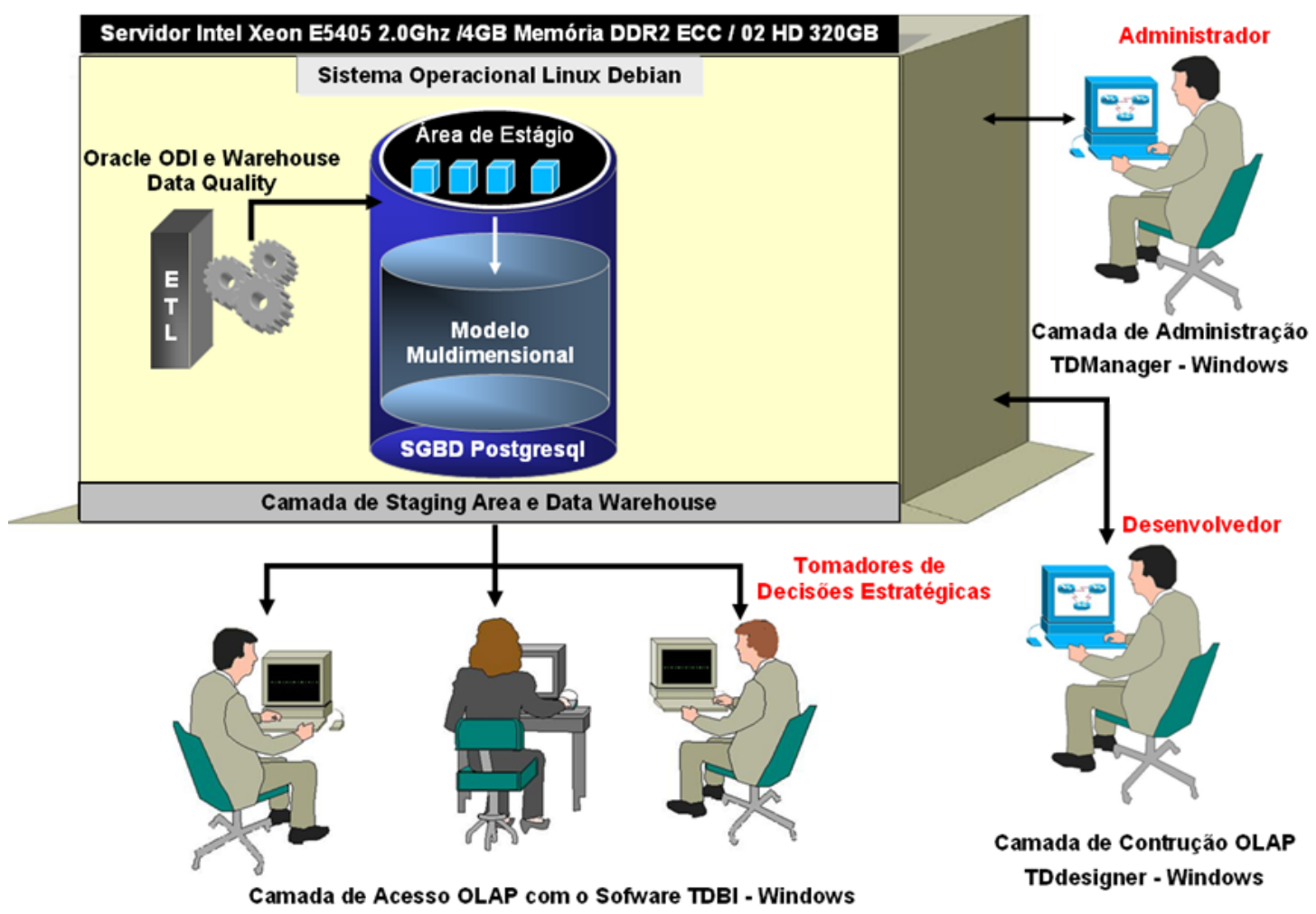

Figura 30 - Tecnologias Utilizadas no Ambiente Computacional Implementado 


\subsection{RESULTADOS DO ESTUDO DE CASO}

Os resultados do estudo de caso demonstraram benefícios significativos em utilizar Sistemas de Informação e Inteligência Empresarial na análise de falhas em Sistemas Críticos. Tais benefícios vêm ao encontro dos fundamentos teóricos desta Tese, ao demonstrar que a necessidade de se obter informação e conhecimento, em menor tempo possivel, transcende o âmbito administrativo e está presente nas necessidades básicas dos tomadores de decisões estratégicas em Sistemas Críticos.

Os aspectos que envolveram a busca por Indicadores Estratégicos de Confiança (IEC) no Sistema Metroviário tornaram legítima a percepção de que durante a execução de consultas OLAP de falhas, para subsidiar decisões estratégicas, o fator tempo torna-se, de fato, um dos pontos mais críticos, quando contextualizado no processo decisório.

\subsubsection{Consultas OLAP realizadas no Ambiente Protótipo}

As consultas OLAP realizadas no ambiente protótipo contribuíram para o desenvolvimento de análises qualitativas e quantitativas para a aferição de amostras correspondentes aos Indicadores Estratégicos de Confiança (IEC) selecionados no Sistema Metroviário estudado.

As amostras de análises qualitativas foram realizadas por meio de consultas OLAP do tipo ad-hoc com o objetivo de identificar a existência de possíveis erros latentes em equipamentos fixos e materiais rodantes. O parâmetro escolhido para identificar tais falhas foi fazer sua seleção com o Diagnóstico de "Sintoma não Identificado". Os demais Indicadores Estratégicos de Confiança (IEC), serviram de parâmetro para investigar, com maior profundidade, resultados individualizados para cada falha com "Sintoma não Identificado" e, auxiliar os tomadores de decisões a compreender diferentes aspectos de tal diagnóstico. A Tabela 4 apresenta os resultados aferidos. 
Tabela 4 - Análises Qualitativas de Falhas no Sistema Metroviário

\begin{tabular}{|c|c|c|c|c|c|c|c|c|}
\hline \multirow{2}{*}{$\begin{array}{l}\text { Atributo } \\
\text { Confiança }\end{array}$} & \multicolumn{8}{|c|}{ Dimensões (IEC) } \\
\hline & Natureza & Tipo de Falha & Diagnóstico & Módulo & Fornec. & Local & Data & Equipe \\
\hline \multirow{4}{*}{ 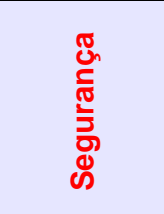 } & \multirow{4}{*}{$\begin{array}{l}\text { Sistema de } \\
\text { Proteção } \\
\text { (ATP) }\end{array}$} & \multirow{4}{*}{$\begin{array}{c}\text { Computacional } \\
\text { (microproces- } \\
\text { sador) }\end{array}$} & \multirow{4}{*}{$\begin{array}{c}\text { Sintoma } \\
\text { não } \\
\text { identificado }\end{array}$} & \multirow{4}{*}{$\begin{array}{l}\text { MOD } 6 \\
\text { Receptor de } \\
\text { código de } \\
\text { velocidade }\end{array}$} & \multirow{4}{*}{ D } & \multirow{4}{*}{ Linha C } & $13 / 02 / 07$ & \multirow{4}{*}{ MC_3 } \\
\hline & & & & & & & 01/07/08 & \\
\hline & & & & & & & $11 / 03 / 08$ & \\
\hline & & & & & & & $19 / 08 / 08$ & \\
\hline \multirow{4}{*}{ 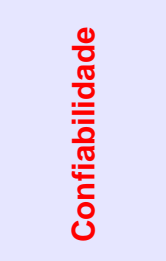 } & \multirow{4}{*}{ Trem } & \multirow{4}{*}{ Pneumática } & \multirow{4}{*}{$\begin{array}{c}\text { Sintoma } \\
\text { não } \\
\text { identificado }\end{array}$} & \multirow{4}{*}{$\begin{array}{l}\text { Compressor } \\
\text { do carro } \\
3284\end{array}$} & \multirow{4}{*}{ A } & \multirow{4}{*}{ Linha A } & $14 / 06 / 05$ & \multirow{4}{*}{ MC_1 } \\
\hline & & & & & & & $27 / 06 / 05$ & \\
\hline & & & & & & & $18 / 07 / 05$ & \\
\hline & & & & & & & 10/04/06 & \\
\hline \multirow{5}{*}{$\begin{array}{l}\frac{0}{0} \\
\frac{\pi}{0} \\
\frac{0}{0} \\
\frac{0}{\frac{0}{2}} \\
\frac{0}{0} \\
\frac{0}{0}\end{array}$} & \multirow{5}{*}{$\begin{array}{c}\text { Sistema de } \\
\text { Alimentação } \\
\text { Elétrica }\end{array}$} & \multirow{5}{*}{$\begin{array}{c}\text { Elétrica } \\
\text { (Energização) }\end{array}$} & \multirow{5}{*}{$\begin{array}{c}\text { Sintoma } \\
\text { não } \\
\text { identificado }\end{array}$} & \multirow{5}{*}{$\begin{array}{c}\text { Disjuntor } \\
\text { Termomag- } \\
\text { nético }\end{array}$} & \multirow{5}{*}{$\mathrm{F}$} & \multirow{5}{*}{$\begin{array}{l}\text { Subestação } \\
\text { Retificadora }\end{array}$} & $14 / 03 / 06$ & \multirow{5}{*}{ MRS1 } \\
\hline & & & & & & & 05/06/06 & \\
\hline & & & & & & & $16 / 01 / 07$ & \\
\hline & & & & & & & 07/03/08 & \\
\hline & & & & & & & $17 / 06 / 08$ & \\
\hline \multirow{4}{*}{$\begin{array}{l}\frac{0}{2} \\
\frac{\pi}{0} \\
\frac{\overline{2}}{0} \\
\frac{\pi}{\pi} \\
\frac{0}{0} \\
\frac{1}{2} \\
\frac{\pi}{2}\end{array}$} & \multirow{4}{*}{$\begin{array}{c}\text { Falsa } \\
\text { ocupação } \\
\text { intermitente } \\
\text { (presença } \\
\text { da } \\
\text { manutenção } \\
\text { na via) }\end{array}$} & \multirow{4}{*}{$\begin{array}{c}\text { Elétrica } \\
\text { (Sinalização) }\end{array}$} & \multirow{4}{*}{$\begin{array}{c}\text { Sintoma } \\
\text { não } \\
\text { identificado }\end{array}$} & \multirow{4}{*}{$\begin{array}{c}\text { Eletrônica } \\
\text { de Circuito } \\
\text { de Via - } \\
\text { ECV } 2\end{array}$} & \multirow{4}{*}{ G } & \multirow{4}{*}{ Linha A } & $11 / 07 / 06$ & \multirow{4}{*}{ MC_1 } \\
\hline & & & & & & & 27/08/06 & \\
\hline & & & & & & & $11 / 04 / 06$ & \\
\hline & & & & & & & $10 / 04 / 08$ & \\
\hline
\end{tabular}

O objetivo deste tipo de análise é possibilitar aos tomadores de decisões estratégicas identificarem diferentes aspectos de falhas mediante o cruzamento de dados disponíveis no modelo dimensional implementado. A análise qualitativa, por tratar-se de indutiva, pode favorecer a descoberta de fatos novos, ou ainda, o esclarecimento dos fatos já conhecidos.

Os resultados apresentados na Tabela 4 exemplificam a capacidade analítica do ambiente proposto, ao possibilitar a combinação entre os oito Indicadores Estratégica de Confiança (IEC) do Sistema Metroviário estudado e o Atributo Confiança. Ressalta-se, contudo, que as amostras selecionadas correspondem a uma pequena parte das possibilidades disponíveis no ambiente. No exemplo da Tabela 4, uma possível ação a ser tomada seria revisar os sensores de detecção de falhas, ou ainda, revisar os manuais técnicos que descrevem procedimentos para a identificação de tais sintomas. 
As possibilidades variadas de consultas OLAP qualitativas permitiram a análise dos Indicadores Estratégicos de Confiança (IEC) sob diferentes aspectos, como por exemplo, identificar a sazonalidade de falhas por módulos, fornecedores, locais, data, entre outros. Os resultados das consultas OLAP quantitativas indicaram a capacidade de transformar grandes volumes de dados, até então dispersos no ambiente operacional, em informações de grande importância para orientar os tomadores de decisões estratégicas no Sistema Metroviário. A Tabela 5 apresenta uma síntese de tais consultas.

Tabela 5 - Análises Quantitativas de Falhas no Sistema Metroviário

\begin{tabular}{|c|c|c|}
\hline Dimensões & Falhas & Total \\
\hline \multirow{3}{*}{ Natureza da Falha } & Falha em Material Rodante (trem) & 6268 \\
\hline & Falha em Equipamentos Fixos & 1145 \\
\hline & Falha no Controle Operacional Centralizado & 37 \\
\hline \multirow{4}{*}{ Tipo de Falha } & Falha Mecânica & 3919 \\
\hline & Falha Elétrica & 2596 \\
\hline & Falha Pneumática & 795 \\
\hline & Falha Humana & 140 \\
\hline \multirow{4}{*}{ Diagnóstico da Falha } & Falha Técnica & 4754 \\
\hline & Falha de Sintoma não Identificado & 2350 \\
\hline & Falha por Manutenção Indevida & 206 \\
\hline & Falha por Operação Indevida & 140 \\
\hline \multirow{6}{*}{ Módulo Falho } & Falha no Sistema de Comando de Portas & 1987 \\
\hline & Falha no Sistema de Sinalização de Portas & 1789 \\
\hline & Falha no Sistema de Freios & 1439 \\
\hline & Falha no Sistema de Tração & 985 \\
\hline & Falha no Sistema de Proteção (ATP) & 768 \\
\hline & Falha no Sistema de Operação Automática (ATO) & 482 \\
\hline \multirow{4}{*}{$\begin{array}{l}\text { Fornecedor do } \\
\text { Módulo }\end{array}$} & Falha por Fornecedor D & 3787 \\
\hline & Falha por Fornecedor B & 1876 \\
\hline & Falha por Fornecedor $\mathrm{C}$ & 915 \\
\hline & Falha por Fornecedor $\mathrm{A}$ & 732 \\
\hline \multirow{5}{*}{ Local da Falha } & Falhas na Linha $\mathrm{A}$ & 4189 \\
\hline & Falhas na Linha B & 1741 \\
\hline & Falhas na Linha C & 391 \\
\hline & Falhas no Pátio de Manobras J & 671 \\
\hline & Falhas no Pátio de Manobras I & 458 \\
\hline \multirow{6}{*}{ Tempo da Falha } & Falhas em 2008 & 1654 \\
\hline & Falhas em 2007 & 1511 \\
\hline & Falhas em 2006 & 1290 \\
\hline & Falhas em 2005 & 1287 \\
\hline & Falhas em 2004 & 987 \\
\hline & Falhas em 2003 & 721 \\
\hline \multirow{2}{*}{$\begin{array}{c}\text { Equipe de } \\
\text { Atendimento }\end{array}$} & Falha atendida pela equipe de Manutenção Corretiva 1 e 2 & 4731 \\
\hline & Falha atendida pela equipe de Manutenção Corretiva 3 & 2719 \\
\hline
\end{tabular}




\subsubsection{Possíveis Decisões Estratégicas Definidas na Análise do Estudo de Caso}

As possíveis decisões estratégicas tomadas no Sistema Metroviário estudado, apresentadas neste tópico, referem-se a cenários hipotéticos construídos para o desenvolvimento desta Tese. Com base no ambiente protótipo construído e considerando o resultado das consultas OLAP da Tabela 5, sugere-se algumas decisões estratégicas e ações de melhoria nos itens a seguir.

\section{a. Decisões Estratégicas na Perspectiva da Concepcão:}

No aspecto da segurança, considerando a dimensão Módulo Falho, nota-se que as falhas estão distribuídas entre o Sistema de Comando de Portas, Sistema de Sinalização de Portas, Sistema de Freios, Sistema de Tração, Sistema de Proteção (ATP) e Sistema de Operação Automática (ATO). Neste caso, há varias alternativas. Uma delas refere-se a verificar quantas dessas falhas foram inseguras e, se necessário, solicitar aos fornecedores revisão geral de projetos para tais módulos.

No aspecto da confiabilidade, o total das falhas apresentadas na dimensão Natureza da Falha caracteriza-se como um importante subsídio estratégico para decidir, por exemplo, se os projetistas devem analisar os indicadores de confiabilidade dos módulos falhos e, se necessário, revisar as taxas de falhas de tais indicadores.

Já no aspecto da disponibilidade, a dimensão Tipo de Falha apresenta o total de falhas Mecânicas, Elétricas, Pneumáticas e Humanas. Neste caso, uma possível alternativa é readequar os mecanismos e procedimentos redundantes para mitigar os efeitos de novas falhas $e$ manter a disponibilidade do sistema.

Finalmente no aspecto da mantenabilidade, considerando a dimensão Diagnóstico da Falha, nota-se que há entre os totais de falhas apresentados, falhas referentes à Manutenção e Operação Indevida. Tais falhas, quando 
contextualizadas no nível estratégico da organização, podem, por exemplo, indicar a necessidade de sanções disciplinares aos operadores e técnicos responsáveis, ou ainda, demandar investigações para analisar se existem possíveis erros latentes que induzem ao erro, tais operadores e técnicos de manutenção.

\section{b. Decisões Estratégicas na Perspectiva da Operação:}

No aspecto da segurança, analisando os números apresentados na dimensão Tipo de Falha, em especial as falhas do tipo humana, verifica-se a necessidade estratégica de analisar se todas as falhas foram seguras, e ainda, identificar possíveis problemas de interface homem-máquina na operação do sistema.

No aspecto da confiabilidade, considerando a dimensão Módulo Falho, notase que há um número expressivo de falhas no Sistema de Sinalização de Portas. Neste caso, uma das possíveis decisões estratégicas é identificar os horários de maior incidência de falhas e eventualmente solicitar revisões de projeto visando readequar os indicadores de confiabilidade dos módulos que suportam alta demanda durante a operação comercial.

Já no aspecto da disponibilidade, nota-se um número crescente de falhas na dimensão Tempo da Falha. Neste caso, faz-se necessário, por exemplo, um estudo aprofundado para identificar a relação entre as ocorrências de falhas e o aumento de usuários no sistema. Tal aferição torna-se um importante recurso estratégico para mensurar e estimar o tempo médio entre trens (headway) nos setores de maior incidência de falhas.

Finalmente no aspecto da mantenabilidade, os números apresentados na dimensão Local da Falha indicam os locais de maior incidência de falhas. Neste caso, uma alternativa plausível pode estar na readequação dos treinamentos operacionais para, se possível, mitigar os efeitos das falhas e manter a operação do, ainda que sob restrições temporárias. 


\section{c. Decisões Estratégicas na Perspectiva da Manutenção:}

No aspecto da segurança, considerando a dimensão Local da Falha, nota-se há um grande número de falhas distribuídas entre as linhas $\mathrm{A}, \mathrm{B}$ e $\mathrm{C}$, e Pátios de Manobras J e I. Neste caso, uma das possíveis decisões estratégicas é implementar mecanismos preditivos de proteção nos pontos de maior criticidade para aumentar a proteção do sistema e, se possível, evitar incidentes e acidentes.

No aspecto da confiabilidade, a quantidade de ocorrências de falhas dos fornecedores A, B, C e D, apresentadas na dimensão Fornecedor do Módulo, pode indicar, por exemplo, a necessidade estratégica de readequar os procedimentos de Manutenção Centrada em Confiabilidade (Reliability Centred Maintenance - RCM).

Já no aspecto da disponibilidade, as falhas indicadas pela dimensão Tempo da Falha podem sugerir a necessidade de readequar a distribuição das equipes técnicas ao longo do sistema para, nos casos de eventuais falhas, restabelecerem os serviços prestados no menor tempo possível.

Finalmente no aspecto da mantenabilidade, considerando a dimensão Natureza da Falha, a quantidade de falhas apresentadas, especialmente em Material Rodante (trem), podem indicar a necessidade estratégica de solicitar aos fornecedores a revisão nos procedimentos de manutenção preventiva, ou ainda, impor sanções legais a tais fornecedores por eventuais procedimentos de manutenções preventivas inadequados.

As possíveis decisões estratégicas aqui apresentadas, exemplificaram as inúmeras possibilidades de utilizar os recursos do ambiente proposto nesta Tese, como um dos principais subsídios analíticos para os tomadores de decisões estratégicas no Sistema Metroviário estudado. Contudo, o delineamento teórico e empírico aqui apresentado não considerou a eficácia das possíveis decisões tomadas, objeto de um possível estudo futuro. 


\subsubsection{A Influência do Tempo na Tomada de Decisões Estratégicas em Projetos de Sistemas Metroviários}

O risco na Tomada de Decisões Estratégicas em projetos de Sistema Metroviários é proporcional aos impactos causados ao ambiente em que este sistema está inserido. Em grandes tragédias em Sistemas Aeronáuticos, por exemplo, os investigadores têm constatado que os fatores que desencadearam falhas poderiam ser previamente identificados e analisados e, que tais fatores poderiam ter sido eliminados da sequência de acontecimentos, neutralizando o seu efeito, mesmo para aqueles sobre os quais o homem não tem controle, como intervenções climáticas, por exemplo (AIRSAFETYGROUP, 2009).

Em Sistemas Metroviários, o intervalo de tempo disponível para a tomada de decisões é de extrema importância para desenvolver ações corretivas no sistema. $O$ tempo disponível para se tomar decisões pode influenciar, significativamente, a qualidade dessas decisões. Ao considerar o conhecimento dos especialistas, estima-se que, quanto maior for o intervalo de tempo disponível para a tomada de decisões estratégicas, maior serão as ações mitigadoras de falhas no sistema.

Considerando-se o intervalo de tempo como fator crítico para a tomada de decisão estratégica em projetos do Sistema Metroviário, na Figura 31 é apresentado um cenário $(A)$, no qual o tempo da decisão $\Delta t_{D}$ é reduzido em função do tempo dispendido com a coleta de dados $\Delta \mathrm{t}_{\mathrm{C}}$ somado ao tempo dispendido com a análise de dados $\Delta t_{A}$. Neste caso, o desenvolvimento de ações mitigadoras de falhas pode não ser suficiente.

Por outro lado, no cenário (B) da Figura 31, o intervalo de tempo para a tomada de decisão $\Delta t_{D}$ é bem maior do que o do cenário $A$. Neste caso, entende-se que o desenvolvimento de ações mitigadoras de falhas é muito mais adequado. 
(A)

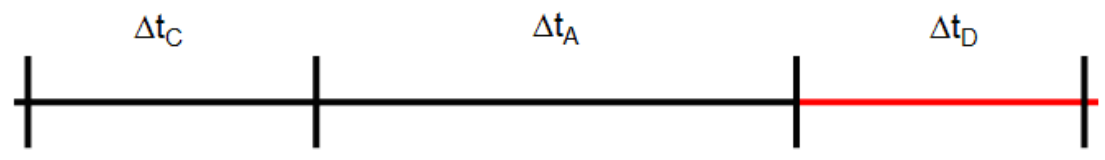

(B)
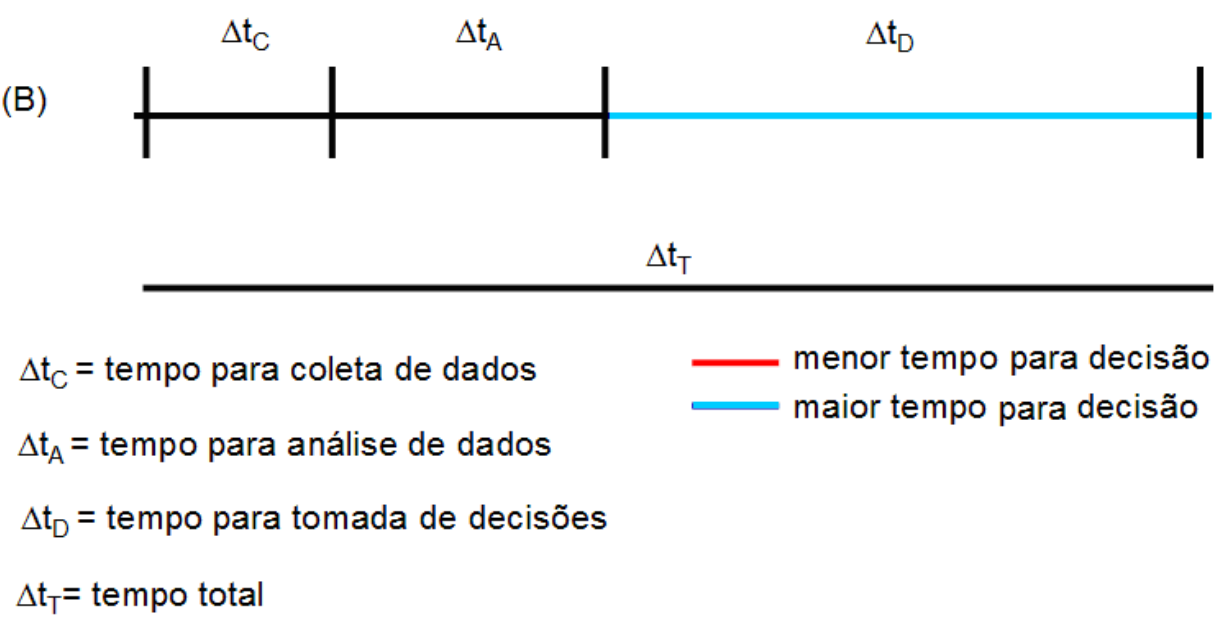

Figura 31 - Variável de Tempo na Tomada de Decisões Estratégicas em Projetos de Sistemas Metroviários

\subsubsection{Valor Agregado das Decisões Estratégicas em Sistemas Metroviários}

O valor agregado das decisões estratégicas em Sistemas Críticos está na redução de tempo dispendido com a obtenção das informações necessárias para decidir. No Sistema Metroviário, o valor agregado nas decisões estratégicas no sistema está no tempo dispendido com ações relacionadas ao Atributo Confiança (segurança, confiabilidade, disponibilidade, mantenabilidade). Espera-se que, quanto maior for o tempo dispendido com a qualidade das decisões estratégicas, maior será o valor agregado ao sistema.

Ao traçar um paralelo com segmentos de negócio, sabe-se que agregar valor aos negócios tornou-se uma premissa básica para a permanência da organização no mercado cada vez mais competitivo. Produzir e comercializar com mais qualidade e menor custo é um dos maiores desafios das organizações, o que não difere de um Sistema Metroviário que tem como premissa básica oferecer o serviço de transporte público com segurança, confiabilidade, disponibilidade e sustentabilidade ambiental, para a população que depende desse sistema. 
O desafio de proteger pessoas que dependem direta e indiretamente de Sistemas Críticos, exige que as organizações provedoras desses sistemas otimizem o tempo dispendido com decisões estratégicas e ações de melhoria que agreguem valores reais ao sistema, mitigando constantemente os efeitos e conseqüências das falhas.

A Figura 32 apresenta um gráfico relacionando o Valor da Decisão (eixo vertical) e os tempos envolvidos (eixo horizontal). Nesse gráfico, a linha vermelha indica que o processo de tomada de decisões é feito sem o auxílio de Sistemas de Informação, enquanto que a linha azul indica que a tomada de decisões conta com o apoio de tais sistemas. Ressalta-se, na figura, o menor tempo para a obtenção dos dados necessários ao processo de tomada de decisões, no caso de se contar com Sistemas de Informação, antecipando a etapa de análise e, consequentemente, a tomada de decisão e a concretização das ações envolvidas. Tal fato está indicado no eixo de tempo da Figura 32.

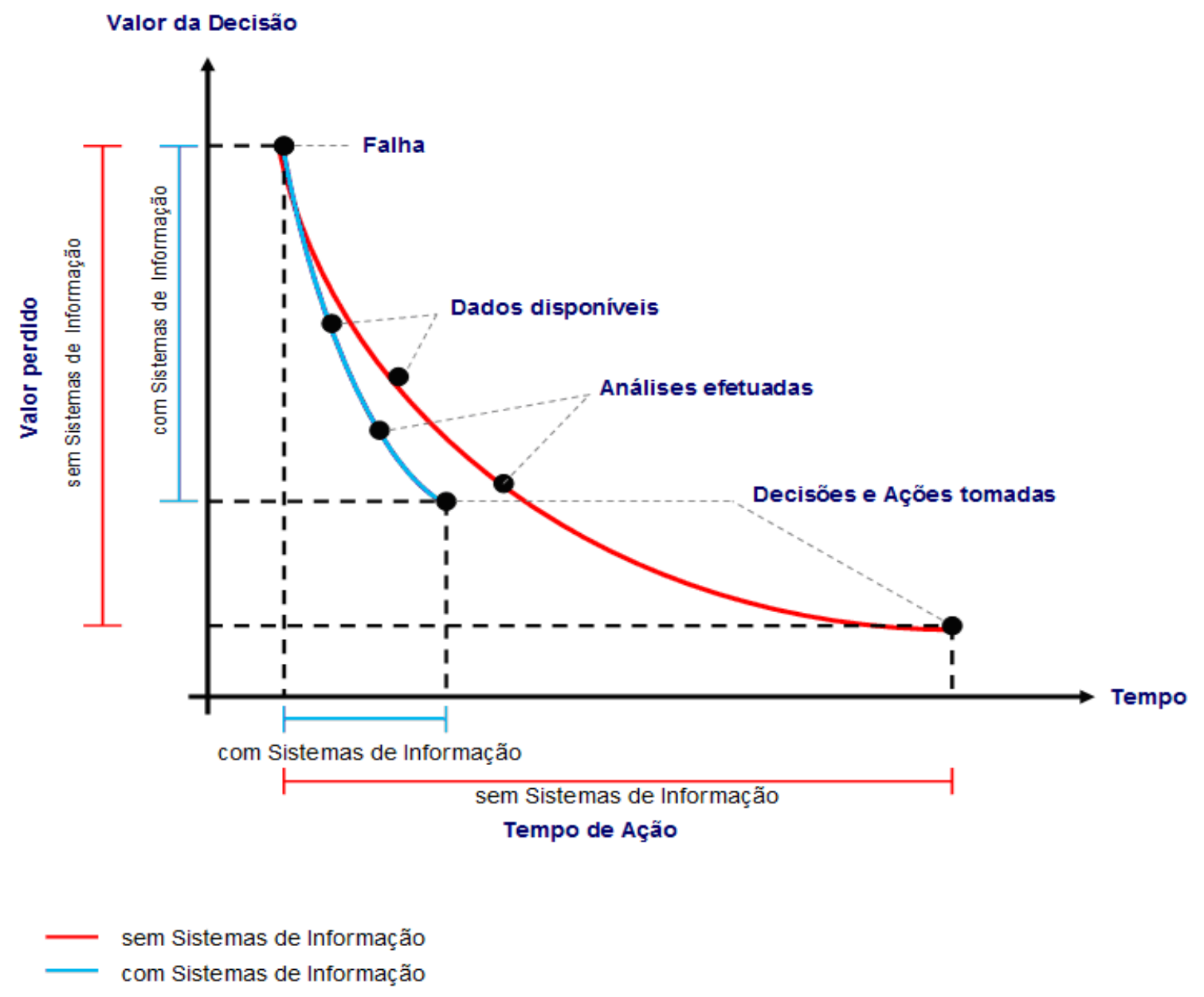

Figura 32 - Valor agregado na decisão estratégica, adaptado de (JUDITH, 2006) 
A proposta de utilização de Sistemas de Informação ilustrada na Figura 32 vem ao encontro dos preceitos abordados nesta Tese e enfatiza ainda mais a relação entre o tempo e a tomada de decisões.

\subsubsection{Análise do Fator Tempo no Processo Decisório}

A análise do fator tempo no processo decisório contextualiza-se como um dos principais pontos abordados nesta Tese. Um possível parâmetro para comprovar a viabilidade da proposta apresentada é considerar, sob o aspecto da cognição e do conhecimento, que o aumento do tempo para tomar decisões estratégicas pode contribuir com a análise de maior número de variáveis, e com isso, diminuir a incerteza e favorecer os resultados da decisão. Neste sentido, o cálculo proposto considera as variáveis: tempo total $\left(\Delta \mathrm{t}_{\mathrm{T}}\right)$ tempo de coleta e preparação dos dados $\left(\Delta \mathrm{t}_{\mathrm{C}}\right)$, tempo de análise dos dados $\left(\Delta \mathrm{t}_{\mathrm{A}}\right)$ e tempo para a tomada de decisões $\left(\Delta \mathrm{t}_{\mathrm{D}}\right)$, conforme ilustrado na Figura 31.

Utilizando-se como exemplo os ensaios realizados no Sistema Metroviário, ilustrados nas Figuras 14 e 15, nos quais, em um intervalo de 13 dias foram dispendidos, no primeiro cenário, sem utilizar Sistemas de Informação, 2 dias para coletar os dados dos ambientes operacionais, 10 dias para analisar a informação e 1 dia para tomar decisões. Já no segundo cenário, utilizando recursos de Sistemas de Informação, foi dispendido aproximadamente 1 dia para coletar os dados e analisar as informações, e os demais 12 dias ficaram disponíveis para a tomada de decisões estratégicas. A Tabela 6 apresenta uma síntese de tais cenários

Tabela 6 - Fator Tempo nas Decisões Estratégicas

\begin{tabular}{|l|c|c|c|c|c|}
\hline \multirow{2}{*}{ Cenários } & \multicolumn{4}{|c|}{ Variáveis em dias } & Resultado \\
\cline { 2 - 6 } & $\Delta \mathrm{t}_{\mathrm{T}}$ & $\Delta \mathrm{t}_{\mathrm{C}}$ & $\Delta \mathrm{t}_{\mathrm{A}}$ & $\Delta \mathrm{t}_{\mathrm{D}}$ & $\frac{\Delta \mathrm{t}_{\mathrm{D}}}{\Delta \mathrm{t}_{\mathrm{T}}} \times 100$ \\
\hline Sem Sistema de Informação & $\mathbf{1 3}$ & $\mathbf{2}$ & $\mathbf{1 0}$ & $\mathbf{1}$ & $\mathbf{7 , 6 9 \%}$ \\
\hline Com Sistema de Informação & 13 & \multicolumn{1}{|c|}{1} & 12 & $92,30 \%$ \\
\hline
\end{tabular}

Analisando as amostras apresentadas nos cenários da Tabela 6, pode-se concluir que a redução do tempo em coletar, preparar e analisar dados de falhas no Sistema Metroviário estudado pode aumentar o tempo das decisões, e favorecer a 
implementação de ações de melhorias no Atributo Confiança do sistema.

Ressalta-se, contudo, que ao utilizar Sistemas de Informação e Inteligência Empresarial como um recurso estratégico em projetos de Sistemas Críticos, a opção em tomar decisões estratégicas com maior ou menor dispêndio de tempo, cerne da problemática apresentada nesta Tese, passa a ser exclusivamente do decisor, ou seja, no exemplo da Tabela 6, o tomador de decisões é quem decide utilizar, ou não, os 12 dias disponíveis para implementar ações de melhoria no sistema. 


\section{CONCLUSÕES}

\subsection{RELEVÂNCIA DO PROBLEMA}

A era da informação e do conhecimento, contextualizada no mundo contemporâneo, trouxe mudanças expressivas no aspecto decisório das organizações. Neste cenário de avanços tecnológicos, os tomadores de decisões estratégicas deparam-se com volumes cada vez maiores de dados, produzidos pelas rotinas das organizações e registrados em sistemas computacionais que auxiliam a execução de tais rotinas. Em contrapartida, os mesmos tomadores de decisões deparam-se com intervalos de tempo cada vez menores para coletar e analisar dados e obter informações relevantes para apoiar processos decisórios.

Nesse sentido, no âmbito administrativo, cada vez mais ganham importância Sistemas de Informação que integram e sintetizam dados de fontes internas e externas à organização, utilizando ferramentas de análise quantitativa e qualitativa, comparações complexas, simulação e outras facilidades para apoiar a tomada de decisão dos estrategistas da organização.

No âmbito de Sistemas Críticos, constantemente são tomadas importantes decisões estratégicas para prover segurança, confiabilidade, disponibilidade e mantenabilidade ao sistema. No entanto, a demora em demasia e a imprecisão em identificar situações de risco e perigo em módulos de Sistemas Críticos podem retardar a implementação de ações de melhorias nos mecanismos de proteção do sistema, tornando-o mais vulnerável a incidentes e acidentes de grandes proporções.

\subsection{RESULTADOS ALCANÇADOS}

Após o desenvolvimento da Análise Inteligente de Falhas para Apoiar Decisões Estratégicas em Sistemas Críticos, foi possível constatar, com os ensaios realizados no Sistema Metroviário, a viabilidade técnica e funcional da utilização de Sistemas de Informação e Inteligência Empresarial como um recurso estratégico a ser 
aplicado nas rotinas decisórias de projetos de concepção, operação e manutenção do sistema estudado. Tal constatação caracteriza-se como um importante resultado atingido neste trabalho, no qual ressalta-se que o emprego de Sistemas de Informação e Inteligência Empresarial pode contribuir, diretamente, com a mudança da postura reativa dos tomadores de decisões estratégicas, para uma postura proativa, dada a rapidez com que se obtém a informação.

Outro importante resultado alcançado refere-se à redução expressiva do tempo para coletar, armazenar, integrar e analisar os dados do ambiente operacional, conforme comprovado no estudo de caso. Ressalta-se contudo, que sem a utilização da Análise Inteligente de Falhas para Apoiar Decisões Estratégicas em Sistemas Críticos e, ao considerar que os dados do ambiente operacional estavam dispersos, as iniciativas analíticas, até então utilizadas, aumentariam, significativamente, o dispêndio de tempo para obter as mesmas informações e ainda, poderiam contribuir com interpretações discrepantes e equivocadas das ocorrências de falhas registradas nos sistemas operacionais. Tal constatação foi observada, empiricamente, após a realização de consultas sem Sistemas de Informação.

A independência de acesso aos dados propiciada pelo ambiente computacional implementado também pode ser um resultado positivo, uma vez que, os dados operacionais podem ser transferidos para o Data Warehouse, do ambiente operacional, em horários que não afetariam esses ambientes e, a partir daí, tais dados poderiam ser acessados, conforme a necessidade de se obter informações para apoiar processos decisórios, sem interferir nos ambientes operacionais.

Outro resultado expressivo refere-se aos aspectos analíticos observados nas consultas realizadas no ambiente computacional desenvolvido para implementar a proposta. Tais aspectos demonstraram a facilidade e a amplitude de execução de consultas qualitativas e quantitativas de falhas com os recursos da ferramenta OLAP utilizada. O uso de tal ferramenta favoreceu o acesso direto aos Indicadores Estratégicos de Confiança (IEC), pelos próprios consumidores da informação, ou seja, os tomadores de decisões estratégicas, sem a necessidade da intervenção de especialistas em computação. 
O método proposto para desenvolver o modelo dimensional do ambiente computacional utilizado para a implementação da proposta deste trabalho, tendo como base a definição de Indicadores Estratégicos de Confiança (IEC), constitui-se em outro resultado interessante, tendo em vista a contribuição acadêmica sintetizada em tal método, até então, não registrada na literatura específica.

Além disso, o modelo dimensional construído para o estudo de caso exemplificou a alta capacidade de, com um único modelo, dar significado aos dados de falhas que estavam dispersos em vários sistemas operacionais distintos, e prover informações a diferentes perspectivas de projetos no sistema estudado.

Neste caso, pode-se dizer que os objetivos especificados para este trabalho foram atingidos, já que a utilização de recursos de Sistemas de Informação e Inteligência Empresarial, mostrou-se totalmente viável na utilização por instituições provedoras de Sistemas Críticos.

\subsection{TRABALHOS FUTUROS}

Este trabalho não considerou toda a abrangência da aplicação de Sistemas de Informação e Inteligência Empresarial para analisar falhas e apoiar decisões estratégicas em projetos de Sistemas Críticos. Nesse sentido, uma primeira proposta para trabalhos futuros é transpor os aspectos conceituas, aplicados no Sistema Metroviário, para outros Sistemas Críticos como Sistemas Aeronáuticos, Nucleares, Navais entre outros.

Uma segunda sugestão refere-se à implementação de recursos complementares como Data Mining, recurso contextualizado academicamente como Descoberta de Conhecimento em Bases de Dados (Knowledge Discovery in Data Base - KDD).

Outra sugestão de trabalhos futuros remete-se à exploração aprofundada de recursos de Balanced Scorecard (BSC), para definir metas de falhas para os Indicadores Estratégicos de Confiança (IEC), e compará-las com ações de melhorias implementadas no sistema após a tomada de decisões estratégicas. 
Outras possibilidades de trabalhos futuros, já no aspecto tático e operacional de análise de falhas em Sistemas Críticos, refere-se à possibilidade de integrar ao ambiente computacional implementado, recursos relacionados à engenharia de confiabilidade, utilizada no Sistema Metroviário estudado, como RCM, FTA, FMEA, FMECA, Análise Weibull, entre outros.

Por fim, uma ultima sugestão, já no que se refere ao ambiente computacional implementado neste trabalho, é o acréscimo de novas tabelas e atributos dimensionais e novos valores na tabela fato do modelo dimensional implementado. No que tange à carga periódica de dados propõem-se estudar novos mecanismos computacionais para diminuir o tempo de transferência dos dados entre os ambientes operacionais e o Data Warehouse. Finalmente, no aspecto da qualidade de dados, propõem-se complementar os recursos de ETL com a utilização de ferramentas de Data Quality para melhorar ainda mais a qualidade da informação utilizada para a análise de falhas e tomada de decisões estratégicas em sistemas com características de criticidade semelhantes às do Sistema Metroviário estudado. 


\section{REFERÊNCIAS BIBLIOGRAFIAS}

AFP. AGENCE FRANCE-PRESSE. Acidentes no Sistema Metroviário. Disponível em : $\leq$ http://www.afp.com/afpcom/pt/>. Acesso em: 10 mar. 2007.

AIRSAFETYGROUP. Prevenção de Acidentes Aéreos - Aspectos históricos. Disponivel em: $\quad$ http://www.airsafetygroup.com.br/show.php?not=83\&titulo=1 $>$. Acesso em: 14 fev. 2009.

ALMEIDA JR, J.R. Segurança em Sistemas Críticos e em Sistemas de Informação - Um Estudo Comparativo, Tese (Livre Docência) - Escola Politécnica da Universidade de São Paulo, São Paulo 2003. 191p.

ALMEIDA JR, J.R.; CAMARGO JR. J.R.; CUGNASCA, P.S. A Segurança de Software em Aplicações de Controle Metroviário e de Tráfego Aéro, The IEEE Latim America Transactions, Vol. 6, n.1, March 2008, p.106 - 113.

ALVESSON, M.; KARREMAN, D. Odd couple: making sense of the curious concept of knowledge management. Journal of Management Studies. 38(7), 2001, p.995 - 1018.

ANAC - AGÊNCIA NACIONAL DE AVIAÇÃO CIVIL. Passageiros por $\mathbf{k m}$ Transportados. Disponível em : <http://www.anac.gov.br/estatistica/estat27.asp $>$. Acesso em: 12 mai. 2009.

ANGELONI, M. T. Elementos Intervenientes na Tomada de Decisão. Ci. Inf. Brasília, 2003, vol.32, n.1, pp. 17-22.

AVIZIENIS, A. "Design of Fault-Tolerant Computers," Proc. 1967 Fall Joint Computer Conf., AFIPS Conf. Proc., vol. 31, 1967, p. 733 - 743.

AVIZIENIS, A.; LAPRIE, J. C.; RANDELL, B.; LANDWEHR, C. Basic Concepts and Taxonomy of Dependable and Secure Computing, The IEEE Transaction on dependable and secure computing, Vol. 1, n.1, January-March 2004, p.11-33. 
AZVINE, B.; CUI, Z.; NAUCK, D.D.; MAJEED, B. Real Time Business Intelligence for Adaptative Enterprise. The IEEE Computer Society. International Conference on E-Commerce Technology and the $3^{\text {rd }}$ IEEE International Conference on Enterprise Computing, E-Commerce, and E-Services, 2006.

BARBIERI, C. BI - Business Intelligence: Modelagem e Tecnologia. Rio de Janeiro: Axcel Books do Brasil, 1 a. ed., 2001.

B2BMAGAZINE. O prêmio Padrão de Qualidade em B2B. Disponível em: $\leq$ http://www.administradores.com.br/artigos/premio padrao de qualidade em b2b $\geq$. Acesso em: 12 fev. 2008.

BNDES - BANCO NACIONAL DE DESENVOLVIMENTO. Sistemas Metroviários. Disponível em: $\leq$ http://www.bndes.gov.br/>. Acesso em: 15 jun. 2008.

CALIXTO, E. Uma metodologia para gerenciamento de risco em empreendimentos: Um estudo de caso na Indústria de petróleo. XXVI ENEGEP - Fortaleza, CE, Brasil, 9 a 11 de outubro de 2006.

CAMARGO JR, J.B.; ALMEIDA JR, J.R.; CUGNASCA, P.S. Análise de Risco de um Sistema de Controle de Transporte Público. Revista dos Transportes Públicos, São Paulo, v. 28, n. 110, 2006, p. 7-16.

CAMARGO JR, J.B. Metodologia de Análise de Risco em Sistemas Computacionais de Aplicação Crítica. Tese (Livre Docência) - Escola Politécnica da Universidade de São Paulo, São Paulo, 2002. 142p.

CENIPA - CENTRO DE PREVENÇÃO DE ACIDENTES AERONÁUTICOS. Relatório de Perigo. Disponível em $\leq$ https://www.defesa.gov.br/ $>$. Acesso em: 30 jul. 2008.

CHIAVENATO, I. Introdução à Teoria Geral da Administração, $7^{a}$ ed., Rio de Janeiro. Ed. Elsevier, 2003, p.474 - 476. 
CHOO, C. W. A Organização do Conhecimento: Como as Organizações Usam a Informação para Criar Significado, Construir Conhecimento e Tomar Decisões. São Paulo: SENAC, 2003, p. 25 - 34.

CHUNG, W.; CHEN, H.; NUNAMAKER, J. "Business Intelligence Explorer: a knowledge map Framework for Discovering Business Intelligence on the Web". Proceedings of the $36^{\text {th }}$ The IEEE Hawaii International Conference on System Science, Big Island, Hawaii, 2003, 10 p.

CPTM. COMPANHIA PAULISTA DE TRENS METROPOLITANOS. Intervalos Realizados entre Trens. Disponível em : <http://www.cptm.sp.gov.br/>. Acesso em: 13 mai. 2008.

DAVIS, J. P.; MACDONALD, A. D. J.; MARASHI, S. E. Integrated Performance Measurement to Support Strategic Decision Making in Engineering Organizations. The IEEE International Conference on System Sciences, 2007.

DHIRAJ. K. P. Fault Tolerant System Design. Prentice Hall, 1996.

DRUCKER, P. Post-Capitalist Society. New York: Harper Collins, 1993.

DWBrasil. Técnicas OLAP. Disponível em: <http://www.dwbrasil.com.br/html/olap>. Acesso em 18 set. 2008.

EDGE GROUP, Empresas Brasileiras que utilizam Business Intelligence. Disponível em $\leq h t t p: / / w w w . e d g e g r o u p . c o m . b r / t e l a s / e x i b e$ relatorios.asp $>$. Acesso em: 23 jan. 2007).

EMBRAER - EMPRESA BRASILEIRA DE AERONÁUTICA. Aviação Comercial. Disponivel em $\leq$ http://www.embraercommercialjets.com.br/english/content/home/>. Acesso em: 12 jul. 2008.

FSF - FLIGHT SAFETY FOUNDATION. Accident Prevention. Disponível em: <http://www.flightsafety.org/pubs/ap 2004.html>, Acesso em: 21 ago. 2008. 
GAIN - GLOBAL AVIATION INFORMATION NETWORK. Grupo de Trabalho de Práticas de Segurança de Vôo dos Operadores Aeronáuticos. Operator's Flight Safety Handbook: Manual de Segurança dos Operadores Aeronáuticos. Tradução Guardyan Net Comércio e Serviços Ltda. Porto Alegre: EDIPUCRS, 153 p. 2004.

GARTNER GROUP. The Growth of Business Intelligence, Disponivel em: $\leq$ http://www.gartner.com/technology/research.jsp $>$. Acesso em: 8 mai. 2008.

HAGEN, J. What a technology can do for the company's customer is the ultimate bottom line. Sybase - Case Study of Sybase. Disponível em: $\leq$ http:// www.sybase.com/detail>. Acesso em: 23 mai. 2008.

GONÇALO, C. R. Barreiras Cognitivas: Uma Perspectiva Decisiva para Promover Estratégia de Conhecimento no Desempenho da Atividade Organizacional. Revista Produto \& Produção, vol. 8, n. 2, jun 2005, p. 25 - 36.

HART, M.; ESAT, F.; ROCHA, M.; KHATIEB, Z. Introducing Students to Business Intelligence: Acceptance and Perceptions of OLAP Software. Issues in Informing Science and Information Technology, vol. 4, 2007, p. 105 - 123.

HAYES, J.; ALLINSON, C.W. Cognitive Style and its Relevance for management practice. British Journal of Management, vol. 5, n.1, 1994, p.53- 71.

HOUAISS, A. Dicionário Eletrônico Houaiss da Língua Portuguesa. Rio de Janeiro, Ed. Objetiva, 2007.

IAEA - INTERNATIONAL ATOMIC ENERGY AGENCY. Nuclear Power. Global Status. Look at Nuclear Power Generation Around the World and its Future Prospects. Bulletin Vol. 49, n. 1, março de 2008.

IATA - INTERNATIONAL AIR TRANSPORT ASSOCIATION. Flight Data Analysis (FDA) Service. Disponível em : <http://www.iata.org/ps/intelligence statistics >. Acesso em: 3 mai. 2008. 
ICAO - INTERNATIONAL CIVIL AVIATION ORGANIZATION. Padrões para a Aviação Civil. Disponível em : <http://www.icao.int/>, Acesso em: 23 jul. 2008.

IDC - INTERACTIVE DATA CORPORATION. Panorama de Utilização e de Investimentos em Ferramentas de Business Intelligence. Disponível em <http://www.idc.com/research/searchresults.jsp?sid=0 > . Acesso em: 13 ago. 2006.

IEC - FUNCTIONAL SAFETY ELECTRICAL/ELECTRONIC/PROGRAMMABLE IEC 61508-1 STD 4-1997. Electronic Safely elated Systems. International Electrotechnical Commission., 1997

INMON, W. H . Building the Data Warehouse. 4th edition. USA: Hungry Minds Inc., 2005.

Corporate Information Factory - Disponível em: <http://://www.inmoncif.com>, Acesso em: 10 mai. 2007.

Data Mart Does not Equal Data Warehouse - Disponível em: $\leq$ http://www.dmreview.com/article sub.cfm?articleld=1675> , Acesso em: 4 jul. 2008.

ISA - INSTRUMENTATION SOCIETY OF AMERICA. Safety Integrity Level, disponível em: $\leq$ http://www.isa.org/>. Acesso em; jun. 2008.

JANE'S - JANE'S URBAN TRANSPORT SYSTEM 2006 - 07. (Hardcover), 25th edition, Ed. Mary Webb, 2007.

JUDITH, R. D. Right-Time Business Intelligence: Optimizing the Business Decision Cycle. Business Intelligence Network 2006. p. 8, janeiro de 2006.

KAPLAN, R. S.; NORTON, D. P. Using the Balanced Score Card as a Strategic Management System. Harvard Business Review, 1996, p. 75 - 85

KIMBALL, R. Data Warehouse Toolkit. New York: John Wiley \& Sons, Inc., 1a. ed., 1996. 
KIMBALL, R.; REEVES, L.; ROSS, M.; THORNTHWAITE, W. The Data Warehouse Lifecycle Toolkit: Expert Methods for Designing, Developing, and Deploying Data Warehouses. Wiley Computer, 1998.

KIMBALL, R.; ROSS, M. The Data Warehouse Toolkit. Guia completo para modelagem. Editora Campos, 2 ed. Rio de Janeiro, 2002.

LABROSSE, D.; LÉVY, P. Notas sobre a Planetarização e a Expansão da Consciência. In: Tecnologias Educacionais. Revista Pedagógica, Porto Alegre, Artmed, ano 3, n 9, 1999, p. 7-10.

LAFRAIA, J. R. B. Manual da Confiabilidade, Mantenabilidade e Disponibilidade. Rido de Janeiro, Qualitymark: Petrobrás. 2001.

LAUDON, K. C.; LAUDON, J. P. Sistemas de Informação Gerencial, Pearson Prentice Hall, $4^{\text {a }}$ Ed., São Paulo, 2007.

Sistemas de Informação. LTC, 1999.

LES, C. A Hazard Analysis of Human Factors in Safety-Critical Systems Engineering. ACM International Conference Proceeding Series; Vol. 162 archive Proceedings of the 10th Australian workshop on Safety critical systems and software, Vol. 55, 2006.

LEVESON, N. G. Safeware Systems Safety and Computers. New York: Addison Wesley Publishing Company, 1995, 680p.

LUHN, H. P. A Business Intelligence system. IBM Journal of Research and Development, Oct 1958, p. 314-319.

MARCONIN, A. J.; ABACKERLI, A. J. Uma Proposta de Estimativa de confiabilidade Utilizando Dados de Campo. XXIII Encontro Nacional de Engenharia de Produção - Ouro Preto, MG, Brasil, 21 a 24 de out de 2003, p.1-5. 
MATHEUS, R.; PARREIRAS, F. Inteligência Empresarial versus Business Intelligence: Abordagem Complementares para o Apoio à Tomada de Decisão no Brasil. Congresso anual da sociedade brasileira de Gestão do Conhecimento, São Paulo, 2004, p.3 - 7.

METRO - COMPANHIA DO METROPOLITANO DE SÃO PAULO. Metrô de São Paulo. Disponível em <http://www.metro.sp.gov.br>. Acesso em: mai. 2009.

. Informativo

Gerencial de Manutenção, Acervo Técnico, abril de 1994. . Informativo

Gerencial de Operação, Acervo Técnico, maio de 2000.

Informativo

Gerencial de Concepção, Acervo Técnico, fevereiro de 2001.

MURRAY, E. J. Classifying knowledge Management Systems Based on Context Content. Proceedings of the 39th Annual Hawaii IEEE International Conference on System Sciences Track 7, Janeiro de 2006, p. 156.

NASA - NATIONAL AERONAUTICS AND SPACE ADMINISTRATION. Aviation Safety Reporting System - ASRS. Disponível em : <http://asrs.arc.nasa.gov>. Acesso em: out. de 2008.

NEA - NUCLEAR ENERGY AGENCY. Nuclear Regulatory Challenges Related to Human Performance. Nuclear Regulation : OECD, 2004.

NGUYEN, T. M.; SCHIEFER, J.; TJOA, A. M. Data Warehouse Design 2: Sense \& Response Service Architecture (Saresa): an Approach Towards a Real-Time Business Intelligence Solution and its Use for a Fraud Detection Application. Proceedings of the 8th ACM international workshop on Data Warehousing and OLAP - DOLAP. Nov. 2005.

NONAKA, I; TAKEUCHI, H. Criação de conhecimento na empresa. $5^{\text {a }}$ ed. Rio de Janeiro: Campus, 1997. 
NOBELPRIZE. The Decision-making Process Within Economic Organizations 1978. Disponível em : $\leq$ http://nobelprize.org/>. Acesso em : 27 jan. 2009.

OLIVEIRA, A.; ALMEIDA JR, J.R. FAI: Model of Business Intelligence for Projects in Metro-Railway System. In European Safety and Reliability Association, 2008, Valência, Espanha. Annual Confence. London: 2008. v. 1. p. 3177-3181.

OLIVEIRA, D. P. R. Sistemas de Informações Gerenciais. São Paulo: Atlas, 12a Edição, 2008.

ONU - ORGANIZAÇÃO DAS NAÇÕES UNIDAS. Population Division of the Department of Economic and Social Affairs of the United Nations Secretariat, World Population Prospects: The 2006 Revision and World Urbanization Prospects: The 2005 Revision, Disponível em: <http://esa.un.org/unpp>, Acesso em jul. 2008.

. History of the United Nations and Chernobyl. A Unified Message of Hope for Chernobyl. Disponível em: <http://www.un.org/ha/chernobyl/history.html , Acesso em: out. 2008.

OHSAS - OCCUPATIONAL HEALTH \& SAFETY ADVISORY SERVICE 18002. Norma OHSAS 18001:2007. Risck Tecnologia, São Paulo, 2003, 96 p.

OTANI, M.; MACHADO, W. V. A Proposta de Desenvolvimento de Gestão da Manutenção Industrial na Busca da Excelência ou Classe Mundial. Revista Gestão Industrial, v. 04, n. 02, 2008, p. 01-16.

PEDROSA F, E. L. Desafios e Melhores Práticas de BI. IV Congresso de Inteligência Competitiva - Sucesu - São Paulo, 2006.

PMI - Project Management Institute. PMBOK Guide - A Guide to the Project Management Body of Knowledge. $3^{\circ}$ ed. 2008.

PORTER, M. E. What is Strategy? Harvard Business Review, Nov/Dec.1996 p.6178. 
POE, V.; KLAUER, P.; BROBST, S. Building a Data Warehouse for Decision Support. New Jersey: Prentice Hall PTR, 1998.

PRESSMAN R. S. Engenharia de Software. $6^{\text {a }}$ Ed., Mcgraw Hill Brasil, 2006, 752p.

REASON, J. Human Error: Models and Management. BMJ, v.320, 2000, p.768 770.

SHELDON, F T.; JERATH, K. Assessing the Effect of Failure Severity, Coincident Failures and Usage-Profiles on the Reliability of Embedded Control Systems, ACM Symposium on Applied Computing, p.826, 2004.

SIMON, H. A. Theories of Decision-Making in Economics and Behavioral Science. The American Economic Review, v. 49, n. 3, 1959, p. 253-283.

SOMMERVILLE, I. Engenharia de Software. $8^{a}$ Ed., São Paulo: Addison Wesley, 2007, p.14- 40 .

SVEIBY, K. E. A Nova Riqueza das Organizações, $1^{\text {a }}$ Ed. Rio de Janeiro, Campus, 1998, p 3.

TAFNER, S. L.; BERNHARDT, A. Business Intelligence: Ferramenta de Aquisição de Informação e Conhecimento como Diferencial Competitivo no Processo Decisório. Revista de Divulgação Técnico-Científica do ICPG. Vol. 3, n.10, jan.-jun. 2007.

TERRA, J. C. C. Gestão do Conhecimento: O Grande Desafio Empresarial. 3. ed. São Paulo: Negócio Editora, 2001.

VILLEMEUR, A. Reliability, Availability, Maintainability and Safety Assessment, Vol. 2: Assessment, Hardware, Software and Human Factors, John Wiley \& Sons, 1992.

WATSON, H. J.; WIXOM, B. H. The Current State of Business Intelligence. The IEEE Computer, p. 95 - 99, september 2007. 
WEBER, T. Fundamentos de Tolerância a Falhas. Disponível em:

<http://www.inf.ufrgs.br/ taisy/disciplinas/TFslides/> . Acesso em: 15 mai. 2009.

WICKENS, C. D.; HOLLANDS, J. G. Engineering Psychology and Human Performance. 3a. ed. Prentice Hall, 1999.

ZHANG, N.; LU, W.F. A Framework for Managing Enterprise Knowledge for Collaborative Decision Support. The 5th IEEE International Conference on Industrial Informatics, Vienna, p. 517-522, 2007.

ZANGISKI, M. A. S. G.; LIMA, E. P.; COSTA, S. E. .G. Aprendizagem Organizacional e Desenvolvimento de Competências: Uma Síntese a partir da Gestão do Conhecimento. Revista Produto \& Produção, vol. 10, n.1, p. 54 - 74, fev. 2009. 


\section{APÊNDICE}

Especificação dos scripts utilizados para a criação das tabelas do modelo dimensional implementado.

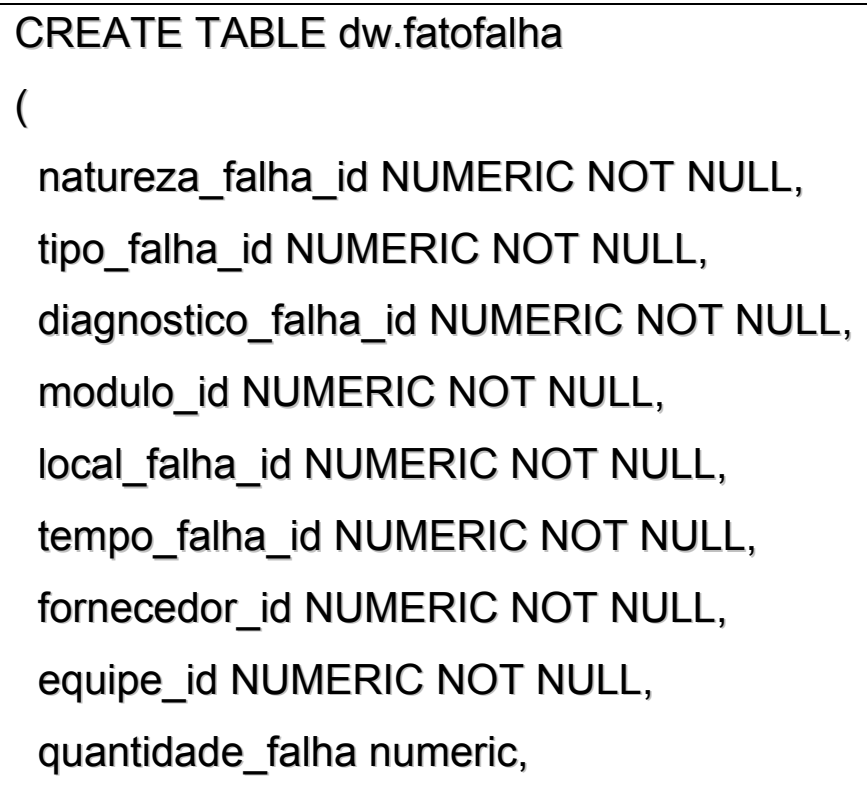

CONSTRAINT pk_fatofalha PRIMARY KEY (natureza_falha_id, tipo_falha_id, diagnostico_falha_id, modulo_id, local_falha_id, tempo_falha_id, fornecedor_id, equipe_id));

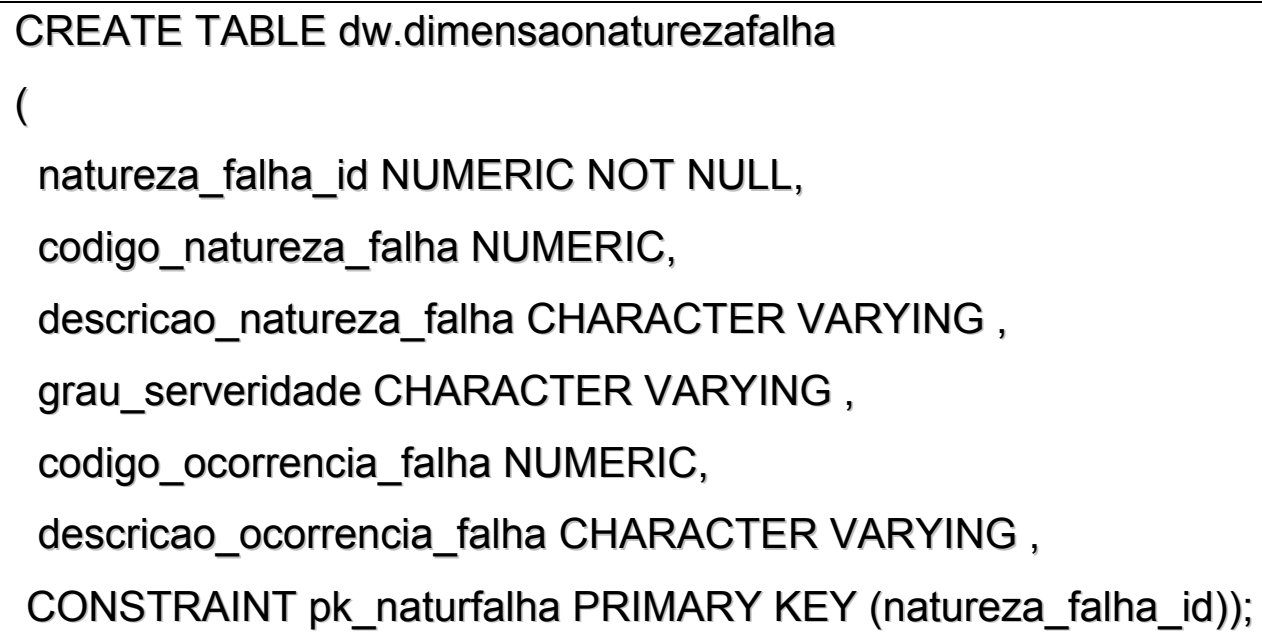




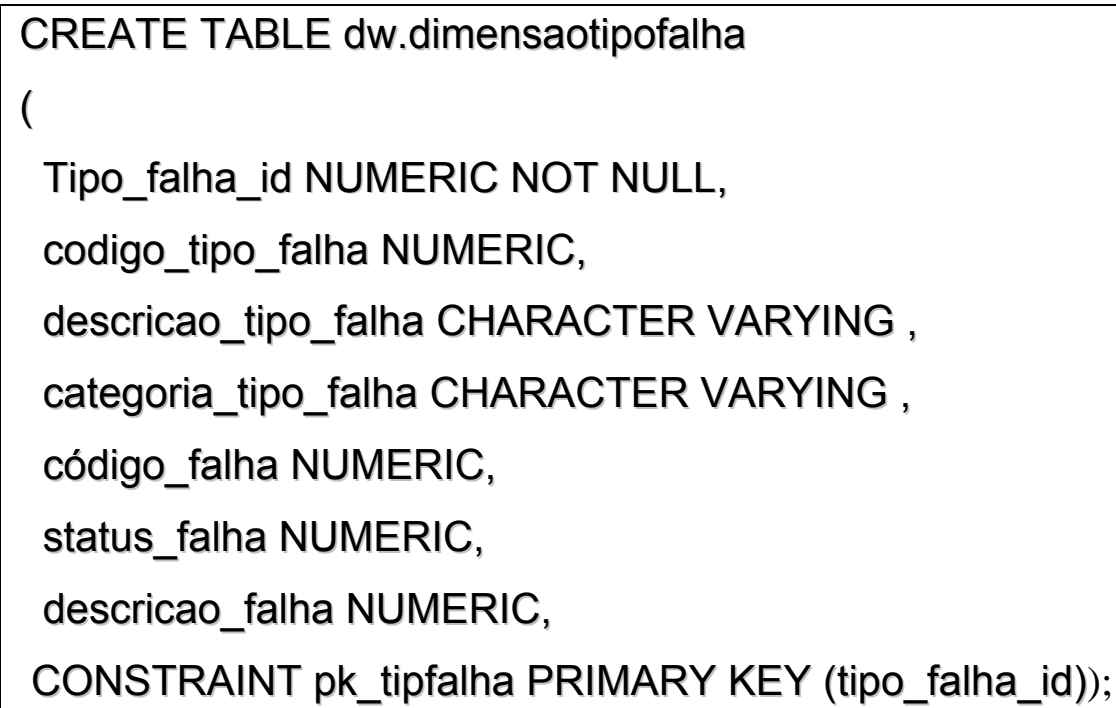

CREATE TABLE dw.dimensaodiagnosticofalha ( diagnostico_falha_id NUMERIC NOT NULL, codigo_diagnostico NUMERIC, descricao_diagnostico CHARACTER VARYING , descricao_sintoma CHARACTER VARYING , responsavel_diagnostico CHARACTER VARYING , CONSTRAINT pk_diagfalha PRIMARY KEY (diagnostico_falha_id));

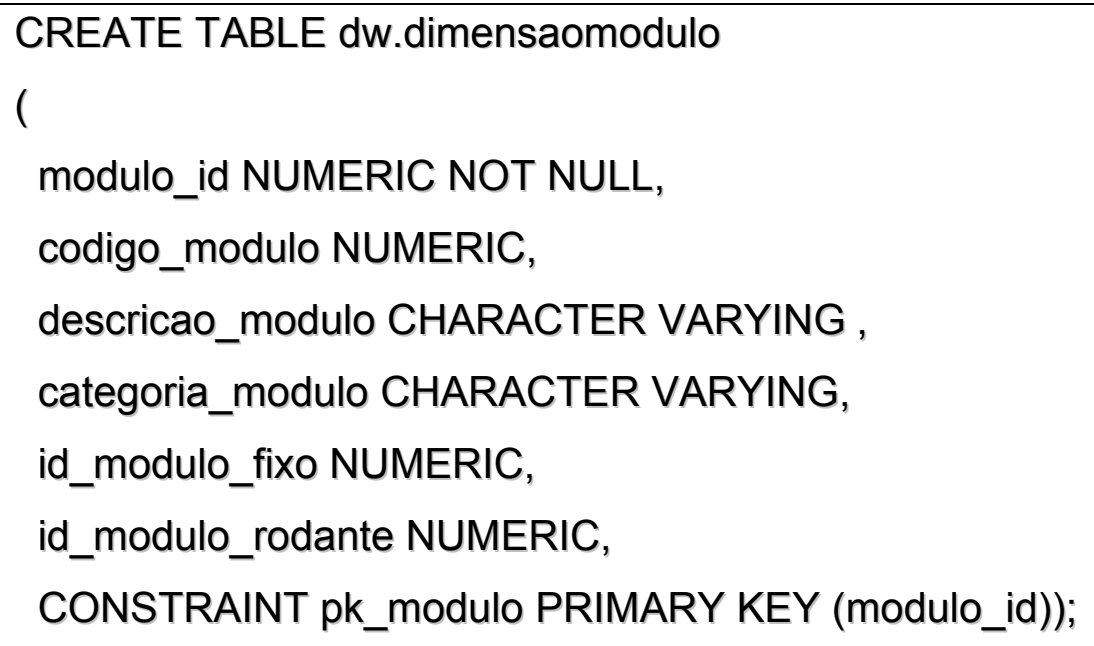




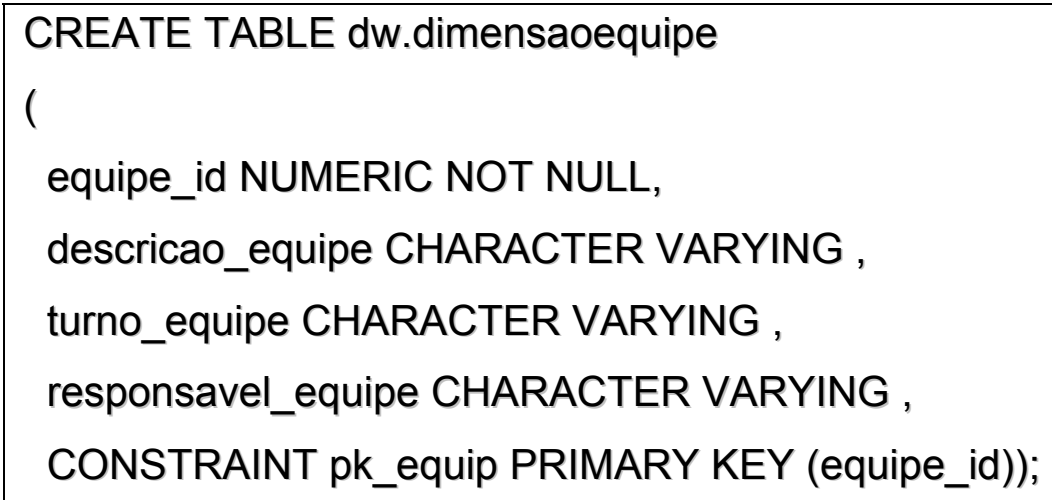

